\title{
INNOVATIVE AND NONTRADITIONAL REVENUE GENERATION IN NEW ZEALAND MUSEUMS
}

\author{
ANNA ABERNETHY
}

2016 


\title{
INNOVATIVE AND NONTRADITIONAL REVENUE GENERATION IN NEW ZEALAND MUSEUMS
}

\author{
by \\ Anna Abernethy
}

\begin{abstract}
A thesis
submitted to the Victoria University of Wellington

in fulfilment of the requirements for the degree of

Master in Museum and Heritage Studies
\end{abstract}

Victoria University of Wellington

2016 


\begin{abstract}
Improving income in museums around the world is vitally important and New Zealand museums are no exception. There is little literature in Museum Studies offering practical strategies for fundraising, with much research focusing on the morality of revenue sources rather than best practice. Research in other disciplines on museum revenue has been problematic as the theories it has attempted to apply are not always applicable. There has also been little research on the local dynamics of revenue generation, and there is therefore an urgent need for practice based research on this topic, such as data for comparative analysis of revenue sources.
\end{abstract}

Responding to gaps in the current literature this thesis analysed innovative and nontraditional revenue generation in three Wellington museums. Innovative and nontraditional revenue encompasses programs, partnering, fundraising, museum-operated businesses, venue hire, museum and third-party websites, phone applications for smartphones, crowdsourcing and ecommerce. Pragmatism provides the research paradigm for this empirical study into current professional practice. The paradigm was enhanced by several concepts including Hansen and Birkinshaw's, Innovation Value Chain. To examine the local museum situation, data was gathered from the Museum of New Zealand Te Papa Tongarewa; the New Zealand Cricket Museum; and Pātaka Art + Museum. Semi-structured interviews with key staff and revenue records were analysed following qualitative and quantitative methods.

There were several key findings which highlighted the direct and indirect benefits of innovative and nontraditional revenue. External partnerships, museum staff and volunteers were highlighted as crucial for revenue viability. Ethics and perceptions of revenue also affected revenue generation. Overall the research enhances our knowledge of museum economics in the New Zealand context. I argue that commercial operations need to be integrated into museum practice and that the benefits of this approach should be demonstrated to all staff. Finally, several recommendations are made which I believe will enhance the future practice of revenue generation in New Zealand museums. 


\section{Acknowledgements}

Someone once said it takes a village to raise a child; it takes a legion to support a thesis. I am enormously indebted to my supervisor Conal McCarthy for his guidance, encouragement and good humour. Special thanks to Neil Quigley for his guidance on economics and Annie Mercer for her support.

I would like to gratefully acknowledge the key participants in this study. Many thanks to Darren Milsom, Phillip Smith, Jamie Bell and Zara Hawthorne for sharing their wisdom and experiences in revenue generation.

To the Te Papa Host team, you are some of the unsung heroes of the museum world, thanks for listening and sharing your thoughts.

A very special thank you to Richard Taylor and Tania Rodger for teaching me and kick starting this experience

To my wonderful husband and extraordinary mum thanks for all the countless hours of support, guidance and love. Special thanks to my stepdad Michael for giving me the benefit of his academic experience. A big thanks to Jaimie-Leigh Jonker and Michael for all their thoughts and help in editing the final document.

And finally, to my amazing kids Hugo and Audrey who have put up with mum writing this for most of their lives, never ever give up. With a little confidence, a bit of luck and a heck of a lot of hard work, you can do anything. 


\section{Contents}

Abstract $\quad$ i.

Acknowledgements ii.

Contents iii.

List of Figures iv.

Introduction 1

Chapter One: Research Design 20

Chapter Two: Results 29

Chapter Three: Analysis $\quad 59$

$\begin{array}{ll}\text { Chapter Four: Discussion } & 78\end{array}$

$\begin{array}{ll}\text { Conclusion } & 91\end{array}$

References $\quad 99$

$\begin{array}{ll}\text { Appendices } & 112\end{array}$ 


\section{List of Figures}

Figure INT.1 Industrial age model $\quad 9$

$\begin{array}{ll}\text { Figure INT.2 Knowledge age model } & 10\end{array}$

$\begin{array}{ll}\text { Figure INT.3 The gaps in the existing literature } & 19\end{array}$

Figure INT.4 Toi Object Space, Pātaka Museum and Art Gallery. 26

Figure INT.5 The New Zealand Cricket Museum 27

Figure 2.12012 - 2013 Percent of total income 30

Figure 2.2 2013 - 2014 Percent of total income 31

Figure 2.32014-2015 Percent of total income 32

Figure 2.4 Individual responses closed question results $\quad 57$

Figure 2.5 Overall responses to closed questions by interviewees 58

Figure CON.1 KA model revised 96 


\section{Introduction: Museums and Revenue Generation}

Many contemporary museums aspire to be institutions of inspiration. They acquire, preserve and communicate heritage from one generation to the next. Their collections are important on many levels, including their social, symbolic and economic value. From an economic perspective, the financial value of a museum's collection is paradoxical. It makes a museum asset rich but these assets cannot be liquidated like a commercial business because museum ethics discourage collection deaccession. As museums face an era of increasing financial restraint, how do they balance mission and financial imperatives (Silberberg and Lord 2015)?

One of the answers may be to think outside of traditional funding parameters (Brodie, Kane, and Clark 2012). This proposition is explored throughout this study as it addresses the following questions: do innovative and non-traditional revenue sources improve the financial viability of New Zealand (NZ) museums? If so, how?

The road to financial viability in museums has been paved with good intentions. Museums were historically viewed as a public good and given extensive financial support. Perceived by many as separate from business, there was little need to generate revenue (Dickenson 1993, 222). Museum staff considered administration and liaising with funding providers a nuisance (Boylan 2006, 417). The mandate of museums was primarily education and collection care (Hudson 2014, 86).

Today museums face increasing demands to fulfil a variety of public roles and some have attempted reinvention and renewal (Weil 1990; Anderson 2004). The value of museums, their missions and social purpose, has been a key research area; recent work by Carol Scott (2015) and David Fleming (2015) are just two examples. But while the museum paradigm may have shifted, and has had to be more open to issues such as marketing, management and finance, questions about museums and their economics remain.

Current research on museum economics offers few practical strategies for fundraising. When museum revenue has been researched, the major focus has been on ethics and specific revenue. The practicalities of museum finances have rarely featured in the 
literature (Rentschler, Hede, and White 2007). The limitations of current research on this topic and the urgent demand for more work in this field inspired me to embark on this study.

Another source of inspiration was the question of financial viability. This thesis considered whether it was possible to determine the financial viability of museums. Extraneous events and complex financial structures seem to make it difficult to assess. It thus appeared more appropriate to focus on a topic which could generate positive outcomes for the income of a museum regardless of operating size or resources. Innovative and non-traditional revenue generation offers a broad research scope which can be tailored. The timeframe of this study could not accommodate an exploration of Maori themes; these would be valuable to include in future studies.

My personal interest and background prompted me to choose this topic. My involvement with the Museum of New Zealand Te Papa Tongarewa (TP) began in 1999. I have held a variety of roles with TP including hosting revenue generating exhibitions. I have seen how commercial exhibitions such as Time Warp have shaped visitor impressions.

Besides my experience front of house at $\mathrm{TP}$, my time managing a cultural attraction has also prompted me to undertake this research. The Weta Cave in Miramar, Wellington, is Weta Workshop's boutique retail film experience. The business relies on generating commercial revenue for funding. While acting as manager I found that business strategy was essential for delivering the organisation's mission. When I compared operations at The Weta Cave with that of a museum the clear differences between them raised questions for me. I wondered about synergies between business strategies and museum mandates. What resources could assist museums to operate as a non-profit business and a museum? Could museums be more financially viable? Are there new ways to make money in museums? Seeking answers to these questions and more, this research began with a review of current literature. 


\section{Literature Review: The business and theory of museum finances}

To break down the issues under consideration the review is structured in sections. Section one describes museums and revenue generation in the context of Museum Studies. It considers museum history and how traditional museum roles may have affected revenue generation. The relationship between museums, local councils and national governments is also analysed. Particular reference is made to the evaluation of museums by external parties. Section two contemplates existing research on the economics of museums. Concepts discussed include business models, economic theory and their association with revenue generation. Section three examines innovative fundraising practices with specific reference to technology and relationship management. It looks at the dual benefits of digital revenue generation. Social enterprise models are examined with regards to revenue diversification. Revenue opportunities from recent cultural changes in NZ are also discussed. Section four considers the environment in which NZ museums operate. It highlights key issues in this environment such as private sector support and competition. Revenue raising strategies are also analysed.

\section{Museum Studies and Economics}

This scope of this literature review is interdisciplinary, encompassing both Museum Studies and Economics. To establish an initial framework for the study a range of terms have been defined below. There is an absence of consensus on the definition of Museum Studies (Aquilina 2011). Generally, Museum Studies is seen as the history, ethics and philosophy of museums (Dubuc 2011, 498). The field of Economics sits outside of this sphere but offers a way to expand the scope of research on museums (Johnson and Thomas 1998, 76). This expansion of Museum Studies, by drawing on subjects like Economics, could develop applied theory alongside theorised practice (Labrum and McCarthy 2005, 9). Managerial Economics, which is what many museum professionals understand by 'management', is the study of directing scarce resources to manage costs (Png 1998, 2).

Besides outlining the fields of Museum Studies and Economics, it is relevant here to define the following terms. Despite no global consensus, museums can be defined as:

.... a non-profit, permanent institution in the service of society and its development, open to the public, which acquires, conserves, researches, communicates and exhibits the tangible and intangible 
heritage of humanity and its environment for the purposes of education, study and enjoyment (International Council of Museums 2007).

Museum business models define the how and why of museum operations (Falk and Sheppard 2006, 18). Business models highlight customers, values, communication strategies, relationships, activities, resources, operating environment and costs. The terminology in this study has drawn from several sources which define revenue generation. Massey, Quinn, and Museum of New Zealand $(2001,32)$ provided the definition of traditional revenue supply; their definition covers admissions, concessions, retail, memberships, grants, governmental help and private donations. Non-traditional revenue generating practices are defined as per Orinda's study (Orinda 2008, 4). This encompasses programs, partnering, fundraising, museumoperated businesses, venue hire, museum website and third-party websites. Innovative revenue is defined according to the work of Brodie, Kane, and Clark $(2012,37)$. The authors' definition included phone applications for smartphones, crowdsourcing and e-commerce.

Crowdsourcing is one example of the new interactive relationships between museums and communities. These relationships contrast markedly with the historical relationships between museums and their communities. In the $18^{\text {th }}$ century, museumpublic relationships were semi-private (Bennett and Lumley 1988, 63). By the $19^{\text {th }}$ century museums were perceived as a tool for creating civilised societies (Turner $2001,2)$. In the 1950s, Hudson $(2014,86)$ noted the role of museums was considered separate from the business world. The mission of a museum was to educate and hold collections in perpetuity. The value of museums as a public good was acknowledged by extensive support from the state. There was thus little impetus for museums to become enterprising (Dickenson 1993, 222). This lack of impetus is one factor which accounts for the lack of economic research on museums. Of the research available, notable examples include Lord and Lord (2009) and Silberberg and Lord (2015, 3).

One area of note with regards to economic research and museums is social services. Social services such as museums are provided by governments or private organizations. These services are often involved in building communities and providing opportunities. Social services research such as Scott $(2015,2)$ and Selwood 
and Davies (2015) provides useful background on financial management in museums. NZ government policy on supplying income to social services has affected museums (Selwood and Davies 2015). For example, during the 1970s government policies were established for evaluating social services. Assessments were based on quantitative measurements. Compliance with government agendas factored in assessments (Scott 2015, 9). In the 1990s assessment criteria were developed with the inclusion of social and economic targets. The role of museum staff began to evolve from curator to business person. There was pressure to focus on work which could be evaluated, or face a reduction in funding (Barton 2008; Arnold 2015). Recent studies of museums have considered the overall value of museums (Scott 2015,9). Debates often focused on economic value, which is the extent to which something enhances our well-being. Economic value has benefits to society which are greater than or outweigh its costs (Holden 2004, 31). The full scope of economic value ranges from commercial to non-market values.

Despite these definitions of economic value, its measurement and application is debated. Tusa $(2007,157)$ for example, critiqued measurements of the economic benefits of cultural projects such as the Bilbao Guggenheim. Holden $(2004,31)$ criticised quantitative and numerical data evaluation models. Despite these critiques few alternative evaluation models have been proposed. Frameworks that meet government criteria and articulate the views of museums have been slow to develop (Scott 2015, 25). A key factor in this slow growth is the disagreement around the attributes of value. Devising interpretable evidence around the different kinds of value in collections is challenging (Legget 2006, 310). For example, recent research has not resolved the question of intrinsic value in museums. As economists Bakhshi, Freeman, and Hitchen $(2009,15)$ articulate:

There is a contradiction between the plea that the intrinsic value of art should be accounted for, and the idea that it is beyond accounting. If art really is beyond valuation, there is no point complaining that it has been valued improperly. If it really cannot be assigned a value, it cannot sensibly also be argued that policymakers can take this value into account.

When intrinsic value has been quantified in evaluation models it has provoked debate. Some such as Clark (2014) have adapted evaluation models which include intrinsic value. Others such as (Hong 2014,102), critique the inclusion of intrinsic values in 
models. One example of a model featuring intrinsic value is the Cultural Value Triangle (Hewison and Holden 2013, 70). This model argued that the value of culture can be broken down into three clear areas, intrinsic, instrumental and institutional. Hong (2014) critiqued Hewison and Holden's theory on the basis that it was trying to do two things at once. It attempted to link the unique value of culture while at the same time offering a unit of analysis. Hong's paper also considered the New Zealand (NZ) Ministry of Culture and Heritage's $(\mathrm{MCH})$ work on evaluation models. It was part of a wider Cultural Trends series in 2014 on measuring cultural value (Scott 2014). On the basis of the research available it appears that evaluation is an emerging subject in Museum Studies (Scott 2015). As for future trends, partnerships may be crucial; for example, the MCH and TP partnership on evaluation (Hong 2014).

Current research on museums suggests that there has been a shift in the way that NZ museums are evaluated and financed. During this current study, the implications of this shift for revenue generation will be discussed. Value research has also provided this study with a key concept. This thesis adopts the idea that value has many interpretations. Throughout the thesis, the many values of innovative and nontraditional revenue are demonstrated.

\section{Economic theory and business models}

The literature on economics and business offers insights into how museums approach revenue generation. These insights have informed the framework used in this thesis in terms of the questions and structure. The theory of a museum as an economic unit or a firm has been explored in several papers (Feldstein 1991, 3; Johnson and Thomas 1998, 7; Frey and Meier 2006, 14). The firm concept focuses on the idea that a museum converts inputs (resources) into outputs (products and services sold). It earns the difference between what it spends on inputs and what it gains in revenue (Carlton and Perloff 1994, 11). Several management techniques offered by the 'firm' model are not always applicable to museums. NZ museum collections cannot be treated as a financial asset, despite deaccessioning debates. There is no potential to generate a return from an alternative use of collection items. Given that this strategy is not transferable, the application of the firm model may be problematic for museums and is not therefore included in the research design of this study. Some available research which covered the firm model neglected contemporary revenue sources. Feldstein's 
work (1991) for example does not cover museum shops, cafes and functions. Its value for benchmarking the findings of this study was thus reduced and influenced the decision to not use the firm model.

Some earlier studies conceptualised museum operations as transactions. Kotler and Kotler $(2000,273)$ considered the relationships between museums, visitors and supporters as an exchange of benefits and costs. Many of Kotler and Kotler's (2000) ideas demonstrate and support the idea of relational capital. Relational capital is the set of relationships between institutions and people. These relationships stem from a strong sense of belonging and cooperation (Capello and Faggian 2005, 77). The existence of high relational capital may be indicative of the stability of a museum; this stability could support revenue generation. Relationships and revenue generation have thus been explored in this study.

As for collections and revenue generation, Grampp $(1989,172)$ offers an interesting argument, that by discounting collections as a revenue source museums underestimate capital costs. His research reflects a discussion in economic literature on the costs associated with museums. One common theme in these discussions is inadequate costing (Bailey and Falconer 1998, 7). Accurate costing is essential for viable pricing of museum services (Png 1998, 39). Some costing theories discussed in current literature include the zero cost theory. Zero costing is based on the idea that the set up and opening costs in a museum are mostly independent of visitor numbers. The theory argues that the marginal cost of an extra visitor is close to zero. While Frey and Meier $(2006,5)$ support the theory of zero costs, Bailey and Falconer $(1998,7)$ critique the zero costs argument. The authors maintain it has no bearing on the long run marginal costs of museum operations. Conclusive findings on congestion costs in museums are also scarce. Despite the research of Maddison and Foster $(2003,173)$ data is still limited. While economic data on museums is limited, economics is still valuable as an academic discipline (Johnson and Thomas 1998, 1). It offers a tool for evaluating possible conflicts in museum practice and steps away from debating the social role of museums. Economic research focuses on general principles and rules (Johnson and Thomas 1998, 2). While often conceptual this research offers a different perspective to other disciplines so there is value in considering economic research on museums alongside that of other disciplines. 
When considering revenue initiatives, business management research offers insights on how companies approach innovation. Some prior research on museum economics has incorporated business theory. Examples include Massey, Quinn, and Museum of New Zealand (2001, 7); Feldstein (1991, 3); Johnson and Thomas (1998, 7); Frey and Meier (2006, 14). After these papers, Anthony, Duncan and Siren's (2014) paper warrants further research. The authors theorised a framework for defining innovation using the Minimum Viable Innovation System (MVIS). MVIS highlights the difference between building ad hoc innovation versus reliable, strategic innovation. This model could enable museums to evaluate innovations that strengthen ongoing business. It could also be used as a tool to consider the viability of new revenue sources. MVIS outlines several characteristics necessary for successful innovation. Alongside these characteristics MVIS argues in a similar manner to that of Luoni (2011), and suggests that successful leadership involves consistent practice.

Organisations must consider their specific circumstances and tailor their operations. The concepts of leadership and innovative practice suggested by MVIS are evaluated over this study. MVIS offers a framework for defining innovation practices. This framework is crucial as there is an absence of common definitions for innovation.

MVIS was examined for this study alongside the Innovation Value Chain (Hansen and Birkinshaw 2007). The Innovation Value Chain (IVC) was developed from five major projects on innovation in business. The authors analysed innovation in 120 product developing projects and 100 corporate units. What evolved from their findings was an idea that innovation in an organisation has three key stages of development. Managers were identified as having a series of responsibilities at each phase. The IVC is explored from several angles in this study. The responsibilities of managers have been analysed alongside key components for successful innovation.

Some economic records have practical applications when assessing innovative and non-traditional revenue generation. Relevant records include the balance sheet, revenue records and the profit and loss account.

1. The balance sheet is a 'snapshot' of the assets and liabilities of an organisation at a given moment. Usually the end of the financial year (Finney 1944, 1). By comparing the figures of balance sheets from the end of one year to the next it is possible to see if an organisation has changed its net worth. 
2. Revenue records break down innovative and non-traditional sources of revenue. For example, an increase in retail revenue in a given year can show the effectiveness of new sources such as exhibition retailing. In the next chapter, the methodology, explains the approach taken to revenue record analysis in this study.

The business model used by a museum could affect its ability to capitalise on revenue research. Falk and Sheppard $(2006,21)$ have outlined one traditional model: the industrial age model.

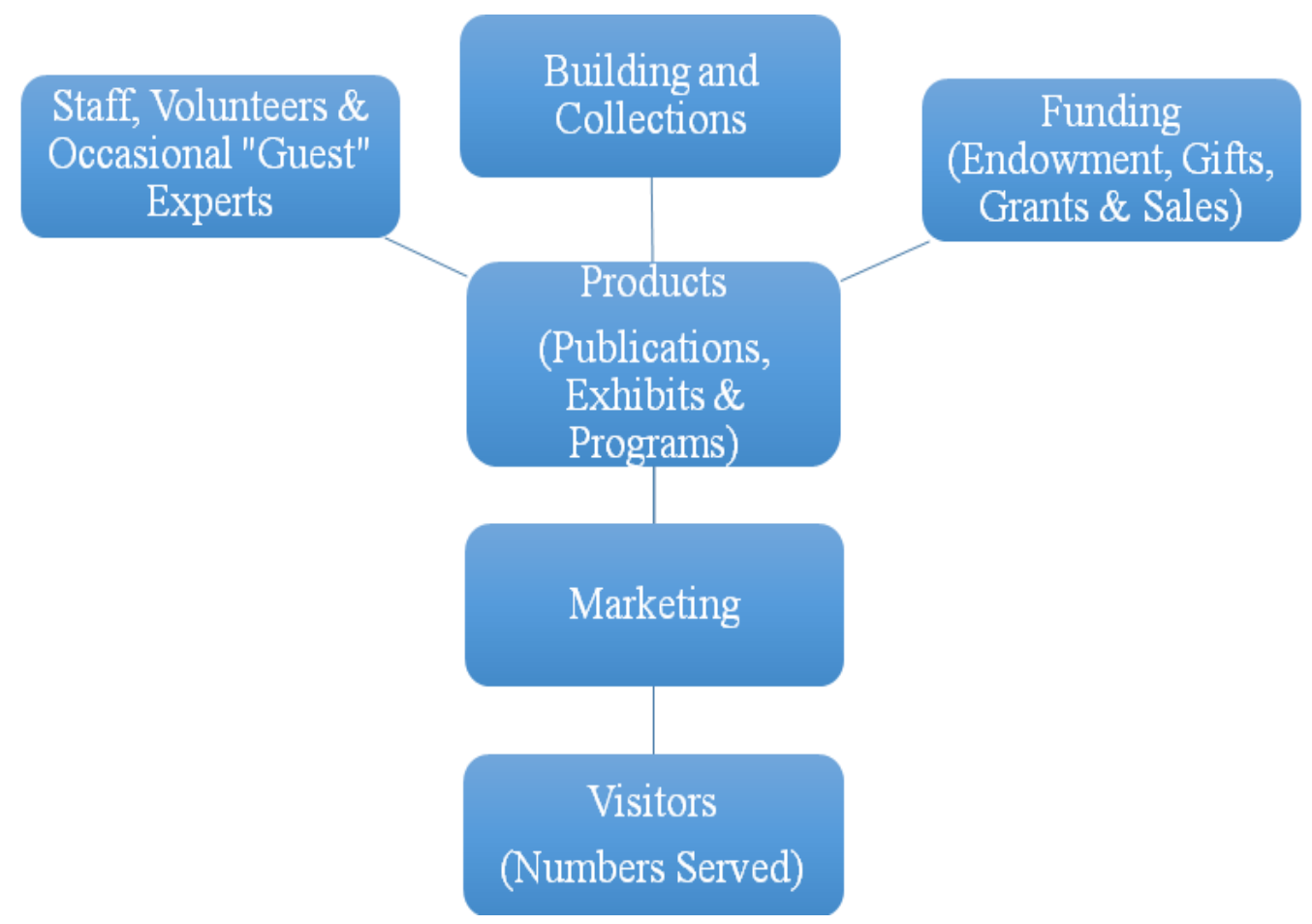

Figure INT.1: Industrial age model

As Figure INT.1 demonstrates, the industrial age model is linear with a top down framework. Management is based on the notion that the museum is the 'authority'. There are essentially no avenues for feedback from visitors and museum personnel. 'Success' is measured by visitor numbers, catalogues sold and resources consumed. It is based on the theoretical premise that museums are only tangentially linked to the external environment. Falk and Sheppard argue that this is the 'build it and they will 
come' approach to doing business. A museum in this model functions like an island separated from the world (Falk and Sheppard 2006, 22).

Several scholars argue that the industrial age model is outdated. It does not acknowledge the external environment surrounding museums. As a result, this model may fail to address threats from other leisure time providers. The industrial age model does not embrace the notion of shared authority, which can offer new insights into collections and create reciprocal partnerships (Puklowski 2014). Blending entrepreneurial practices with the social and educational functions of museums may be crucial for the future (Shaw 2014). Falk and Sheppard $(2006,23)$ have suggested a strategy for creating this blend in the knowledge age business model.

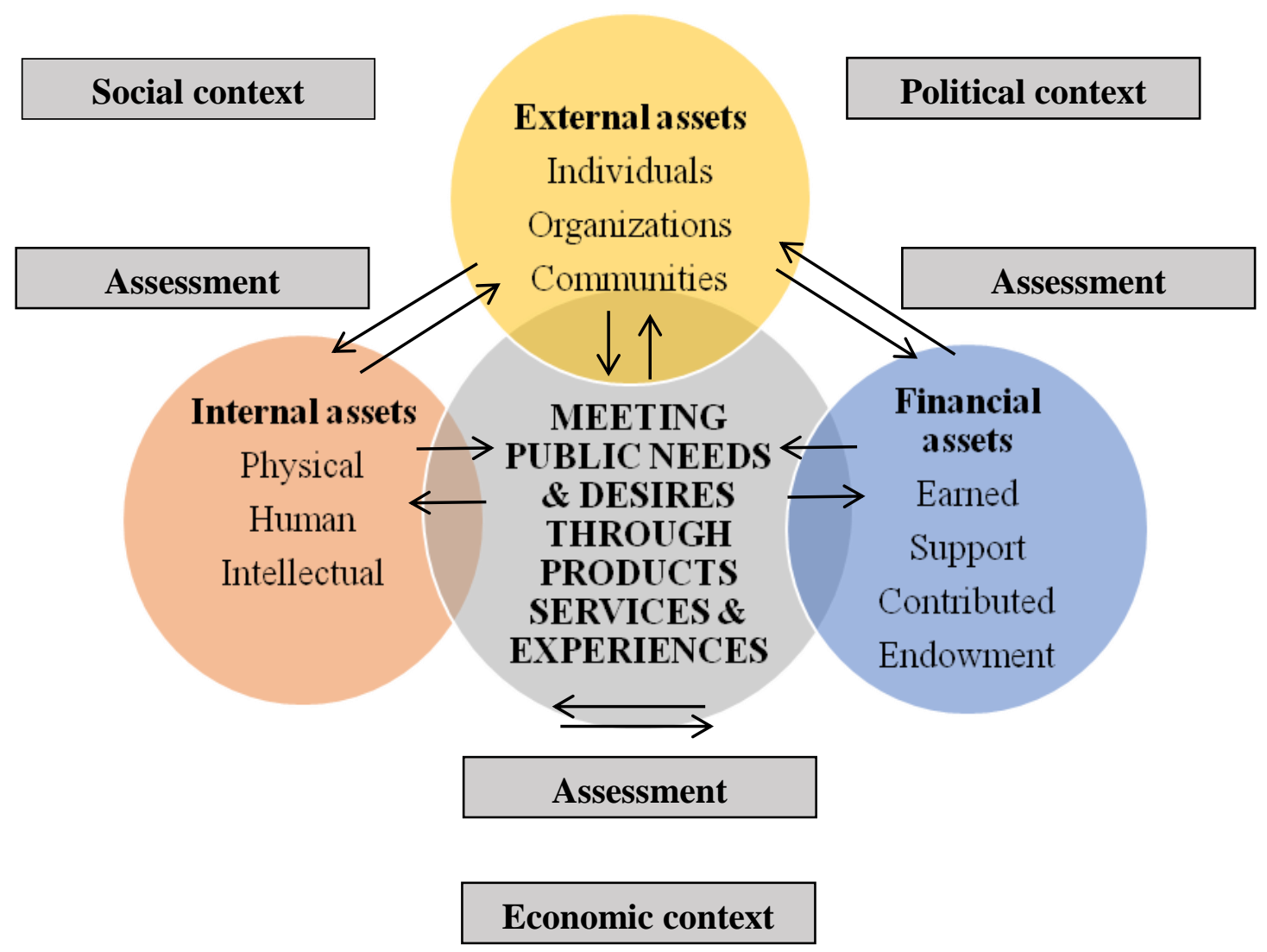

Figure INT.2: Knowledge age model

At the centre of the model is a focus on visitor needs and an interrelationship between both internal and external entities. It emphasises that business begins with the consumer and it situates a museum within the eco-system of its larger society. The basis of the model focuses on systems in which all pieces interact and feedback to 
each other. The theories of Falk and Sheppard (2006) parallel Massey, Lewis, and Museum of New Zealand (2002). Both papers acknowledge the influence of the external environment of a museum on its internal operations. Little American bias is apparent in the findings of Falk and Sheppard (2006); this research therefore included the knowledge age model in its analytical framework. This model has illuminated relationships between museum practice and revenue. It defined research boundaries and assisted with terminology in the study. The model also offered a way to identify and prescribe research questions.

\section{Innovation and opportunity}

The paucity of research data can be viewed as diminishing the viability of innovative and non-traditional revenue. However, this does not discount the opportunities from these revenue sources which could link commercial operations and museum practice. The indirect benefits of revenue may have implications for collection management and social enterprises. This idea of revenue having indirect benefits is explored throughout this thesis and suggests that the contribution of commercial practices in museums could extend beyond income.

Limitations in research data continually plague innovative and non-traditional revenue. A museum wanting to experiment with these sources cannot be guided by data to ensure success. There is little data to test web marketing initiatives such as GROUPON (Rega 2011, 58). But despite the potential issues, web marketing initiatives could offer opportunities for cultural exchange. As Henning $(2013,599)$ articulates:

Digital media offer possibilities for control, but also for relinquishing control. This is not about the "gamification" of museums (i.e. the use of games and the harnessing of the pleasures of play to engage visitors and increase visitor numbers). It is about a model of play that involves aesthetic pleasure, participation, and collective engagement, a "delirious" loss of control and uncontainability - extending endlessly beyond the walls of the museum, into everyday experience, across media and bodies, and back again.

Henning suggests digital media is a vehicle for participation. This is a significant theory in the context of the Cultural Philanthropy Taskforce (CPT) report $(2010,15)$. The CPT report concluded that current generations may wish to actively participate as 
donors. The 'arm's length approach', favoured by previous generations of private NZ donors may not be relevant. Platforms such as crowdsourcing could offer interactive platforms for museums and their communities. The application of crowdsourcing in museums may have practical applications beyond revenue generation. Crowdsourcing could be used to describe collection items through the use of metadata (Oomen and Aroyo 2011, 11).

Early initiatives in $\mathrm{NZ}$ on crowdsourcing and revenue generation include the web seminars produced by Creative New Zealand (2014). Beyond these seminars, research in NZ on crowdfunding is in its infancy. It is an interesting point of contrast to that of the United States where some academics such as Brabham (2016) have started to debate the implications of crowdfunding for public arts funding. The absence of NZbased research is also notable given the number of successful crowdfunded campaigns. Christchurch Art Gallery's 'Back the Bull' is just one example. Despite these successes, the revenue source remains under researched.

Besides cultural collaboration, Henning $(2013,596)$ also provides astute comments on image sharing:

Twenty years ago, writers and curators anticipated the impact of the combination of computers and telephone technology for the dissemination of images, but they could not foresee the ways in which mobile phones equipped with cameras and apps such as Instagram, Flickr, and Facebook, would contribute to making image sharing such a common cultural practice. Only recently has the discussion of the digital image shifted towards an interest in the cultural and philosophical consequences of practices of transmitting, sharing, and transforming images.

Many museums have responded to the image debate by releasing images online (Museums Aotearoa 2005, 13). Projects include Digital NZ and the National Register of Archives and Manuscripts (NRAM). Current examples of collections online include National Library Australia, TP and Auckland Museum. Images follow a variety of licenses; examples include copyright and commercial use (Creative Commons 2014). TP Collections Online was initially greeted with concerns about image exploitation and reduced revenue. These concerns have not eventuated. The revenue generated by Picture Library/Media Sales and Licensing unit in TP has 
remained stable. TP has also saved on operational costs. The TP website allows the public to process image requests (Kingston and Edgar 2015). As well as revenue benefits this innovation has offered a new tool for community engagement with collections. The idea of revenue as a medium to bring new tools for community engagement is explored in this current research.

There appear to be several key pieces of research which advocate for further exploration of online collections. Mason and McCarthy $(2008,65)$ argue for strategy around online developments. Powell $(2016,53)$ advocates for a copyright forum for museums to discuss image licensing. Beyond Powell (2016) there is other NZ based research in this field, Collections Online, the TP online collection project has been studied by Creative Commons ${ }^{1}$ (Heritage 2014). Some international research on online collections is also worthy of note. In relation to revenue generation Pekel $(2014,13)$ provides a useful analysis. Pekel studied the online collection of the Rijksmuseum. The museum released over 150,000 high resolution images with no use restrictions. The potential loss of image revenue was considered to be offset by possible promotions and sponsorship (Pekel 2014, 15). This change in the museum's attitude could be an interesting shift for revenue generation. Instead of looking solely at the income generated the museum considered the indirect benefits. Revenue generation provided more than just income. This study will compare local examples of revenue generation with this scenario. It will determine whether revenue generation can provide more than just income.

The indirect benefits of revenue with reference to social enterprise is commented on by Doherty $(2011,2)$. Social enterprise is a commercial activity focused on delivering social or environmental outcomes. Social enterprise offers opportunities for innovative practice and diversified revenue. A contemporary example of social enterprise is the UK Museum of East Anglian Life. Alongside traditional revenue, they generate income from courses, prisoner rehabilitation, events and garden produce. Academics such as Ford (2012) have debated whether museums are already social enterprises. Others have argued that social enterprise is a viable operational

${ }^{1}$ Creative Commons is an advocacy group supporting copyright management in the cultural sector in New Zealand. 
model (Hewison and Holden 2013, 131). The relevance of social enterprise in revenue is considered in this research.

On a related note to the concept of a museum as a social enterprise is the idea of a museum as a 'third space' (Bloom et al. 2013). Third spaces are public venues for informal social engagement outside of home or work. They invite individuals and strangers to engage with each other (Oldenburg 1989). Third spaces can range from commercial areas such as museum cafes through to exhibitions. Considering the concept of a third space for a museum could redefine visitor engagement. As Connolly (2010) notes, creating a museum as a 'third space' may be central to its function as a community stakeholder. It may move museums beyond conventional notions of building attendance and revenue streams. In this study, the 'third space' concept has highlighted some indirect benefits that can result from revenue, and has allowed me to consider if revenue generation enhances a visitor's experience.

\section{New Zealand museums and revenue sources}

The final section of this literature review gives a brief overview of museums in NZ. It introduces some key NZ museum issues which are explored in this thesis and considers what bearing these issues have on innovative and non-traditional revenue.

Per population, NZ has a large number of museums. In 2013 there was one museum for every 9500 people (McCarthy 2014). The majority of these museums are small volunteer-based organisations; mid-size and large institutions are in the minority (Museums Aotearoa 2005, 3). TP is currently the largest museum in NZ. Early NZ museum collections often focused on natural history, with a strong geology focus. Museum interest in Māori culture and ethnology grew in the early $20^{\text {th }}$ century. In parallel with this development, research and public education became more important. Following the Second World War, echoing international trends, a large number of NZ museums opened. These new museums often specialised thematically on subjects such as transport or heritage parks. The New Zealand Cricket Museum (NZCM), for example, opened in 1986. The volume of museums in NZ continued to grow throughout the 1990 's and into the $21^{\text {st }}$ century. The modern museums which opened during this time such as Pātaka Museum and Art Gallery (P.) were often serving dual purposes. Today NZ has over 450 public museums and galleries, out-numbering many 
other popular leisure time entertainments (Blundell 2014). In $2012 \mathrm{NZ}$ museums received just over $\$ 135$ million in revenue, of which $\$ 36.5$ million came from central government. A proportion of this was for capital works - over the past 13 years the Government has awarded some $\$ 93$ million to redevelopment projects.

As NZ museums continue to redevelop they may be facing a different society from that under which they originated. NZ museums operate in a small economy with a relatively small population: just under 4.5 million as of 2016. It may be that social changes such as the increasing age of the NZ population may have a significant effect on the viability of any revenue in the future. Leisure participation in retirement is another factor to be considered when investigating possible opportunities. There may be opportunities for museums to provide for the needs of lifelong learners in the future. Does capitalising on these opportunities come down to attitude? As NZ museums have aged and developed the composition of their workforce has changed (Davidson and Shaw 2015). While the numbers of professionally trained museum staff are increasing in NZ, negative attitudes to 'business' are still common (LloydJenkins 2014, 6). Attitudes do not always seem to reconcile with strategy, as a 'business unit' is a core function in many NZ museums. What may have motivated a museum to incorporate business may be key to its attitude (Massey, Quinn, and Museum of New Zealand 2001, 11). These motivators do not appear to be straightforward. Performance measurements, for example, have had a varying impact on revenue. As Jenkins $(2014,6)$ notes, the implementation of performance measurements on NZ museums has varied. The forecasting by councils and government has been diverse with expectations peaking and declining. These variations may not be a catalyst for innovative or non-traditional revenue generation. As Hewison and Holden $(2013,106)$ argued, public funding may well have led to organisations being stuck in an uncreative rut. This thesis will consider whether museum revenue is unduly influenced by legislation and external policy.

Methods for breaking an uncreative cycle could include seeking guidance from museum associations which support professional practice. Revenue generation is acknowledged in the ICOM code of ethics (International Council of Museums 2004):

The governing body should have a written policy regarding sources of income that it may generate through its activities or accept from 
outside sources. Regardless of funding source, museums should maintain control of the content and integrity of their programmes, exhibitions and activities. Income-generating activities should not compromise the standards of the institution or its public.

There is little guidance offered by this code on the delivery of revenue generation. Although it documents some ethical principles it does not say much about generating revenue ethically. For example, there is no guidance on working with volunteers who generate museum incomes. Possibly the attitudes of museum staff may have a bearing on the viability of revenue generation, which is considered in this current research. The role of volunteers in revenue generation in museums will also be examined.

Many NZ museums have generated indirect revenue from private philanthropy in the form of volunteer work. NZ museums surveyed in 2014 received over 100,000 hours in volunteer work (Davidson and Shaw 2015, 50). However, when it comes to financial support NZ has less private philanthropy than Australia (AU) (Cultural Philanthropy Taskforce 2010, 6). Methods for developing private revenue in NZ museums differ from the United States (US) (Hazledine 2011, 65), as NZ museum trustees are not required to personally contribute and cultivate revenue. Board members cannot be sued or made liable in museum operations (Genoways and Ireland 2003, 48 ).

Besides philanthropy, competing with other visitor attractions is another key issue (Frey 1998). Competition for resources, such as council revenue, have increased (Museums Aotearoa 2005, 10) and other external forms of support have not offset this pressure . Greater competition in the marketplace has not correlated with higher levels of support.

Beyond support, Morris Hargreaves McIntyre (2012, 22) highlights the unmet demand for culture in Wellington. Understanding these demands could enable museums to capitalise on this opportunity. A pertinent summary of key issues in visitor demand is provided by Frey and Meier (2006). They identified determinants on visitor motivation as including time, an institution's tone and admission prices. Visitor attendance may be countercyclical (Skinner, Ekelund Jr, and Jackson, 2009, 
2). If demand does indeed increase when the economy is slow, a diversified income may be more viable. Can innovative and non-traditional revenue provide this diversity? This study will explore this possibility.

Diversification is an issue faced across the museum sector, and museum marketing has had to balance economics and innovation (Rentschler, Hede, and White 2007, 21). Marketing managers often make pricing decisions which can be crucial for revenue (Wright and Lees 2003,11). Pricing is a subject with an extensive history in Museum Studies; notable NZ research papers include Admission charges - the issues (Museum of New Zealand and Lindsay 1994). The research framework of this paper was robust and analysed a wide range of issues. It considered, for example, the impact of admission charges on low socioeconomic groups, but it paid little attention to the museum's external environment in its admission policy. It also offered no time-frame for a review of the policy so the ongoing viability of the national museum's approach to admissions revenue could be considered problematic.

Wellington Museums Trust ${ }^{2}$ has also conducted notable mixed method research on admissions $(2014,8)$. The trust considered public attitudes to charging and the practices of other cultural institutions. The study was motivated by the Trust's need to balance operational costs and funding. While focussed on practical considerations, it appears to be a reactive as opposed to proactive response to the museum's financial circumstances. In terms of academic research it marks a departure from the tradition in international museum research of debating the ethics of charging (Rentschler, Hede, and White 2007).

On a related note, there are a range of academic debates on free admission and visitor spending. Arguments vary; Ipsos $(2003,9)$ argued that visitor spending on ancillary services is higher when entry is free. Steiner $(1997,19)$ disagreed, finding that visitor purchases decline when entry is free. Regardless of the implications of free admission, Silberberg and Lord $(2015,9)$ comment:

the ability to achieve higher non-admissions earned income as a result of large numbers of visitors actually depends on how entrepreneurially

\footnotetext{
${ }^{2}$ In 2016 Wellington Museums Trust rebranded to Experience Wellington. They retain the name Wellington Museums Trust Incorporated as their legal name.
} 
a museum approaches larger visitor volumes. For example, the product line of a retail store or restaurant may need to change with a shift in the profile of visitors.

On the basis of this statement it would appear that innovation may be key in every form of revenue in museums. This notion is explored during the interviews conducted as part of this thesis.

Museum retail has been perceived as a panacea to decreasing income. Recent international trends include store expansions, satellite stores and increased ecommerce (Thau 2008, 9). Little development has occurred with museum satellite stores in NZ. The TP shop satellite store in central Wellington closed in 2013. Ecommerce development has also been challenging. Research has highlighted the need for more detailed empirical evidence (Mason and McCarthy 2008). Museums may also lack the technology and necessary staff for e-commerce (Brodie, Kane, and Clark 2012, 33). Mason and McCarthy $(2008,77)$ argue that these resourcing issues could be more prevalent in smaller institutions. This possibility is explored through the interview data of this study. Baudet $(2014,11)$ suggests that resourcing must address professional development. Museums need to develop retail skills and train retail staff in museum practice. This argument supports interrelationships in museum operations, another concept explored in this study.

Despite Baudet's work, there is limited research on museum retail. Of the research, available some clear trends can be noted. Partnerships and advocacy are helping to sustain retail (Brodie, Kane, and Clark 2012, 33). For example, the Museum Shop Association of Australia was established to support museum stores. The organisation provides professional development, advocacy and information (Museum Shops Association of Australia 2010). Other examples of advocacy for revenue development include the NZ National Digital Forum. Established in 2001, the forum supports ecommerce initiatives. Recent forum presentations such as Firth (2015) have introduced new revenue initiatives, these include museums' innovation hubs. Innovation hubs are entrepreneurial residential programs. The latest hub has been established at TP and opened in August 2016. Whilst at an early stage, this initiative is examined here. It would appear that Mahuki has the potential to invigorate and add 
vibrancy to TP (Mack 2016). The impacts of external advocacy initiatives associated with revenue generation are also explored.

The future of many museums may look like social businesses (Yunus 2007).

Museums are often pressured to consider social problems and be self-sustainable

(Clare 2014, 10). Current research has documented this pressure and provided insights on economics and museums. Falk and Sheppard (2006) considered traditional business practice and then theorised strategies for museums. Despite these strategies there are still gaps in current knowledge. In relation to the literature surveyed for this review, the gaps in the existing literature can be broken down into four areas:

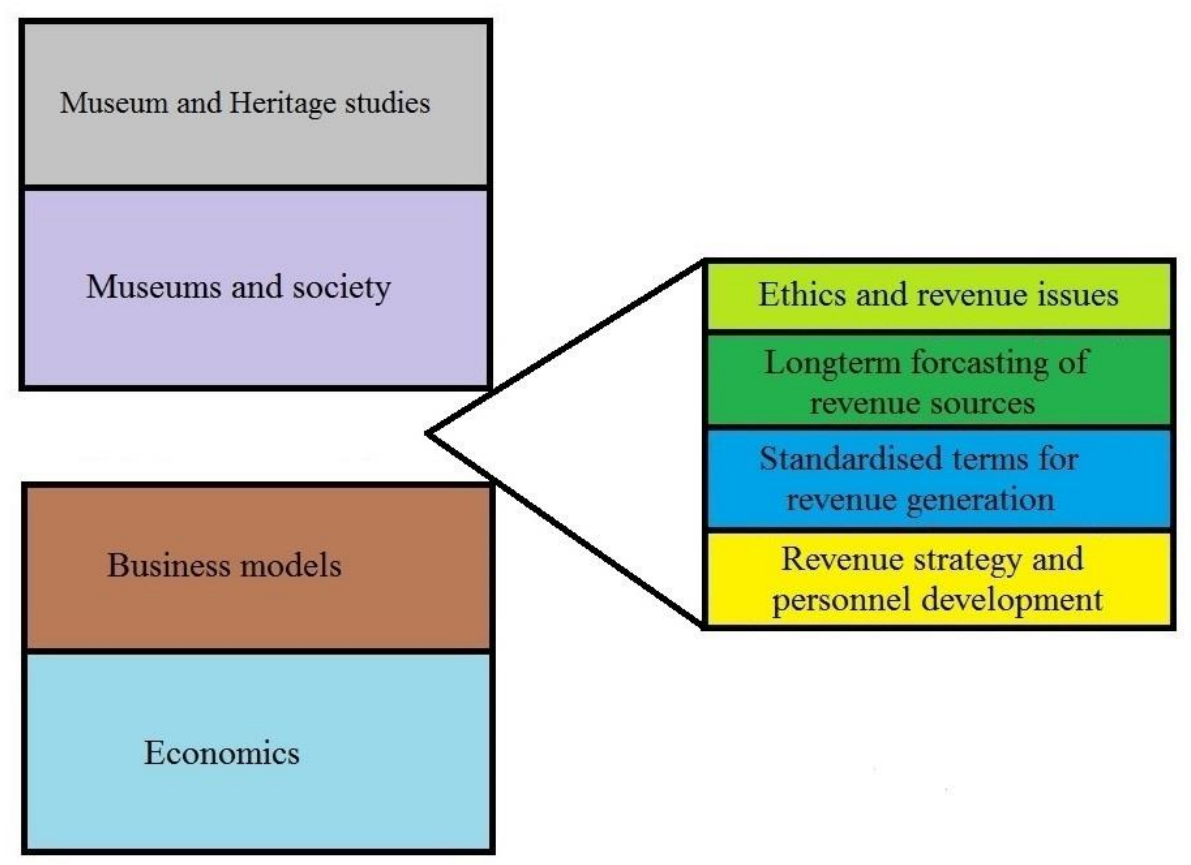

Figure INT.3 The gaps in the existing literature

This thesis has considered these gaps and sets out to provide more knowledge on the situation in NZ. By drawing on theory outside of Museum Studies it has found ideas which consider innovation. MVIS and IVC have been used here along with the theories of Falk and Sheppard (2006) to provide a theoretical frame work for the study. Resulting findings highlight fundamental factors in innovative revenue as scoped by the research question. The following chapter explains how these findings were generated by outlining the research design. 


\section{Chapter One: Research design - Sampling New Zealand Museums}

\section{Introduction}

During the introduction to this thesis some issues with the financial viability of museums were discussed. As shown in the literature review above, current research has rarely focused on museums and revenue practices. There is also little data available for comparative studies concerning revenue. Alongside data, infrastructure issues make the examination of new revenue avenues challenging.

Many of these challenges have been faced by the institutions included in the case studies below. Museums examined include The New Zealand Cricket Museum (NZCM.), Museum of New Zealand Te Papa Tongarewa (TP) and Pātaka Museum of Arts and Cultures (P.). To consider these museums, analytical frameworks were drawn from business management research. These frameworks provided a strategy for identifying the key elements which make revenue viable. These elements have then been considered alongside the direct and indirect benefits of revenue.

This chapter describes the research design and the methodology for this thesis. It also provides background context for the case studies and looks at how the data were presented. The chapter is divided into sections. It begins by outlining the overall research design. It discusses the research aim, paradigm and the study questions. The next section in the chapter focuses on research methods. A general overview of the case study museums is provided in section three. The chapter concludes by giving an overview of the thesis.

\section{Research design}

This study aimed to contribute to the body of knowledge on museum economics through the study of revenue generation practices. Pragmatism has been adopted as the research paradigm for this study. There is a wide range of museum models in NZ so it seemed appropriate to use a flexible paradigm. This paradigm also offered ways to accommodate the diverging opinions on revenue. Early pragmatists

...rejected the scientific notion that social inquiry was able to access the 'truth' about the real world solely by virtue of a single scientific method (Mertens 2015, 35). 
The relationship between Pragmatism and mixed methods research has been articulated from different angles. Some academics contend that Pragmatism provides a philosophical foundation for mixed methods research. Others argue that Pragmatism could provide philosophical support for mixed methods approaches (Tashakkori and Teddlie 2010, 95). For the purposes of this study, Pragmatism was employed as a philosophical stance for how the research was approached. This approach fits the empirical research into current professional practice in museums.

Pragmatism guided the choice of mixed methods for the studies research design. The Knowledge Age business model (KA) (Falk and Sheppard 2006, 22), the Minimum Viable Innovation System (MVIS) (Anthony, Duncan, and Siren 2014) and the Innovation Value Chain (IVC) (Hansen and Birkinshaw 2007) were also used in the research design. These three theories prescribed the boundaries of research and established terminology and guided the formulation of interview questions.

Qualitative and quantitative methods were used involving both primary and secondary data. Initial planning for the study reviewed the work of Sutherland (2006) and Allan (2008). Sutherland's (2006) work informed the decision to look at case studies. The limitations of existing research and revenue terms also encouraged this approach. It seemed impossible to deliver a comprehensive comparative inquiry or a survey of revenue, so it was appropriate to focus solely on case studies and innovative and nontraditional revenue.

Three case studies were drawn together for the research. Their existing revenue records outlined income from innovative and non-traditional revenue. Primary data, in the form of interviews, were tailored to the study. The research drew upon the empirical evidence in the MVIS and the IVC to develop interview questions. These questions considered the contribution of innovative and non-traditional revenue and its viability. Overall, the study focused on the following central research question:

Do innovative and non-traditional revenue sources improve the financial viability of New Zealand museums? If so, how?

To break down the issues, a range of sub questions were written as follows: 
What options are available for innovative and non-traditional revenue sources?

Which options are currently delivering revenue for the case study institutions?

Are there other benefits derived from these revenue sources?

What un-met opportunities are there?

How can museums capitalise on their un-met opportunities?

After the questions were formulated an ethics proposal for the study was submitted to the Human Ethics Committee at Victoria University. It outlined the ethical practices used in the study, which included informed consent processes for all interviewees and secure storage of interview data. The project was approved.

\section{Research Methodology}

A range of research methods were used for this study. They included case study research, quantitative analysis of revenue records and qualitative analysis in the form of interviews. Mixing research methods reduced any weaknesses in the research design (Johnson and Onwuegbuzie 2004). Case study research seemed appropriate as it investigates contemporary phenomena in a real-life context. It allowed the study to test how the MVIS and the IVC applied in the real world. By using many sources (Yin 1984, 23) the case studies captured many variables. These included variations in organisational structures (Evans J and Bridson 2013).

Currently Wellington, New Zealand (NZ) has a high volume of museums in a small geographic location. Local case studies offered a way to capture a variety of organisational structures. Similarities were clear among the challenges of Wellington museums and their regional counterparts (Morris Hargreaves McIntyre 2012). Although the decision to use local case studies could also be considered pragmatic as Wellington was the base for the research, selecting local participants maximized data collection and was more manageable for me studying part-time without the resources to travel and conduct research in other centres. 


\section{Quantitative analysis}

Quantitative analysis tools were used to review secondary data in the form of revenue records. Records were requested from each case study for the financial years from 2012 to 2015. Gathering data beyond this time period would not have been possible within the thesis timeframe. The choice of records was determined by the availability of revenue data. Although all museums create a range of economic documents it was found that in practice these documents were not standardised.

The results of the revenue record analysis were coded in a manner like that of Massey, Lewis, and Services $(2002,6)$. Each institution's sources of revenue supply were identified and counted. Existing literature provided the definitions of revenue sources and allowance was made for variations. Over the course of the research the definitions of revenue were modified; the aim of which was to generate a greater depth of analysis/understanding. The final definitions were as follows:

Traditional sources of revenue supply, based on the work of Massey and Quinn (Massey, Quinn, and Museum of New Zealand 2001, 32), Innovative revenue generating practices (principally digitally based) (Brodie, Kane, and Clark 2012, 37).

Non-traditional revenue generating practices (Orinda 2008, 4).

The goal in this initial quantitative stage of the research was to capture the issues and general trends in terms of revenue.

\section{Qualitative research}

After the issues and trends were established they were explored using qualitative research tools. Qualitative tools were used in the form of semi-structured interviews. The KA business model (Falk and Sheppard 2006, 22) was used with the MVIS and IVC to establish interview questions. Topics discussed included organisational culture, internal and external relationships, strategies, values and motivations. Closed questions were included in the research design to offset any potential bias from the open results. The open and closed questions were asked in non-sequential manner, but in the interests of clarity the results are presented in the next chapter separated into type. A copy of the original questions is supplied in the appendix. 
A pilot test of the interview questions was undertaken with the help of Alexis Hawke, a former retail manager at TP. Her feedback was useful in the configuration of the final questions.

Following the pilot test, interviews were carried out with key informants from the three museums. The informants selected for interview were:

Darren Milsom, Manager, Te Papa Cafes.

Phillip Smith, Director of Te Papa Enterprises.

Jamie Bell, Director, The Cricket Museum.

Zara Hawthorne, Financial and Reporting Coordinator, Pātaka.

Informants were selected on the basis of their knowledge and experience with revenue generation. In the case of TP two informants were interviewed to determine if there was a divergence of opinions on revenue; they were selected from units involved in both revenue strategy and day to day operations.

Participants signed a consent document and were informed of their rights to withdraw from the study. A transcript of the interviews was supplied to interviewees for them to check and or amend before publication.

\section{Case studies}

Many of the institutions contacted were unable to take part in the study; other institutions agreed and then withdrew due to restructuring and lack of available resources. Despite the withdrawal these organisations still offered useful insights.

The institutions that agreed to take part provided a variety of organisational models. The final institutions were:

The New Zealand Cricket Museum (NZCM.)

Pātaka Museum of Arts and Cultures (P.)

The Museum of New Zealand Te Papa Tongarewa TP

The Museum of New Zealand Te Papa Tongarewa TP is located on Wellington's waterfront. The museum opened in 1998 and was part of a new generation of 
museums which embraced new museology. New museology focuses on the visitor experience rather than the collections (Vergo 1997). TP was an intended radical departure from its predecessor, the National Museum and Art Gallery (McCarthy 2011). Alongside a heavy visitor focus the museum was required to be 'commercially positive'. When the project was approved by the NZ government a clause required the museum to generate a quarter of its income (Tramposch 1998, 348). As a consequence, the museum developed many sources of revenue generation. The most controversial of these revenue sources was semi-educational fun rides (Williams 2005,82 ). While the rides have been removed, TP commercialism is still criticized in some academic quarters (Espiner 2015).

Today, TP continues to maintain a free entry with charges for special exhibitions. Currently TP receives 50 percent of its funding from government and is required to earn the other 50 percent. This rule has been greeted by the museum with a degree of acceptance. As TP Chairman Evan Williams comments:

In the museum world, it's reasonably unusual for a museum to earn half its total revenue and that is an accepted fact of life at Te Papa already. Of our own accord, we are looking at increasing our nonCrown revenue through further commercial revenue. The board doesn't look at that as a problematic balancing act, or even a particularly delicate one. It is simply a fact of life in today's world internationally that culture and heritage institutions receive funding from public sources, those sources are under pressure, and museums must take steps to create revenue independent of government sources while maintaining their full public service functions. We think we do that successfully and will do more of it (2016).

Recent TP initiatives to generate income include an Innovation Hub and the TP Foundation. Currently promoted on the TP website, the TP Foundation is promoted as:

dedicated to supporting the work of Te Papa and its vision of changing hearts, minds, and lives. It will launch with a patrons and bequests programme in 2016....We raise funds for Te Papa's acquisitions, exhibitions, research, education, publications, and digital projects (Museum of New Zealand 2016). 
On a related note, Pātaka Museum of Arts and Cultures (P.) has also recently established a foundation. Unlike TP the Gallery is promoting the foundation via a standalone website linked to the organisation's main site. The language used to promote the foundation seems inclusive in its approach and highlights the gallery's aim and needs:

We are on a mission. We are offering you the opportunity to partner with Pātaka Art + Museum by joining our newly created Pātaka Foundation. If you share our belief in the power of art to make a real difference to peoples' lives, help Pātaka build on its ambitious exhibition programme by making funds available for special projects that would not otherwise be possible within our operating budget (Pātaka Foundation 2016).

The tone of this promotion appears reflective of the organisation's collaborative origins and approach. Operating under the Porirua City Council, P. opened in 1998 in Porirua City. P. has developed a reputation for showcasing Māori and Pacific arts, as well as contemporary NZ Asian and international arts and culture (Pātaka Art + Museum 2016). P. is the result of an amalgamation of the Porirua Museum and Page 90, a local community art gallery. Both organisations needed space and funding to expand, the Porirua Council encouraged their amalgamation. The museum that was subsequently formed has several innovative approaches to revenue. Pātaka's dealer gallery was the first in NZ to be attached to a public gallery (Pātaka Art + Museum 1999). P. also shares its facility with a local library, community meeting rooms, a commercial café and commercial office spaces.

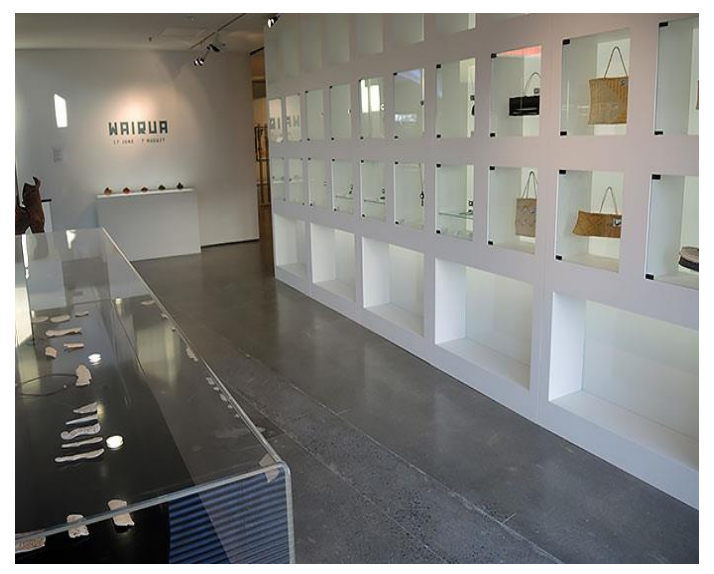

Figure INT.4: Toi Object Space, Pātaka Museum and Art Gallery. Photography courtesy of Pātaka 
The NZCM is also located in a shared facility: The Basin Reserve, NZ's oldest active test cricket ground (The New Zealand Cricket Museum 2016). The NZCM. began in 1986 at the New Zealand/Australia cricket test with a small display by the international umpire Stan Cowman. The display inspired John Oakley, who went on to establish a museum in the Basin's former tea rooms. The Museum opened in 1987 and became formally known as the NZCM. in 2002 (Donoghue 2013). NZCM.'s permanent collection is an eclectic mix of cricket history. It also hosts a range of temporary exhibitions. Its building faces a challenging future as it requires significant earthquake improvements (Gilbert-Potts 2014). The museum maintains an active online profile through a website, Twitter and Facebook. Museum merchandise is sold online via Trade Me and NZCM. accepts online donations. Entry to the Basin site is by donation. Besides weekends and Mondays, the museum is open during cricket matches.

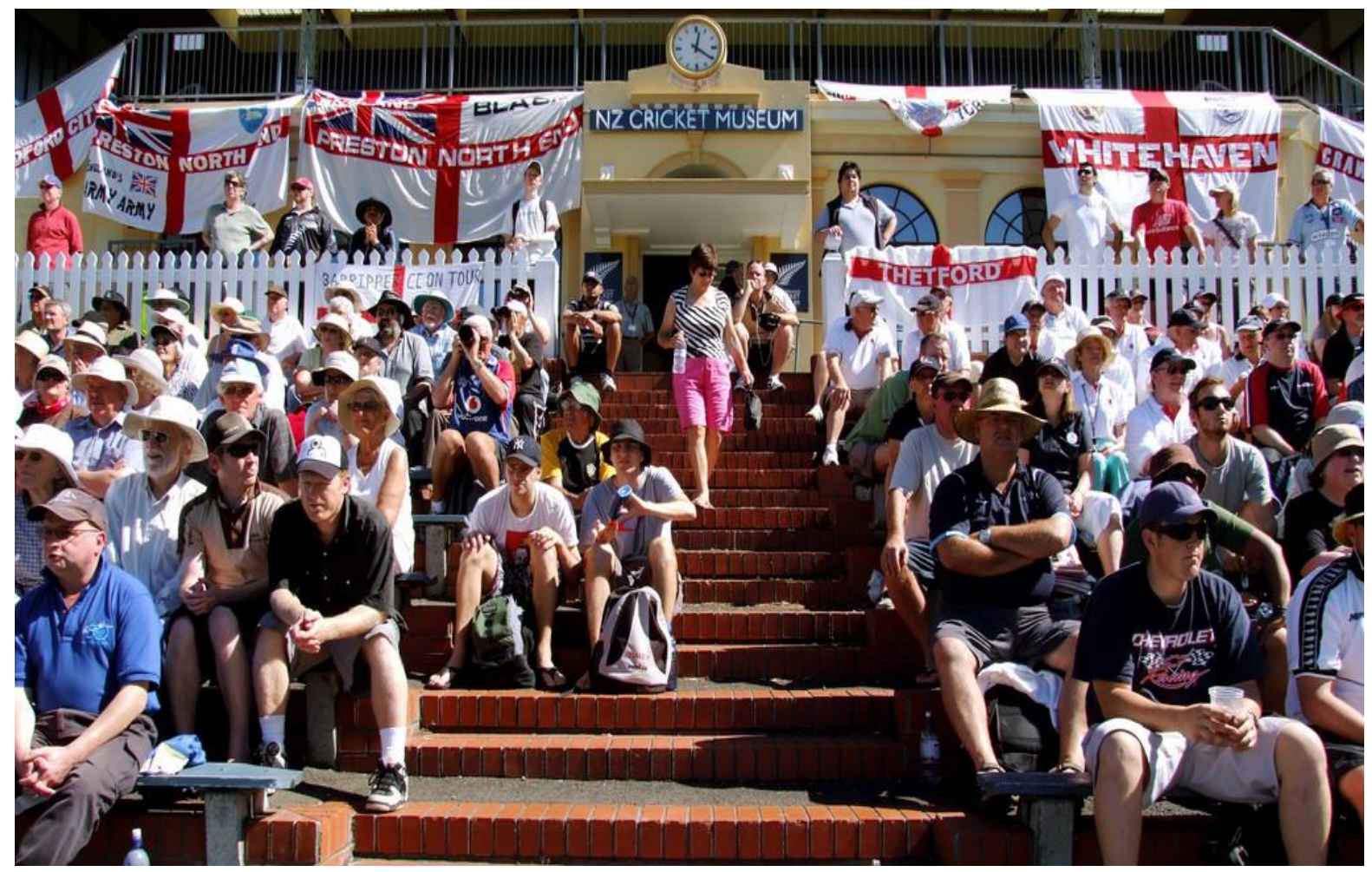

Figure INT.5: The New Zealand Cricket Museum ${ }^{\circ} \underline{w w w . f i v e r . d e}$ 
This chapter has outlined the research design and methodology which I have employed to address the question: do innovative and non-traditional revenue generation improve the financial viability of Wellington Museums? If so, how? In this chapter, Pragmatism has been established as the overall philosophical approach to the research. The analytical framework for this thesis has been discussed and an overview has been provided of the three case studies. In the next chapter, I present the results from the revenue record analysis and interviews. Chapter three provides an analysis of the findings of the research. Chapter four discusses interpretations and theoretical propositions on the results. The final conclusion chapter threads together concepts and practical considerations to develop an argument in relation to the research topic and presents implications and recommendations of this research. 


\section{Chapter Two: Results}

\section{Introduction}

In the interests of clarity, I have taken a pragmatic approach to the presentation of this chapter and divided the results into three sections. Section one demonstrates the revenue sources for the case study institutions, section two presents pertinent responses from the staff in these institutions to open-ended revenue-focused questions and section three graphs responses to closed questions on revenue-generating practices. An analysis and discussion of these results follows in the subsequent chapters. A copy of the questions, information document and consent form for the interviews is in the appendix of this thesis.

\section{Revenue sources}

The following graphs identify sources of revenue supply for the case study museums. The most frequent sources of museum revenue are presented first. These data have been obtained from secondary sources; namely the museums' revenue records. For clarity and ease of comparison the revenue sources have been split across two graphs. To best demonstrate the contribution of innovative and non-traditional revenue sources to income, revenue sources are presented as a percentage of the museum's income.

Financial years from 2012 to 2015 have been examined. The 2012-2013 financial records for Pātaka Museum of Arts and Cultures (P.) were not available for technical reasons. "Facility leases" and "Hire of Museum space" are listed as two separate revenue sources in accordance with the financial records of the case study institutions. "Paid visitor programs" includes revenue generated from school and education visits. There was some simplification of the Te Papa (TP) data to ease comparisons. After the financial records of the case study institutions were graphed, results were double checked with the financial team at each institution. 

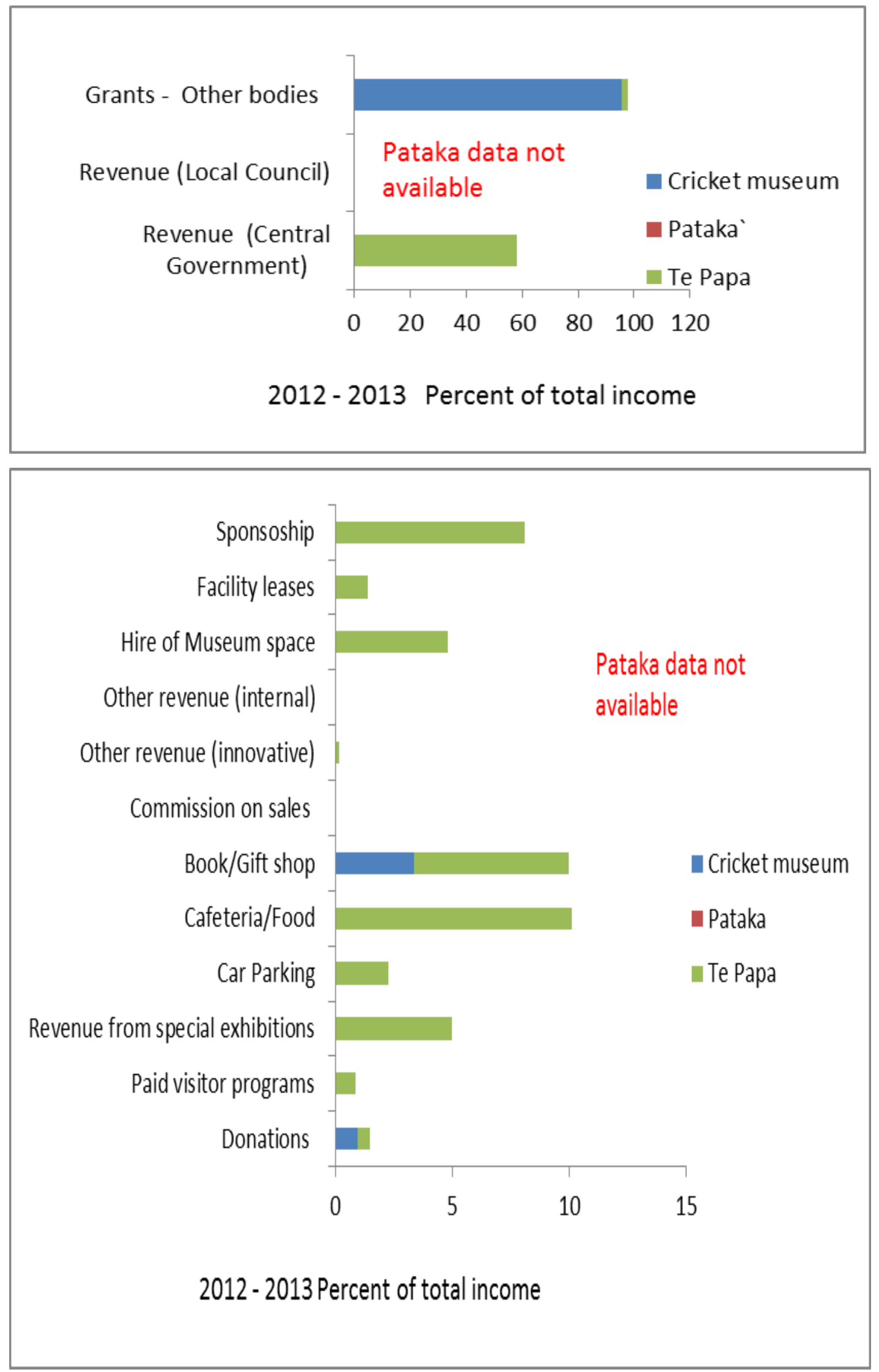

Figure 2.12012 - 2013 Percent of total income 

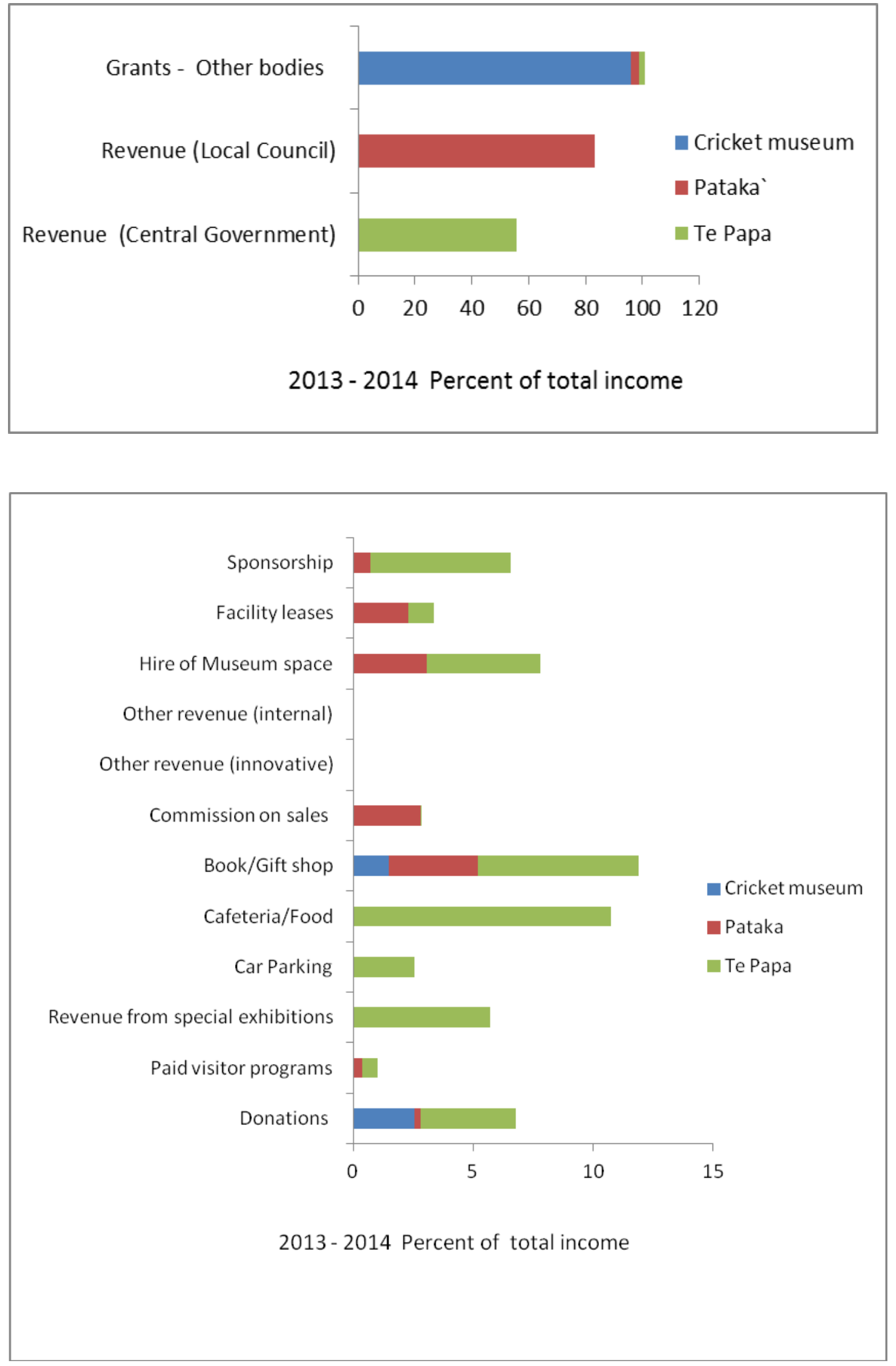

Figure 2.2 2013 - 2014 Percent of total income 

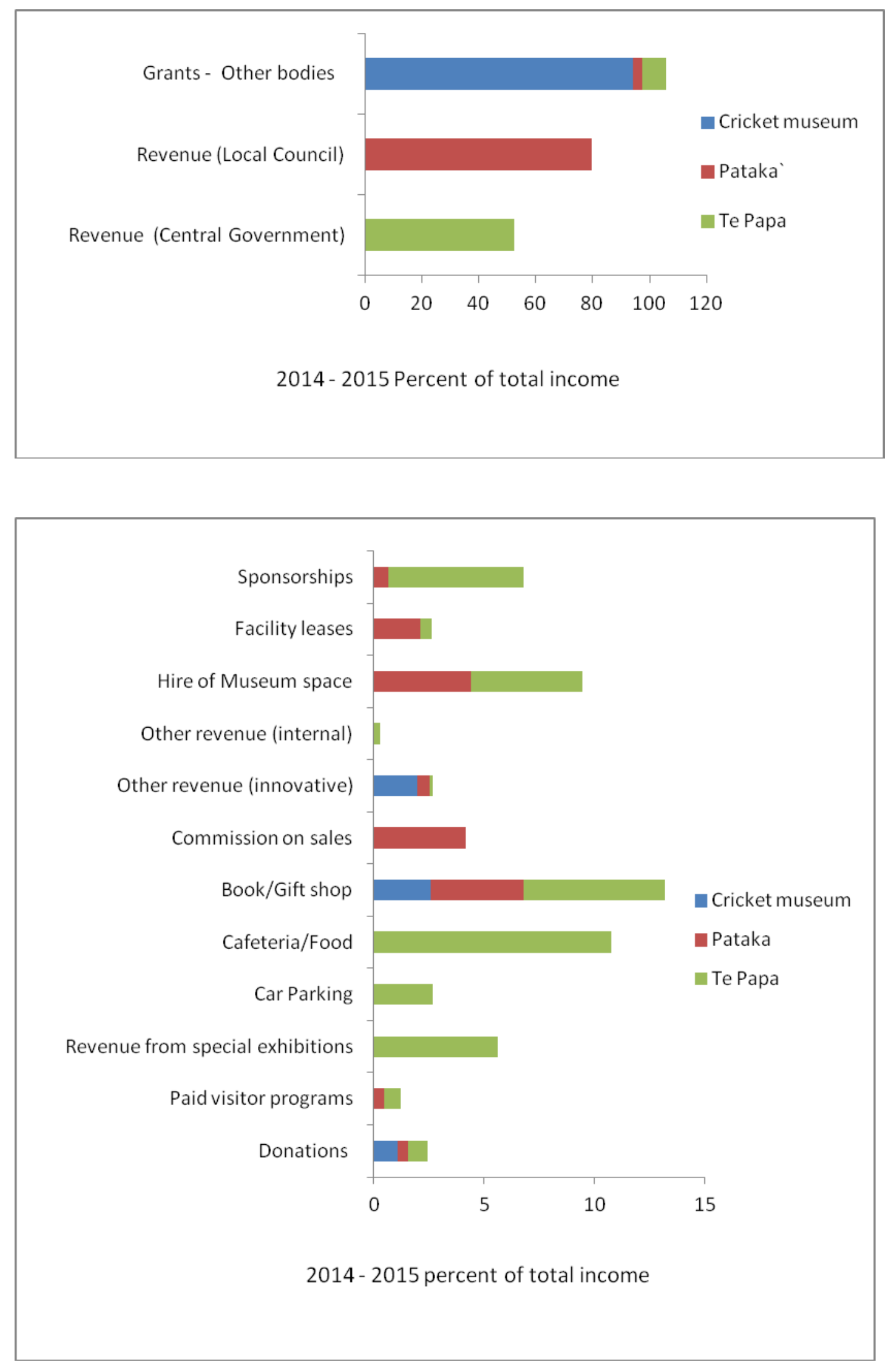

Figure 2.32014 - 2015 Percent of total income 


\section{Revenue generation at the case study institutions.}

Key staff from the case study institutions were asked an average of 35 open questions. Variations in the interviewees' questions were due to specific explorations of some issues in depth, other questions were excluded due to the size and structure of some organisations. The responses have been presented in the order of which participants were interviewed. Some responses to questions have been amalgamated due to thematic relationships and to avoid presenting duplicated results.

\section{Respondents were asked about their role at their museum and about their organisation as a whole.}

Darren Milsom (D.M): I'm the cafe's manager at TP ... My role, essentially, is to man the front of house for hospitality.

Phil Smith (P.S): TP is the national museum of New Zealand. My role is Director of Te Papa Enterprises, which ... encompasses all the commercial activities and ... marketing, visitor services, fundraising and sponsorship...We generate around half the museum's income, the other half coming from the crown funding .... This position ... it's a ... new role and I'm the only person that's done it.

Jamie Bell (J.B): I'm the Director of New Zealand Cricket Museum (NZCM), I'm the only paid staff member, we sit on the edge of the Wellington Museums Trust. We don't directly get any funding or anything like that from them, we get support in terms of financial management and some IT support ... We've got a team of maybe a dozen to fifteen volunteers ... The museum is governed by a board who I report to.

Zara Hawthorne (Z.H): I am the financial and reporting coordinator at P. So, I do the budget management on a day to day basis, I ... do all the admin stuff and then sort of some financial reporting at various stages of the month. P. is a museum and gallery; we are part of the Porirua City Council ... we came up out of the Porirua Museum ... We have a small collection of artefacts and objects and manage the Porirua City Council's art collection. We have exhibitions, mostly art, but some history exhibitions here as well. 


\section{Interviewees were asked about their perception of revenue generation in their museum.}

D.M: Revenue generation, ... has become more and more important in recent times ... we're trying to find revenue where there, perhaps, wasn't revenue before.

P.S: Compared to the museum I'd worked for in the United Kingdom (UK) it .... TP was already more oriented towards revenue generation ... and revenue generation was a much more significant percentage of the funding ... TP 's got some really good facilities and has got some good people working in revenue generation ... Museums traditionally can be, quite ... slow and considered in the way that they work and obviously commercial companies are usually much faster paced or reactive ... In a museum environment that sometimes doesn't work because the wider organisation would really quite like to think about whether or not we should do that ... But the new chief executive is encouraging us to try some new things and move more quickly.

J.B: We don't have a structured approach to it. There have been, at various times, documents drawn up ... But, as it always is in places where you've got one staff member, you spend a long time developing a strategy, but implementing it is another thing ... For a long time, we've relied on New Zealand Cricket to fund us, they have changed the funding model on us now, which is forcing us to look a bit more closely at other ways of generating revenue.

Z.H: We are expected to generate a certain amount of revenue, we have revenue targets which are set in our budget and that comes from the council, and we're also funded by the council as well for any shortfall over and above what we can earn ourselves ... if we earn more than target it actually goes towards our operating budget so we can do a little bit more, well actually it just sort of means that the council has to fund us less. 


\section{Interviewees were then asked to comment on how their museum's approach to revenue generation might compare to similar institutions around the country.}

D.M: I think that we're probably in a unique position, inasmuch as the recent history of TP or the recent financial history of TP has been well documented. So, I think that we perhaps have more of a focus on revenue generation than perhaps other organisations currently. I would like to think that we are doing similar things to other museums around the country in terms of how we go out about generating revenue.

P.S: From my limited visits to other cultural organisations in New Zealand, they are doing income generation, they're generally nowhere near the scale of what we're doing ... And that's kind of two reasons, I think a) they're in smaller population centres and., they haven't got the dedicated facilities. If you look at the Auckland War Memorial Museum, I think that's a really good example, a much more traditional museum building that hasn't got ... a suite of lecture rooms like we've got.

J.B: From experience, it's fairly familiar, I used to work for the Central Stories Museum in Alexandra (Central Stories Museum and Art Gallery) which had two and a half staff, relied on that council for the majority of funding, like we rely on New Zealand Cricket, entry by donation as well and a small shop ... We probably have, even though they've changed the model on us, a more secure relationship with New Zealand Cricket than I'd say most small museums have with local councils. I know that our relationship with New Zealand Cricket is probably stronger that what The Rugby Museum experienced with the New Zealand Rugby Union.

Z.H: I'm not too sure what other organisations do. I understand that other organisations do have revenue earning aspects of their business, like for example TP has a shop and I think a lot of other galleries have small gift shops and rent rooms and spaces and things. So, I think we're probably reasonably similar to other galleries. 


\section{The question of best practice for commercial development within museums was then put to interviewees}

D.M: I've been in the role that I'm in for about fifteen months, so my experiences ... are perhaps more limited than others. But, at the same time that probably gives me a ... fresher perspective ... The best practice, is people who are innovative, people who have a can-do attitude .... Within TP and I can't speak for the wider museum sector, I think what the leadership team is now trying to cultivate is an attitude of 'have you got an idea?' yup, alright, let's just go with it ... let's see if it works and is it something that museums would normally do, no, does that mean that we can't do it.

P.S: If you look at people like MOMA or the TATE I think where they've been really clever is they've leveraged their brand to create commercial products that people want to buy and also, bizarrely... when you look at places where you're paying to get in, the spend [is] usually higher because people go with the mentality that they're going to have to spend money ... The benchmark I see is an increasing importance in revenue generation across the sector .... Everyone's trying to move their commercial operations to a higher standard, create unique retail and catering experiences ... that are linked to the museum, linked to the collections, where people can feel that they're getting a special kind of experience and helps justify the spend.

J.B: Having someone who's dedicated to it, is actually key... You can do all the strategy and development you want, but implementing it is a completely different beast ... the key is actually to work with funding partners ... For us, that's probably getting a little bit more involved with the Museums Trust (Wellington) ... you can't underestimate the amount of time ... knowledge and skill that's required.

Z.H: My perspective of it is to earn as much as we can, however, because of the sort of code of practice of museums and things that possibly isn't appropriate. But my own perspective is to maximise revenue generating opportunities where ever possible. 


\section{Respondents were asked to identify the revenue streams in their museum}

D.M: The biggest contributor as far as I am aware ... is the hospitality side of the business. So that would incorporate myself, the café and Espresso ... the functions team, who deliver private functions throughout the year. Another big one would be the travelling exhibitions ... retail is a big one as well.

P.S: Our hospitality business is our biggest ... we need to invest in our corporate hospitality facilities to update them, and maybe try and create more capacity because we're at capacity... Car parking is significant ... it's very profitable, but obviously relatively fixed capacity and quite competitive in the city. Retail is also very strong ... we've seen particular successes on the back of exhibition retailing. ... Those three areas the backbone of the revenue generated ... they're all relatively mature businesses and they all need investing in ... Smaller areas we've got that generate revenue, paid for visitor tours, that's an area that was quite strong at first and then we had some personnel changes ... we just have to make sure we've got the people resource ... touring exhibitions is the other area. We tour exhibitions domestically and internationally, domestically to be honest is more part of our mandate ... they kind of break-even they don't really make money for us. The big money is in offshore touring and that's again an area that is making us ... a significant amount and again an area we've got plans to grow ... it's got quite a long lead time ... two to three years to go from concept to having it on the floor somewhere and then the challenges are keeping it on the road [be]cause as soon as you put it into storage it's costing you money.

J.B: We have a small shop here; we've just started selling some things on Trade Me. We're licensed with New Zealand Cricket as an official merchandiser which ... offers us a bit more leverage opportunities to get things out there and talk about things to a wider audience, but it also means ... there's a bit more bookkeeping that has to go on behind the scenes... When there's a test match on at the Basin Reserve we hold a book sale as well ... We don't charge for research enquiries ... We would if a big enough one came in. Generally, someone sends in a question and we can answer within the half an hour free you tend to offer ... we've got certain researchers that we work with on kind of a reciprocal basis, some of them have donated all their archives 
to us, another one has written a book that we sell ... we do charge for reproductions of photographs.

Z.H: We get, obviously, funding from the local council, we have some grant funding. Ministry of Education gives us some money to fund our education programs. We have sponsorship from a local business, we get donations, we have art classes and education programs which there are fees for some of them, not for all of them. We also sell work through our Toi Store, and also our Toi Gallery and Our Bottle Creek Gallery ... commission are usually standardized, and its 35\%, including GST in all those spaces. Occasionally, very occasionally if there's a particular artist it can sometimes be different or sometimes if they have a dealer occasionally we've done a split of the commission to the dealer for the artist. We also hire out meeting rooms and also we have two tenants, although one of our spaces is empty at the moment.

\section{Interviewees were queried on the enablers of revenue generation in their museum.}

D.M: The biggest enabler of revenue generation is having people who are ... open to suggestions and open to ideas.... So almost if my boss says to me, right Darren this is your business, run it as if it was your personal business, do what you need to do and without being told at every other juncture no.

P.S: A vibrant exhibition, events, activities program that drives visitation is really important ... if you look at the touring exhibitions we really need the ... curators and collection managers to help create those touring products ... we've got to respect their expertise around the knowledge around those collections but then they've got to work with us and respect our expertise around us knowing what our customers want, knowing what will sell ... a successful commercial operation in a museum won't happen if you just look at the commercial team to deliver ... you need ... a whole organisation focus around it and that doesn't mean that we don't do other things as well that are non-commercial, but you need everyone to buy into operating commercially. 
J.B: Getting on Trade Me has been quite good, because we are really restricted being where we ... When you have a book sale during a test match its great, but the rest of the time it can be a bit of a struggle getting people to come down .... In the past my predecessor would occasionally send books to the UK to be sold ... and that's something that we potentially might look at again. When we get donations of books ... we make sure that the people donating know that, if we already have a copy or we don't need it for any reason it may be sold.

Z.H: We're getting a fairly well established reputation in our shop, the fact that we've had it for such a long time ... so people are coming in and spending money here ... Also, council's very supportive of us earning money .... We see a need to earn money.

\section{The question of whether revenue generating strategies had changed for the museums in recent times was then put to participants}

Note: Darren Milsom chose to skip this question due to his recent employment status.

P.S: I don't think we've seen as significant [a] change as I saw with the organisation I worked in, in the UK, where I ... did go into an organisation where there was a lot more resistance to being commercial and over time we did move that, when I left it had moved quite a long way .... I think just in terms of the level of revenue generation, I think probably it's more in your face here ... probably what we've seen over the last year and probably what we'll continue to see is probably faster decision making around trying new stuff and doing new things.

J.B: Sponsorship is probably one thing that we're looking more to now. We were sort of in a situation when I started when actually the funding that we got from New Zealand Cricket was defined as being part from New Zealand Cricket and part from ANZ. But we had no relationship with ANZ whatsoever ... they didn't get anything out of it. So, what I feel is that the program of activities that we've run for the Cricket World Cup, the touring exhibitions, those sort of things, the way that our presence online has built up, we've actually got a much better case for sponsorship. That's one area where we're working with New Zealand Cricket and their commercial team to approach some of their sponsors to build it up. I think that's one area that's definitely 
changed and then the idea that we create our own merchandise to sell as well is something that's completely new.

Z.H: I think so, I think it's probably become more of a focus because with council you know--, there's a lot of pressure for them not to put rates up.... and sometimes we've been asked to make some savings in our budgets. In which case, we can cover those ... any savings we have to make, we can often look at ways to generate, we'd like to look at ways to generate extra revenue to cover those sort[s] of loss.

\section{Four questions were asked around the recruitment, retention and contribution of volunteers}

D.M: Typically, no, we don't really use volunteers, but I have just accepted a tenweek placement for a 17-year-old girl from Levin ... I'm open to it because, let's be straight up, there's no cost incurred to me, it's another person on the floor ... but, being as soft as I am, I like the idea of being able to give somebody a leg up ... if we were to use this as a trial going forward the time spent getting things ready lessens and lessens.

P.S: As an organisation we don't use volunteers really at the moment, although we do have interns on occasion in different parts of the organisation ... I certainly wouldn't look at volunteers running commercial operations. That feels inappropriate, to have people working for free and generating income, the way we looked at it in the UK and the way if we ever did anything here I would look at it, it would be very much about getting volunteers to do extra stuff that we can't do, not to deliver core services.

J.B: Some of our volunteers have been here for over 20 years ... One of the volunteers is quite an esteemed academic ... so he's cataloguing the library for us and he's doing a bit of research work for us. We've got a couple who are students, so they come in every now and then and do a bit of collection work ... One's a designer, so we've been using him to help design the World War One exhibition panels ... the other ones sit behind the front desk ... welcoming people, selling stuff in the shop. 
Z.H: We do use some volunteers, yes. We have interns from the Victoria University course, we have at least one of those a year. We've also had, at times ... international students, two of those in the past. We've got a young girl who's actually a secondary school student, she's volunteering with us ... We've got the Friends of P. and sometimes they help us out with things, like if we've got a survey ... and also they help with our exhibition openings, come in and help serve drinks and food.

\section{Interviewees were asked to identify the characteristics of enterprising behaviour}

D.M: You need to have that can-do attitude that I talked about. You need to be forward thinking and look at other businesses and how they do things and I think that stretches beyond the museum sector. So, I think it would be very easy to get tied up in the notions that we're a museum and we have to operate solely as a museum. There is a big part of the business which is a commercial enterprise and although we acknowledge that, I think we need to broaden our [view], we don't need to, but as a business, you need to broaden your horizons and try new things.

P.S: Can do attitude, pace, prepared to try things, working together, results orientated, making things happen.

J.B: I think openness to change and openness to ideas is quite a big one, learning, energy.

Z.H: An ability to actually be thinking about what the possibilities are at any one time and being able to, ... being presented with a problem of ... needing to make more revenue and actually... people being able to think and come up with ideas. And then of course I guess there's the implementation and sort of the thinking process through to implement the ideas. Also, I guess a part of it is being able to sell the ideas and communicate the ideas to the team and sell it to get other people on board, that's actually often a very tricky skill. 


\section{Two subsequent questions were posed concerning which of the characteristics identified were the strengths and weaknesses for the museums}

D.M: We've got some new leadership and I think that with that has come a ... need to look beyond the bounds of what we currently do .... one of the weaknesses is that, such a big organisation ... That can potentially be a barrier ... let's say the chief executive has an idea ... he has ...to get a very large number of people on board with that idea. I think that's probably the weakness ... especially when so many people have worked here for so long, which is both fantastic, but can be problematic because they are kind of stuck in their way of doing things.

P.S: Teamwork and results I would say, are probably strengths. Weakness is probably pace, $\ldots$ as an organisation, we can take too long to make decisions ... the red gates are a really good example ... when I asked, when I started, can't we open the red gates so people can come in that way and it was like, oh, no, we can't do that for these reasons ... Rick ${ }^{3}$ started... and said let's just open them and you know, you start unpicking that and going back ... it went to board level as to whether or not we open the red gates and you just think really? Is it that big a deal? And no decision was ever made.

J.B: We're small and we're adaptable and we're very open to being involved with what others are doing ... there was a school holiday program that wanted to come to the Basin Reserve this summer so we set up a program for them, they came in and did it three dollars a head ... Our weakness is that we are small and it's very hard for us to get a big enough box for us to stand on and yell and let people know that we're here. When I started here there was an almost non-existent network outside of the museum ... even in terms of our relationship with New Zealand Cricket.

Z.H: One of the things about working for the council ... there is a way that something has been done for many, many years and ... it can be quite difficult to convince people of the need to change ... I think it is something that I have noticed in wider council, but of course because we work for the council and a lot of people have been

\footnotetext{
${ }^{3}$ Rick Ellis was the CEO of Te Papa from 2014 to June 2017.
} 
here a long time, maybe there is a bit of that that's crept in. I think that everybody here is very positive and optimistic and they're very very creative. So, they can come up with a lot of ideas, but sometimes ... the implementation skills probably are a little lacking, but if they're very very motivated about something they'll implement it.

\section{Respondents were then invited to identify barriers to revenue generation in their museums}

D.M: I haven't really come across barriers ... I've actually been quite surprised about how accepting people have been ... Now I don't know if that's a new thing or whether that's because of this change of leadership or perhaps whether that's just how this organisation works ... the only barriers I really feel that we have are getting other people to like those ideas .... it's just this sort of idea we'll do business this way and to change it is sort of difficult. Why do you want to change it, let's continue doing it the way we do it?

P.S: I would say it's always managing that balance between the core purpose of being a museum and generating revenue and that's always a balancing act as to how far you push things ... Fundamentally the museum is here to, you know, to protect the treasures of the nation, to make those treasures accessible to the public and you know you can argue and you know some museum purists would say revenue generation is a necessary evil to keep the doors open but I think it's that balancing act between emphasis.

J.B: Resources, it's always going to be resources for anything we do that's always the challenge. It's good now we've got some volunteers that can help with other aspects, you know previously it was locked down to sitting here. So, a couple of the ones that have been on here for a longer time I've actually given them some tools to be able to do a bit of collection stuff as well, so upskilling them. But yeah, resourcing is always our biggest challenge

Z.H: The barrier would be that whole sort of thing, like, you know, it's a dirty secret that we have to make money and how it's just such a taboo sort of subject, I was very surprised about. So that would-be barrier to revenue earning, but I think people here, 
do, see, they see the need to earn revenue. I think it's probably the barriers are probably that more external perception of the external expectation not to make money.

\section{Interviewees were asked to describe something enterprising that their} establishment had done in the last three years and to identify what, according to them was enterprising about this case (two questions)

D.M: We have set up a number of initiatives on the plaza outside ... There's a coffee cart ... a mobile ice-cream cart and ... for the long weekend, a barbeque. ... if I can have a coffee cart on the plaza at eight then I've got another window of opportunity for an hour that I wouldn't otherwise have had. The land is there, the coffee cart we've managed to procure from one of our suppliers, so it actually hasn't cost us anything apart from of course the increased wage cost and the overheads of the product we're selling... all sorts of institutions such as this will have an arm of the businesses that is there primarily to generate revenue.... But I think that's typically contained within the bounds of the building so I think it's unusual to think that we've got this offer of the catering of beverages and so on - why don't we take it outside? Why is it that we just do it inside? ... I capture the guests and the visitors to the museum but we are on a piece of land on a very popular stretch of the waterfront. There are lots of people that pass by every day that absolutely have no connection to the museum ... but that doesn't mean that I shouldn't be capturing them as potential customers.

P.S: We sourced and project led on the Tyrannosaurus exhibition ... the final figure for Tyrannosaurus is going to make a profit of about quarter of a million dollars ... we've taken a whole load of costs out of the business over the last two years that held revenue up and we've just done a load of work with Rick and identified a load of new revenue opportunities for next financial year ... We went out and found Tyrannosaurus quite quickly... we project managed it with the view that it would make money .... We actually reduced the price of that exhibition compared to previous exhibitions because ... we wanted ... volume and we wanted repeat visitation ... We held a whole program of audience engagement events, everything from sleepovers to beer tasting for adults ... we did lots of innovative things... We took a 
good, credible, science based museum exhibition, developed by another national museum exhibition and ... we put a load of things around it that made it commercially successful and made the museum money.

J.B: I think getting the licensing agreement with New Zealand Cricket was one example of that. ...It used to be that New Zealand Cricket had a memorabilia partner, a company that when somebody went out and achieved something amazing they would make something and sell it in the global market for them. It's really big in Australia and there's some interest in it in New Zealand .... We've got a photographer who takes amazing photographs for us, he's another volunteer actually, the idea was to create some limited-edition memorabilia. We've found that there's a whole heap of restrictions under the licensing program, but there's still the opportunities... working with the researcher to publish a book ourselves, those kinds of things are all pretty new for us.

Z.H: We do have a P. foundation now, that's something that Helen has worked very hard on with, Roderick Dean... the foundation is allowing us to possibly ..., because we run on the smell of an oily rag. We just recently used Te Mahi ${ }^{4} \ldots$, it was the first time we've ever used anyone like that, we just make our own.... So we're able to probably step up things a little bit more with the foundation.... it's probably seen by people a little bit differently because if you make a donation to P. it goes to Porirua City Council and ... it's kind of like not quite so defined. It does come into our budget, we get it, but people might be more comfortable possibly by saying I'll give P. foundation the money and I guess that perhaps there's [a] sort of a thing with the tax.

Interviewees were asked to finish the sentence: Our organisation is getting revenue for...

D.M: I think our organisation is generating revenue for the future success of the museum. ... We need successful revenue ..., to keep developing the museum, be that exhibitions or cafes.

\footnotetext{
${ }^{4}$ Te Mahi is a specialist design-and-build production company based in Wellington, New Zealand.
} 
P.S: Our organisation is generating revenue ... to help deliver core services and to enhance the visitor experience and to do things over and above the core services.

J.B: Us to stay alive. That's the biggest challenge of, I think, any specialist museum and that's why the support of New Zealand Cricket is so key. Because it's their stuff, their stories, their history.

Z.H: Because we have to. But also, because anything we make over and above our targets does help us do things better.

Interviewees were asked for their thoughts on how transparent an organisation should be about where revenue is spent

D.M: We should be open about where the revenue is spent. I think we should be very transparent; I think there's no need to not be transparent.

P.S: When you've got a public body that's receiving significant government funding, you have to be very transparent and I suppose we are very transparent 'cause it's all in the annual report. I think if you're a private sector organisation you can take a slightly different view ... Internally it's important to be as transparent as you can ... During the last year when we had some financial issues ... we were very transparent with staff around where those issues were, what we needed to do, where we needed to save money and by and large the team stepped up and helped us deliver that.

J.B: In our example, we're governed by a charitable trust so I think we should be very, very transparent .... I find it interesting that in the two years I've been here when I've said to people, 'cause they come up and they say how much does it cost? Well, we just ask you for a donation, I've only had one person in that entire time say, well what's the donation for? and it literally is to keep us running. Where possible organisations should try, and be as transparent as possible.

Z.H: Well, I think that being council, we do have to be quite transparent, because, you know, anyone can ask any questions they want of us through an official 
information request and things like that. ... we're part of the council's annual report every year so, what we spend money on every year is reported. I think probably transparency, particularly with, you know, with a sort of public entity is quite important.

\section{Interviewees were asked to comment on when revenue generation became a necessity for their museum and where their role sits in terms of generation}

D.M: The focus on it heightened from the back end of last year ... There's two sides to the museum ... in previous tenures, the commercial side wasn't as important as the curatorial side ... we're now taking the idea that actually to progress ... we need to have an eye on the commercial side ... my role was to maintain revenue generation, in the last six months it has become increase revenue generation.

P.S: The financial or the business model for this organisation was always that there would be a significant amount of revenue generated ... with free entry museums the government funding covers the cost of the staff and some of the core infrastructure... if you want to do anything above that you've got to be generating income ... I have to help the team deliver operationally, but I also need to ... be planning ahead and... contribute as being part of the senior leadership team.

J.B: With New Zealand Cricket... they guaranteed us $\$ 60,000$ a year for three years. There's a certain amount on top of that, that they will give us ... but that number reduces over the period of the three years ... I know that I have a role to play in revenue generation, but there's a certain aspect where I'm raising money to pay for my own salary which doesn't feel right to me ... if you look at something like our poster as the operational level of revenue generation, we're selling it in the shop, we're selling it online, we're doing really well ... In terms of sponsorship and grants ...I think there needs to be more of a governance focus on that side of revenue generation.

Z.H: There are other parts of the council that don't meet their revenue targets and I'm not quite sure what happens with them ... because we've got a new general manager in that area ... there is a shift ... towards being more accountable ... I'm kind like the 
square peg in the round hole... A lot of the time I'm kind of like the one who's sort of trying to pull everybody back to reality a little bit.

\section{Interviewees were asked to identify the sources of support for their organisation}

D.M: So, we have various sorts of business relationships, one of which is this coffee company ... they've said, in the instance of the coffee cart, here have this, free on loan for this period as long as you're buying coffee from us ... I've tried to develop the whole sort of appearance of coffee within our organisation ... To do that involved quite a lot of design work... the coffee supplier helped us out ... they paid half, we paid half ... I do have a lot of repeat custom... We also do outside catering.

P.S: We've got lots of external stakeholders who have an interest in the organisation in the broadest sense they support us but then they also challenge us about things. We generate more revenue from visitors using our front of house facilities and our corporate hospitality business than we do from sponsorship, but sponsorship and fundraising is another area that's been underdeveloped and under-resourced within the organisation and we've just recently appointed a new head of development .... We've got the Friends, who make a contribution, but they are separate body as well. In terms of revenue generation at the moment it's very reliant on visitation.

J.B: I think Cricket Wellington ... and I think the council beyond the museums trust is probably another one as well. While it's an earthquake prone building, it's a rentfree space for NZCM so that's pretty amazing support.

Z.H: For our recent $50^{\text {th }}$ anniversary, Carrus, which is a local developer, put some money into that. The foundation is possibly raising the awareness that we are looking for sponsorship .... We're supported by the Friends of P. ... each year they run an artist in residence program, they fund that and sometimes if we have specific things that we want to fund they'll give us a donation towards that. We're very popular in the community and we're also very, we're really well positively supported by the council and councillors and things because we are a really positive part of the city. 
Interviewees were asked how, in their view, their museums addressed resource gaps

D.M: Two or two and half years ago, there was a very big restructure... we went through a period where there were a lot of gaps ... the museum then took on a new structure and made new jobs ... it's my understanding that we will be getting even leaner than we are now ... because the focus has changed, some of the areas that would previously be considered like a gap, with the new direction, you might be as bold as to say that they've gone naturally.

P.S: What we're doing is balancing the money we've got to spend versus all the different outputs that we need to achieve. A lot of those are set out in our crown mandate so there are things we have to do ... As a senior leadership team with the new chief executive we've... identified strategic priorities and we've made a decision on what we're going to focus on and what we're not going to do.

J.B: You just find a way. There is a bit of money set aside, it's earmarked for us for potentially having to move the collection ... We've been in talks with Wellington Museums Trust about what might happen to our collection ... Part of us increasing our online presence is about what if we're not in this space anymore? So that we continue to exist, we've got more of our collection online, tell a lot more stories on our website, sell things on Trade Me, those kinds of things.

Z.H: We spend money where we have to but where we can economise we will ... Our team needs to have a lot of skills which they wouldn't necessarily call for in other organisations. In other organisations, a Curator is a Curator and they never get their hands on the tools whereas here a Curator has to be able to use power tools, has to be able to hang artworks, has to be able to carry heavy objects because you've just got to be a jack of all trades. Where we do have to spend the money, we spend the money, we're fully insured, we make sure we take care of things; we have the correct handling procedures for art works. 


\section{Interviewees were asked to identify their museum's target audience}

D.M: I think that our target audience has changed, that's my perception of it and I think that we're continuing to change, ever evolving .... if you look, for example, at some of the fixed exhibitions that have been in this museum for nigh on two decades now and they are in the process of being revamped. I think that the reason they're being revamped is because we've addressed that our target audience is as much locals as it is the international visitors and the visitors from outside Wellington.

P.S: We're targeting New Zealanders; we're also targeting international visitors and you know the family audience is significant for us ... We do punch above our weight if you look at the number of target visitors we get with the population in the country.

J.B: [What] We've tried to do is increase our offering so that different things are for different audiences. So NZCM tends to be for cricket fans that are coming to games ... I've tried to increase stories that aren't about cricket a little bit. Part of what we're doing is trying to tell more Basin Reserve stories as well, so that we become a heritage organisation for the Basin rather than just NZCM but obviously, we can't get away from the fact that our target audience is cricket fans ... Our tone changes in terms of social media. Twitter's probably the best avenue that we've got, we picked up 1000 followers during the Cricket World Cup, we get really good engagement with cricketers on Twitter which is great, but it's kind of more of the Beige Brigade fan level rather than the trainspotting hard-core level that you might get through here ... Through our website, we've got a blog ... it caters to everyone and we tailor it to what's happening ... We want people to see how cricket fits in terms of New Zealand's social history, not just in terms of sporting history.

Z.H: We have done some surveys on that, I probably could get you some actual proper figures for that, but we do know that, for example, for our shop we've got a middle-aged woman, 40 s to 60 s. I know for the shop but it might be slightly different for the galleries. 


\section{Interviewees were asked if they felt that the level of services offered by their museum had changed in the current economic climate}

D.M: I don't know of any specific services that we now charge for that we didn't. More specific to my experience is that we now charge more for experiences than we use to.

P.S: I can't think of anything that we've started charging for since I've been here that we weren't charging for. ... if we look at the kind of collections, research and access area, we're probably doing less stuff. But we're not charging, for example .... We're not charging people to borrow objects for the sake of argument.

J.B: We used our new free entry status as much as possible as leverage with New Zealand Cricket and we will be going back to them again on that angle and sort of reinforcing it a bit more. What I noticed is, particularly on game days, is a lot more kids coming in and coming back and going and grabbing their mates and coming back and that's what I like, I just wanted this place to be as open as possible to people because we do have a lot of barriers in terms of getting people to the Basin Reserve, horrible grey Wellington days where nobody's around, those sort of things, the idea was to try and make it a bit more welcoming and not worry so much about the money.

Z.H: No, I don't think so, no we've been very fortunate because council hasn't actually cut our funding. They haven't increased it, but they haven't cut it. So, we haven't cut our service levels really.

Interviewees were asked their view on whether their museum has a purpose in Wellington's economic development?

D.M: I think that we play a huge part in how Wellington's economic growth ... Being one of, if not the biggest tourism attraction in Wellington means that we have a responsibility to help the local community and the region ... We work fairly closely with local government authorities and people like Positively Wellington Tourism and the different tourism groups to make sure that we keep moving forward 
P.S: We're hugely significant and that's some of the reasons why we get significant funding from Wellington City Council ... we're obviously a national museum, but, a lot of our regular visitors are Wellingtonians and a lot of our repeat visitors are Wellingtonians and certainly Wellington City Council look at us as an attractor to visiting the city and that's both by New Zealanders and overseas visitors.

J.B: I'd like to think so and I certainly think there's an opportunity for us to build that ... I think part of that is the angle where we look to be more of a Basin Reserve museum as well a lot of our visitors are from England and Australia and they come down here because they want to see the Basin Reserve, it's constantly regarded as top five, top ten most beautiful grounds in the world. I think it's the only cricket ground in the world where you can just come in and walk around on any given day ... I think there's a lot more that we can do with it in that regard. With the Cricket World Cup, we worked a lot more with Positively Wellington Tourism to ... I've noticed quite a few website hits coming by way of their page about us. We worked a little bit with Tourism NZ to kind of boost that too.

Z.H: I think potentially in Porirua because, I think, 'cause there is sort of an economic development part of the council and I think that they look at Porirua as a whole and I think that, you know, P. is considered an asset for economic development for attracting people from outside of the area or the city or the region or even international visitors.

\section{Interviewees were asked about their awareness of initiatives to support revenue generation in museums at a national level}

D.M: There's an increased focus at the moment on the project for opening a new museum in Manukau ... as far as I'm aware that's the biggest initiative that's ongoing at the moment to support revenue generation at a more national level to try and get the TP brand further afield than just Wellington.

P.S: I am aware of some stuff that's been done, mainly by MCH (Ministry of Arts, Culture and Heritage) and Museums Aotearoa (MA) and we helped with some of that. For example, Darren in the shop ran a workshop, a retail workshop, for regional 
museum retail managers ... I think we get some benefit, I think probably our benefit is more ..., we get more benefit from looking at offshore ... visiting museums in Melbourne, Sydney, and Brisbane and that's just really about scale. I'm not saying you can't learn anything from anyone smaller but ... you look at the metropolitan and the regional museums across New Zealand, their scale is so much smaller ... our retail business is three and half million, there's no one else in NZ museum-wise whose collecting anything near that level. There's more benefit for us in looking offshore at best practice.

J.B: I'm aware of talks about initiatives ... there's always various kind of speakers funded by ... MA and National Services ${ }^{5}$ that are going around ... it's probably the implementation stuff that I'm not really aware of anything ... I think that's kind of something that happens across museums, in all departments. So, Creative Commons licensing for museums, getting collections up online ... there's a lot of really good conversations ... But then when it gets to the point where you are a museum, where you've got one, two, three staff members, actually being able to implement something like that is a completely different story and it's the same with the revenue generation.

Z.H: Not that I'm aware of ... at the last Gift Fair that Victoria from the shop went to, there was a group meeting ... which was for people from gallery shops. But that's probably not museum related, it might have been more of a private gallery thing.

\section{The question of whether museums should collaborate was posed to interviewees}

D.M: I think we should collaborate in other areas, other than just curatorial. So, my understanding is that we collaborate hugely with other institutions and museums when it comes to collections, we share collections and we share stories, but my view is that actually, we should share more than. That we should take and share ideas about how we do things, like generate revenue, novel ideas. So, we should do more than we do to work collaboratively. How does this museum operate their cafe? How does this museum operate their retail shop? Right, what ideas can we give you?

\footnotetext{
${ }^{5}$ National Services Te Paerangi was established at TP to provide practical and strategic support to the New Zealand Museum sector.
} 
P.S: Yeah, no absolutely and I think we do, I think we network ... certainly our touring exhibition business is ... built off the back of collaboration and working with others.

J.B: Absolutely 100\%, I find there's a lot of museums that are scared of other museums and it's a thing that's kind of symptomatic of small and medium museums. There's a kind of cascade, if you're a small museum and a medium museum comes to you and says, hey, I'd love to work on a project with you and you think, oh no their coming to steal our stuff, they want to take us over. I've seen that happen quite a lot, I've been the person that's been turned away because they were worried I was coming to take over.

Z.H: I think it's great, I think it would be great. We here at P., we have quite an attitude of cooperation with other museums and we really feel like we all have different focuses and different things to contribute, so we're not really competing.

\section{Interviewees were queried on whether they believed there were opportunities for museums to collaborate outside the sector}

D.M: We should be collaborating with local businesses in the local area to develop economic great ... let's take the cafe as an example ... it's not necessarily the most financially viable suggestion, but if we could go to local produce ... and we do use, certainly local cheese in our sandwiches, but if we could go to locally made beverages and locally sourced coffee beans ... maybe that's just a bit of an idealistic idea. But I would love it if we could be a local brand. We're known on a national scale, but let's be known as supporting local businesses.

P.S: I think there's loads of opportunities and I think we do, don't we and that can be anything from research partners like NIWA and EQC through to commercial partners. Some museums outsource their catering and bring in a third-party caterer to run their catering business. I think collaborating with key suppliers ... if you look at some of the work that Darren does in the shop, that's working with key museum suppliers or even collaborating with cruise ship companies to kind of drive visitation. 
J.B: We've got a lot of sports organisations that we should be partnering with ... One of the things I've talked about within the museums trust is that the Cricket Museum's Twitter account has more followers than all of the other institutions combined and you know there's a lot of different tools you can use to measure engagement. On some of them we are more engaging than any other museum in the country even though, Auckland Museum I think's got 23 thousand followers, TP has got 18 thousand we've got about three and a half ... our content is shared a lot more, people respond to it a lot more than other museums and that's because we are firmly in the middle of this cricket community ... museums always talk about being part of the community and those kind of things, but, um, they could do a lot more with working with communities and other groups and organisations and things.

Z.H: Yes, probably, I mean there are complementary sort of areas, aren't there, like you know Internal Affairs and National Library that type of thing so yeah, I would say there would be definitely possibilities.

\section{Respondents were asked for their views on digital developments and revenue generation in museums}

D.M: We've got an increased focus on a digital strategy ... I think that goes hand in hand with increasing revenue generation because I think that if you get the message to people you'll get the visitation ... the focus every year is increasing your profitability, increasing your productivity and I can only do that if I'm getting the people through the door.

P.S: I've got to be honest; it's not my area of expertise, wrong generation, trying to catch up with all of that. I think there's clearly an opportunity around that ... Rick's looking to strengthen the digital team here with more expertise and we will engage with them. On a really simplistic level, having free $\mathrm{Wi}$-Fi drives people into this building to use it and then they buy a cup of coffee ... It's definitely an area that we will look at going forward.

J.B: It's an interesting one in terms of revenue generation. A lot of people think that if you make everything available online for example, then you've got no opportunity to 
generate revenue because people aren't going to come in anymore they can just download your pictures ... the more we've put things online, the more enquires that we've generated to the museum, so donations to the collection are up, research enquiries are up, which means we're sending more, selling rights to photographs ... what we'd like to do in terms of the future of the museum ... We've got plans for a large scale portable museum experience which we could take around games over summer ... and we've talked about the possibilities to kind of crowdfund either aspects of that or the whole thing ... I think for us it's about having products that we can leverage off, that are marketable, that we can sell effectively.

Z.H: We have talked about these things; we're probably just observing at this stage what other museums and organisations are doing and how it's working out for them ... We did at one stage, for our wing down there, our wing above reception, the friends were fundraising for that and we actually suggested that they try a crowdfunding thing but they weren't quite comfortable ... the friends, the committee are retired people so they probably just had no experience of it and just no understanding of it, so they just wanted to go with their .... 


\section{Section three: revenue generating practices}

Closed question results have been presented in the following two graphs. The first graph (Figure 2.4) breaks down the responses of interviewees from the case studies. The second graph (Figure 2.5) illustrates the overall responses to each question.

Results are displayed in the order in which participants were interviewed. All the available results have been detailed; question twelve was skipped with Jamie Bell due to the size and structure of his organisation

$\begin{array}{llll}\text { Darren } & \text { Phillip } & \text { Jamie } & \text { Zara } \\ \text { Milsom } & \text { Smith } & \text { Bell } & \text { Hawthorne } \\ \text { (T.P.) } & \text { (T.P.) } & \text { (NZCM) } & \text { (P) }\end{array}$

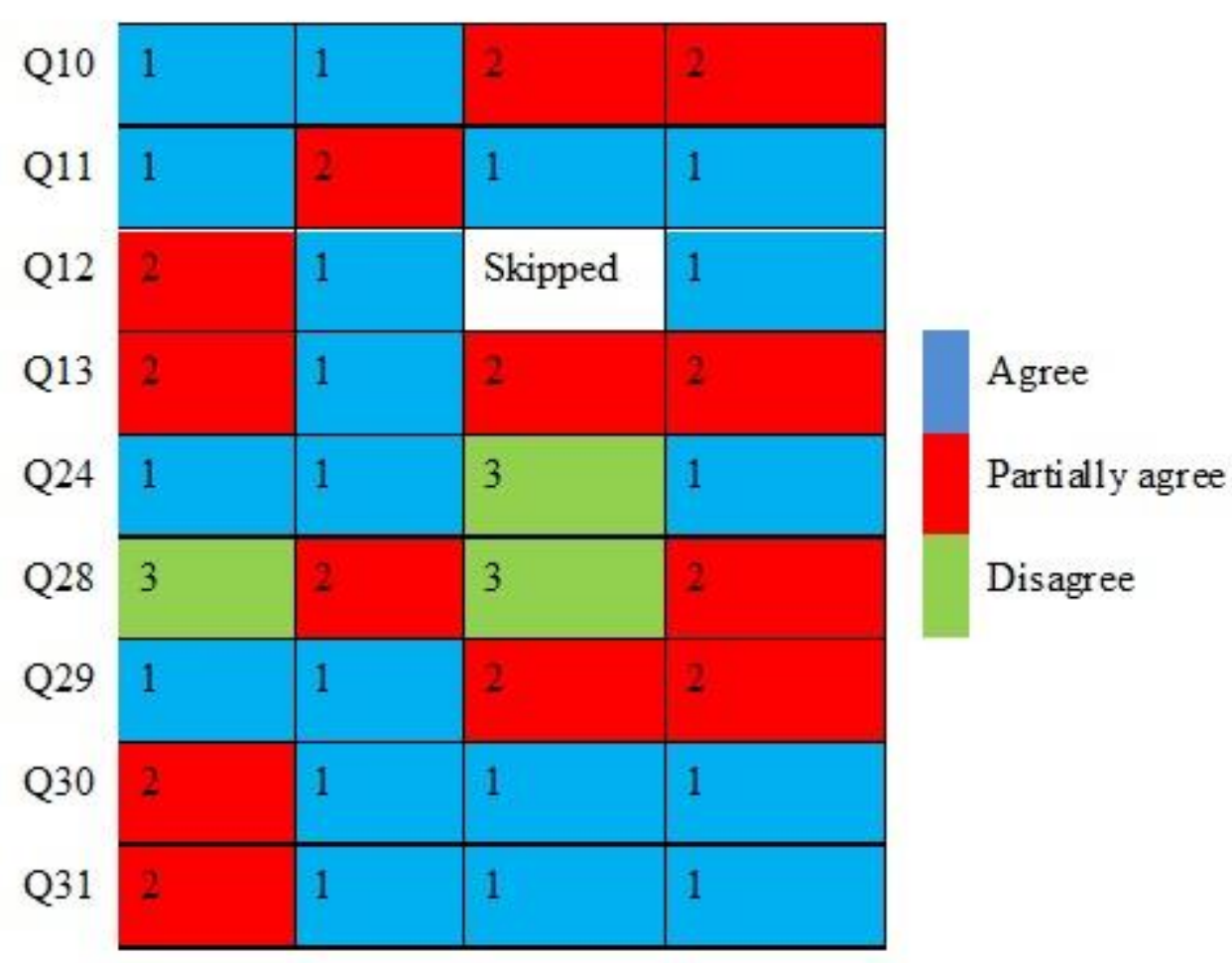

Figure 2.4 Individual responses closed question results 


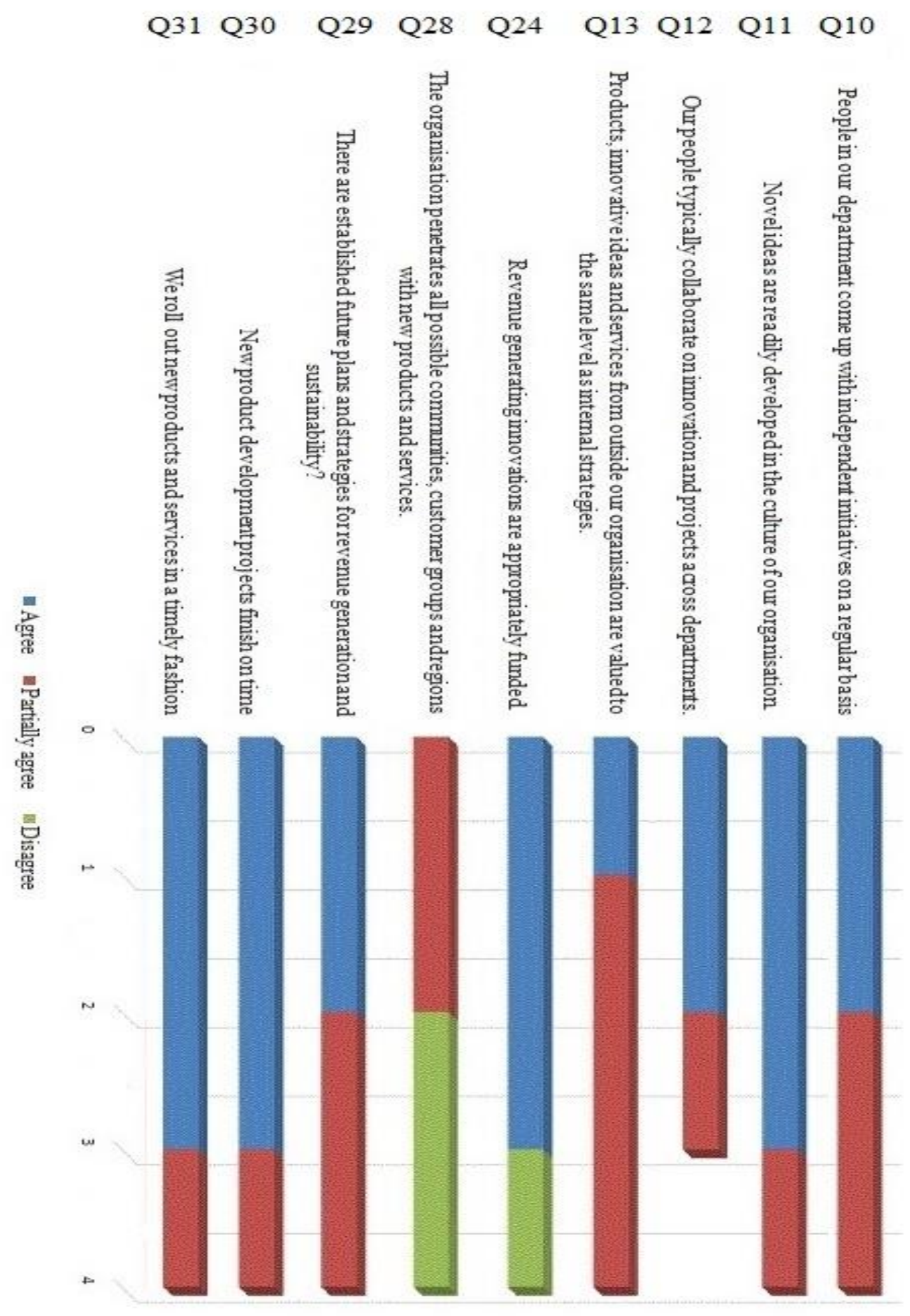

Figure 2.5 Overall responses to closed questions by interviewees 


\section{Chapter Three: Analysis of the Data.}

\section{Introduction}

The purpose of this chapter is to analyse the collected data. The analysis is presented in sections: a general analysis of the importance of revenue generation, an investigation of sources of revenue supply, resources and revenue generation, innovation theory, threats to revenue generation, friends and foundation developments, timeframes, volunteers, ethics, legislation, support for revenue generation, museum management and organisational culture. A discussion of the implications of these findings will follow in the subsequent chapter.

This research was undertaken in two stages; an analysis of revenue records from three case study institutions and interviews with key staff from the institutions. During the interviews a range of open and closed questions, developed from the work of Hansen and Birkinshaw $(2007,11)$, were asked. The final definitions of revenue source used in the analysis include traditional sources of revenue supply, based on the work of Massey and Quinn $(2001,32)$, innovative revenue generating practices (principally digitally based) (Brodie, Kane, and Clark 2012) and non-traditional revenue generating practices (Orinda 2008, 4).

\section{Importance of revenue generation}

The value of revenue generation was expressed in a similar manner by all interviewees. For example, as Phillip Smith and Zara Hawthorne commented;

Our organisation is generating revenue ... to help deliver core services and to enhance the visitor experience and to do things over and above the core services (Phillip Smith (P.S), personal communication, April 9th, 2015).

Because we have to. But also, because anything we make over and above our targets does help us do things better (Zara Hawthorne (Z.H), personal communication, April 7th, 2015).

These statements imply that self-generated revenue is valuable. It enables a museum to deliver more activities than normal. This idea is similarly discussed in the current literature (Lloyd-Jenkins 2014, 6; Clare 2014, 10). But despite a common perception of the value of revenue generation, it is still under researched. For example, little research is available on synergies between museum practice and commerce. 
Such synergies may be important when considered in the context of research on the concept of a museum as a 'third space', a neutral space on public ground where people can gather and connect. The value of museums functioning as this space in their communities is significant; as sociologist Robert D. Putnam notes, we have become increasingly disconnected from structures such as our family, friends and neighbours (Putnam 2001). Commercial operations such as cafes in museums have the potential to be harnessed as neutral spaces, forums for interaction between museums and their communities (Bloom et al. (2013). Darren Milsom's comments provide one example of how commercial operations such as a coffee cart can reach out beyond a museum and interact with different sections of the community:

Why is it that we just do it inside? ... There are lots of people that passed by every day that absolutely have no connection to the museum ... that doesn't mean that I shouldn't be capturing them as potential customers (Darren Milsom (D.M), personal communication, April 3rd, 2015).

Another example of a crossover between commercial operations and the 'third space' forum idea is currently under development at the Museum of New Zealand Te Papa Tongarewa (TP) in its Innovation Hub (Hub). This venture will give museum visitors the chance to interact with and influence the development of new digital projects. At a recent National Digital Forum presentation, Melissa Firth (2015) described the Hub as focusing on entrepreneurship, financial sustainability and fostering partnerships with other organisations to develop innovations that are useful to museums or that relate to culture. According to Firth, visitors to the Hub would be part of a living exhibition, influencing designs through feedback and experiencing the process of development, design and innovation, which, it was hoped, could spark more innovation. Further research into this development was not possible here but could be valuable in the future. While it follows 'participatory' trends in museum practice, conceptually the Hub also takes the museum closer towards democratisation, as the institution is sharing its authority around these projects with external organisations. The Hub has the potential to contribute to the financial viability of TP while at the same time communicating both the museum's mission, vision and values, and the values of Hub participants. 
In addition to the communication of values, revenue generation was also identified by TP interviewee Darren Milsom as being a vehicle for social inclusion in the form of a workplace experience program:

We don't really use volunteers, but I have just accepted a ten-week placement for a 17-year-old girl from Levin. She's going to come and work with us ... I'm going to try and find her a placement with the tour manager as well ... and get her some exposure around the museum ... if we were to use this as a trial going forward the time spent getting things ready lessens and lessens (D.M, personal communication, April 3rd, 2015).

Developing innovative thinking, increasing social inclusion and improving communication were all identified as indirect benefits of innovative revenue practices in museums. Capitalising on these indirect benefits and creating viable innovative revenue generating practices is part of a wider question, which is how museums define and relate to their communities. It interesting to note that the New Zealand Cricket Museum (NZCM) was the only museum to acknowledge a difference between their physical and digital target audiences, as evidenced by Jamie Bell's following comments:

We've tried to do is increase our offering so that different things are for different audiences. So, The Cricket Museum tends to be for cricket fans that are coming to games ... Our tone changes in terms of social media. Twitter's probably the best avenue that we've got, ... Through our website, we've got a blog ... it caters to everyone and we tailor it to what's happening ... (Jamie Bell (J.B), personal communication, April 7th, 2015).

By noting this difference between communities and tailoring the museum's voice to fit the different sections of its audience, there is a continuous circle between virtual and physical visits. This level of multisensory experience in museum interpretation is already researched; examples include MW2016 ${ }^{6}$, but additional commentary from Jamie Bell also highlights a potential area for future research - how revenue generation and museum interpretation could work together:

We're licensed with New Zealand Cricket as an official merchandiser which ... offers us a bit more leverage opportunities to get things out there and talk about things to a wider audience (J.B, personal communication, April 7th, 2015).

\footnotetext{
${ }^{6}$ MW2016 is the annual conference of Museums and the Web held in the United States of America
} 
In this instance, innovative revenue sources such as merchandise licensing have provided the museum with alternative forms of marketing and communication.

\section{Sources of revenue supply}

The data gathered for this research shows clearly, that regardless of size, nontraditional revenue generating practices are making a contribution to the financial viability of all three organisations. While revenue records show that traditional sources of revenue supply provide the majority of a museum's financial support, nontraditional revenue generating practices contribute approximately a quarter of the revenue generated by TP. There is some indication of growth in non-traditional revenue generating practices in the NZCM.

Statistical results from the revenue records were paralleled in case study interviewee responses. Some variation in operational scale is noticeable between TP and medium and small sized institutions, but a commonality in operational strategy for revenue generation is apparent. As Jamie Bell notes:

From experience, it's fairly familiar, I used to work for the Central Stories Museum in Alexandra (Central Stories Museum and Art Gallery) which had two and a half staff, relied on that council for the majority of funding, like we rely on New Zealand Cricket, entry by donation as well and a small shop (J.B, personal communication, April 7th, 2015).

Organisational size does not appear to be a determining factor for museums in undertaking non-traditional revenue generating practices, a finding which correlates with the results of Massey, Lewis, and Museum of New Zealand (2002, 13).

Future analysis of the statistical results of this study on innovative revenue generating practices should consider a potential issue around reporting e-commerce at TP, as it may result in inconsistent data which makes comparison problematic. Overall, revenue records from the three case studies demonstrate that innovative revenue generating practices are not delivering significant income. But, in the case of ecommerce, TP is not currently capturing e-commerce data from third parties in its main financial system (Grant Manson, personal communication, August 10, 2015). This is despite that fact that the revenue value of e-commerce is being tracked by the museum's tour manager (Phil Louie, personal communication, September 25, 2015). 


\section{Resources and revenue generating practices}

Knowledge was identified as a key factor in the ability of museums to generate revenue from innovative revenue generating practices. Although all the case study interviewees indicated an awareness of innovative practices, expertise in digital practices is still developing. Philip Smith comments:

I've got to be honest; it's not my area of expertise, wrong generation, trying to catch up with all of that. I think there's clearly an opportunity around that ... Rick's looking to strengthen the digital team here with more expertise and we will engage with them. On a really simplistic level, having free Wi-Fi drives people into this building to use it and then they buy a cup of coffee ... it's definitely an area that we will look at going forward (P.S, personal communication, April 9th, 2015).

In addition to expertise, the commentary of Zara Hawthorne also highlights that some museums are seeking evidence of success before undertaking a revenue generating practice:

We have talked about these things, were probably just observing at this stage what other museums and organisations are doing and how it's working out for them ... We did at one stage, for our wing down there, our wing above reception, the friends were fundraising for that and we actually suggested that they try a crowdfunding thing, but they weren't quite comfortable ... the friends, the committee are retired people so they probably just had no experience of it and just no understanding of it, so they just wanted to go with their-- ( Z.H, personal communication, April 7th, 2015).

Hawthorne's commentary reinforces the findings of previous research such as that of (Rega 2011, 58), whose results highlighted the importance of detailed empirical evidence for the future of innovative revenue generation. But, this restrained approach to the implementation of innovative practices is not being followed by all the case studies. For example, Jamie Bell offered the following commentary on third party revenue generating platforms such as Trade Me:

Getting on Trade Me has been quite good, because we are really restricted being where we are (J.B, personal communication, April 7th, 2015).

Notwithstanding this expression of support by the museum director, results on the viability of Trade Me sales for the NZCM will not be available until the 2015-16 
financial year (J.B, personal communication, August 4th, 2015) ${ }^{7}$. Thus, testing the viability and contribution of using Trade Me as a revenue generating practice is not possible as the data is not yet available.

\section{Innovation theory and revenue generation}

Alongside evidence-based research, analysis of revenue generating strategies in museums may also support innovative and non-traditional revenue generating practices. The ability to be innovative as an organisation has been examined as one of the requirements for an entrepreneurially successful museum (Coman and Pop 2012). But while museums such as TP talk about being "entrepreneurial by nature” (Museum of New Zealand 2015, 28), academic evidence of entrepreneurialism in the context of innovation is limited; as Johnson and Thomas $(1998,78)$ put it: "we know very little about the innovation and diffusion process in museums".

As a consequence, to analyse innovative and non-traditional revenue practices in a broad context, within the case study institutions, this study has applied perspectives on innovation as defined in the literature of business management. The use of literature from business management in the research of museum economics has precedents. Examples include Massey, Lewis, and Museum of New Zealand (2002,7); Feldstein (1991,3); Johnson and Thomas (1998,7); Frey and Meier (2006, 14).

There are principles expressed in business-based research which are present in museum practice. As Darren Milsom comments:

What the leadership team is now trying to cultivate is an attitude of: have you got an idea? yup, alright, let's just go with it ... let's see if it works and is it something that museums would normally do, no, does that mean that we can't do it (D.M, personal communication, April 3rd, 2015).

The TP leadership strategy is comparable to the Minimum Viable Innovation System (MVIS) developed by Anthony, Duncan, and Siren (2014). This system highlights a number of characteristics necessary for successful innovation and emphasises that

\footnotetext{
${ }^{7}$ Some follow up correspondence was possible with the interviewees, this added to the richness of the data available.
} 
every organisation's leadership must strategise and consider the specific circumstances and objectives of their organisation.

The MVIS also offers a framework for understanding innovation in museums by breaking innovation into two categories: Core Innovations, revenue generating practices which enhance existing offerings or improve internal operations; and New Growth Innovations that generate new sources of revenue growth by reaching new customer segments or new markets. In the context of revenue generation, a number of examples are available of both Core Innovations and New Growth Innovations.

Phillip Smith offered the following example of a Core Innovation at TP using a traditional source of revenue supply, admission tickets:

We sourced and project led on the Tyrannosaurus exhibition ... the final figure for Tyrannosaurus is going to make a profit of about quarter of a million dollars ... We went out and found Tyrannosaurus quite quickly ... we project managed it with the view that it would make money ... We actually reduced the [admission] price of that exhibition compared to previous exhibitions because ... we wanted ... volume and we wanted repeat visitation ... We held a whole program of audience engagement events, everything from sleepovers to beer tasting for adults ... we did lots of innovative things ... We took a good, credible, science based museum exhibition, developed by another national museum exhibition and ... we put a load of things around it that made it commercially successful and made the museum money (P.S, personal communication, April 9th, 2015).

The commentary of interviewees on developing and delivering innovative sources of revenue was reinforced in the results of the closed questions. All three case study institutions were reasonably rich with innovative ideas and had a reasonable rate of converting those ideas to reality.

Darren Milsom and Jamie Bell provided the following examples of new growth revenue generating practices, both non-traditional and innovative in their approach:

We have set up a number of initiatives on the plaza outside ... There's a coffee cart ... a mobile ice-cream cart and ... for the long weekend, a barbeque. ... all sorts of institutions such as this will have an arm of the businesses that is there primarily to generate revenue ... But I think that's typically contained within the bounds of the building so I think it's unusual to think that we've got this offer of the catering of 
beverages and so on - why don't we take it outside? (D.M, personal communication, April 3rd, 2015);

We're licensed with New Zealand Cricket as an official merchandiser which ... offers us a bit more leverage opportunities to get things out there and talk about things to a wider audience (J.B, personal communication, April 7th, 2015).

These non-traditional and innovative revenue generating practices were developing during the timeframe of this study. After trialling a number of out-door initiatives TP now runs an outdoor bar called The Red Gates which opened in 2016. In the case of both the merchandising agreement and the outdoor bar, both initiatives share the notion that museums can generate revenue from developing beyond traditional museum revenue frameworks.

\section{Threats to revenue generation}

This study identified some common threats for both traditional revenue sources and non-traditional revenue. In the case of TP, Phillip Smith highlighted financial resources and capacity as threats:

Our hospitality business is our biggest ... we need to invest in our corporate hospitality facilities to update them, and maybe try and create more capacity because we're at capacity ... Car parking is significant ... it's very profitable, but obviously relatively fixed capacity and quite competitive in the city (P.S, personal communication, April 9th, 2015).

The issues described above, such as car parking and location capacity planning may be applicable to any museum located in a central area. Future empirical work using these or similar considerations as case studies may generate results which are applicable to a number of different museum models.

While the practical considerations highlighted above may be a valuable subject for future research in museum studies, other examples cited by interviewees of Core Innovations which use non-traditional revenue generating practices may not be transferable. NZCM, for example, is able to sell unwanted potential collection items which have not been accessioned as a financial asset. The interpretation of collection management ethics by different organisations may mean that this approach is not 
applicable in all organisational structures. Jamie Bell offered the following description of the museum's collection policy:

When we get donations of books ... we make sure that the people donating know that if we already have a copy or we don't need it for any reason it may be sold (J.B, personal communication, April 7th, 2015).

Phillip Smith also provided an example of a potentially non-transferable revenue generating practice at TP. Despite the relatively high fixed operational costs of museums, TP has been able to reduce their operating costs:

We've taken a whole load of costs out of the business over the last two years that held revenue up (P.S, personal communication, April 9th, 2015).

Whether the scale of TP operations offer the museum a degree of flexibility to downsize can only be hypothesised at this point. Similarly, no data is available as to whether stakeholder expectations have shaped the development of the acquisitions strategy at the NZCM.

\section{Friends and Foundation developments}

While the above examples may not be transferable, all the case study institutions are exploring non-traditional revenue generating practices. Both TP and Pātaka Museum and Art Gallery (P.) have recently developed foundations and the NZCM softlaunched a 'Friends' organisation in September 2015 (J.B, personal communication, September 20th, 2015). Zara Hawthorne offered the following thoughts on the importance of the Pātaka Foundation:

We do have a Pātaka foundation now, that's something that Helen has worked very hard on with Roderick Deane ... the foundation is allowing us to possibly--, because we run on the smell of an oily rag ... we're able to probably step up things a little bit more with the foundation. ... it's probably seen by people a little bit differently because if you make a donation to Pātaka it goes to Porirua City Council and ... it's kind of like not quite so defined. It does come into our budget, we get it, but people might be more comfortable possibly by saying I'll give Pātaka foundation the money (Z.H, personal communication, April 7th, 2015).

What role these revenue sources may play in the future financial viability of these organisations is unknown due to their recent implementation, but it seems reasonable 
to say that the development of foundations and friend's organisations may be a significant trend in the future financial viability of museums.

\section{Timeframes in implementing innovative revenue generating practices}

In the last six months, against the backdrop of a decline in the NZ economy, revenue generating practices at TP have shifted focus. As Darren Milsom comments:

My role was to maintain revenue generation, in the last six months it has become increase revenue generation (D.M, personal communication, April 3rd, 2015).

But despite this change, neither TP nor any of the other case study institutions have been propelled to generate new revenue sources by charging for existing museum services:

I don't know of any specific services that we now charge for that we didn't. More specific to my experience is that we now charge more for experiences than we use to (D.M, personal communication, April 3rd, 2015).

We're not charging, for example--. We're not charging people to borrow objects for the sake of argument (P.S, personal communication, April 9th, 2015).

We used our new free entry status as much as possible as leverage with New Zealand Cricket and we will be going back to them again on that angle and sort of reinforcing it a bit more (J.B, personal communication, April 7th, 2015).

These findings for NZ museums are in contrast with their overseas counterparts, for example, in the United Kingdom (UK), as discussed by Brodie, Kane, and Clark $(2012,37), 14$ out of 44 museums surveyed had increased their admission charges in the last three years.

\section{Volunteers}

The case study institutions share global perspectives on the importance of volunteers for sustainable museums. Echoing the 2012 research of Museums Aotearoa, volunteers were identified as a significant factor in the overall success and sustainability of the institutions (Chen 2014, 12). Volunteers were generating both direct and indirect revenue in a variety of revenue generating practices: 
One of the volunteers is quite an esteemed academic ... so he's cataloguing the library for us and he's doing a bit of research work for us. We've got a couple who are students, so they come in every now and then and do a bit of collection work ... One's a designer, so we've been using him to help design the World War One exhibition panels ... the other ones sit behind the front desk ... welcoming people selling stuff in the shop (J.B, personal communication, April 7th, 2015).

We do use some volunteers, yes. We have interns from the Victoria University course ... We've also had, at times ... We've got a young girl who's actually a secondary school student, she's volunteering with us ... We've got the Friends of Pâtaka and sometimes they help us out with things, like if we've got a survey ... and also they help with our exhibition openings, come in and help serve drinks and food (Z.H, personal communication, April 7th, 2015).

Although research on volunteers and museums is available and there are guidelines for ethical practice between museums and volunteers (Museums Aotearoa 2003; International Council of Museums 2004) revenue generation does not feature. There are no specific studies on volunteers and revenue generation or guidelines on how to supervise and direct volunteers with regards to revenue generation and ethical practice. Were guidelines available, their implementation may be complicated by ethical interpretations. A consensus on the ethics of using volunteers for revenue generation was not apparent in either the case study institutions or within the organisations themselves, as demonstrated by different strategies at the same museum expressed by Darren Milsom and Phillip Smith:

Typically, no, we don't really use volunteers, but I have just accepted a ten-week placement for a 17-year-old girl from Levin ... I'm open to it because let's be straight up there's no cost incurred to me, it's another person on the floor (D.M, personal communication, April 3rd, 2015).

As an organisation we don't use volunteers really at the moment, although we do have interns on occasion in different parts of the organisation ... I certainly wouldn't look at volunteers running commercial operations. That feels inappropriate, to have people working for free and generating income, the way we looked at it in the UK and the way if we ever did anything here I would look at it, it would be very much about getting volunteers to do extra stuff that we can't do, not to deliver core services (P.S, personal communication, April 9th, 2015). 


\section{Ethics}

The broad issue of ethically sustainable revenue generation was raised by all interviewees from a number of different angles:

I would say it's always managing that balance between the core purpose of being a museum and generating revenue and that's always a balancing act as to how far you push things ... Fundamentally the museum is here to, you know, to protect the treasures of the nation, to make those treasures accessible to the public and you know you can argue and you know some museum purists would say revenue generation is a necessary evil to keep the doors open but I think it's that balancing act between emphasis (P.S, personal communication, April 9th, 2015).

The barrier would be that whole sort of thing, like, you know, it's a dirty secret that we have to make money and how it's just such a taboo sort of subject, I was very surprised about. So that would-be barrier to revenue earning, but I think people here, do see, they see the need to earn revenue. I think it's probably the barriers are probably that more external perception of the external expectation not to make money (Z.H, personal communication, April 7th, 2015).

With New Zealand Cricket ... they guaranteed us $\$ 60,000$ a year for three years. There's a certain amount on top of that, that they will give us ... but that number reduces over the period of the three years ... I know that I have a role to play in revenue generation, but there's a certain aspect where I'm raising money to pay for my own salary which doesn't feel right to me ... (J.B, personal communication, April 7th, 2015).

Despite guidelines for ethical practice in museums from ICOM (2004) and Museums Aotearoa (Aotearoa 2003) there are wide debates around the ethics of specific revenue streams such as admission pricing (Rentschler et al. 2004, 4). Issues such as the perception of revenue generation, and many practical considerations such as pricing models, are not currently addressed. Addressing perceptions of revenue generation may be a significant factor in the sustainability of any revenue source in museums as it may enable buy-in from both external and internal stakeholders.

Enabling this buy-in may also involve addressing how organisations communicate.

Closed question results ${ }^{8}$ from this study demonstrated that there are unmet

\footnotetext{
${ }^{8}$ See Figure 2.5
} 
opportunities in terms of the diffusion of ideas both internally and externally for TP and that external diffusion is also an issue for NZCM and P.

\section{Legislation}

The restrictions of legislation on revenue generation in the case study institutions appear to be minimal. For example, analysing the following commentary from Phillip Smith:

We've got lots of external stakeholders who have an interest in the organisation. In the broadest sense, they support us, but then they also challenge us about things ... What we're doing is balancing the money we've got to spend versus all the different outputs that we need to achieve. A lot of those are set out in our crown mandate so there are things we have to do ... (P.S, personal communication, April 9th, 2015).

It is noteworthy that, TP is a crown entity, a body in which the government has a controlling interest, but which is legally separate from the crown (Treasury 2014). The museum was established under the Museum of New Zealand Te Papa Tongarewa Act (1992). From a revenue allocation perspective TP is required to distribute resources to the mandated functions outlined in section 7 of the Act. But beyond some provisions around gifting (see section 19 of the Act) and not allowing third party groups to trade under the TP or national museum brand (see section 23) there are actually no other mandated restrictions on how the museum generates revenue or provisions to support revenue generation.

In the case of NZCM, the museum is registered as an incorporated charity under the Charities Act (2005). The museum's charity status does not restrict it from carrying out profit making activities as long as those profits are used to further it's 'charitable purposes' and are not used to advance private interests such as paying dividends to private stakeholders (Charities Services 2016).

The operation of P. by Porirua City Council takes the form of a business unit, following the legislative provisions of the Local Government Act (2002). There are some restrictions around the museums disposal of endowment property (e.g. collection items). As a revenue source, such disposal could only be realised once and would not provide ongoing income. It is worth noting however that if the revenue 
raised through the disposal of endowment property is placed in an investment fund it can produce an annual return to the museum. Beyond the restrictions on endowment property and the obvious requirements to act in a legal manner, there are again no significant legislative restrictions on how the museum can generate revenue.

\section{Support for revenue generation}

It is interesting to note this absence of legislative restrictions, in terms of the relationship between the Porirua City Council and revenue generation at $\mathrm{P}$, the absence of legislative restrictions could be interpreted as a demonstration of support for the museum and an attempt by the council to foster an environment for creative thinking around revenue generation. Yet at the same time, as Zara Hawthorne's comments demonstrate, the council could also be perceived as penalising the museum for generating extra revenue:

If we earn more than target it actually goes towards our operating budget so we can do a little bit more, well actually it just sort of means that the council has to fund us less (Z.H, personal communication, April 7th, 2015).

Thus, while additional revenue enables the museum to do 'a little bit more', the value of this revenue appears to be countered by the Council's subsequent approach to the museum's funding. The ramifications of this scenario may demonstrate the findings of Hewison and Holden (2013) that public funding can leave organisations stuck in an uncreative rut.

In a similar vein, initiatives to support the use of innovative and non-traditional revenue sources by the Ministry of Arts, Culture and Heritage, Museums Aotearoa and TP National Services have been inferred by the interviewees to be of mixed value:

I am aware of some stuff that's been done, mainly by MCH (Ministry of Arts, Culture and Heritage) and Museums Aotearoa and we helped with some of that. For example, Darren in the shop ran a workshop, a retail workshop, for regional museum retail managers ... I think we get some benefit, I think probably our benefit is more --., we get more benefit from looking at offshore ... visiting museums in Melbourne, Sydney, and Brisbane and that's just really about scale. I'm not saying you can't learn anything from anyone smaller but ... you look at the metropolitan and the regional museums across New Zealand, their scale is so much smaller... our retail business is three and half million, 
there's no one else in NZ museum-wise who's collecting anything near that level. There's more benefit for us in looking offshore at best practice (P.S, personal communication, April 9th, 2015).

I'm aware of talks about initiatives ... there's always various kind of speakers funded by (...) MA and National Services that are going around ... it's probably the implementation stuff that I'm not really aware of anything ... I think that's kind of something that happens across museums, in all departments. So, Creative Commons licensing for museums, getting collections up online ... there's a lot of really good conversations ... But then when it gets to the point where you are a museum, where you've got one, two, three staff members, actually being able to implement something like that is a completely different story and it's the same with the revenue generation (J.B, personal communication, April 7th, 2015).

What these commentaries appear to highlight is that the key issue is not the specific initiative or source, but rather the tailoring of initiatives to the institutions involved. However, partnerships in revenue generation were not ruled out by the interviewees. All three case studies provided examples of revenue generated from partnerships, both indirect and direct in nature:

I think the council beyond the museums trust ..., it's a rent-free space for the Cricket Museum so that's pretty amazing support (J.B, personal communication, April 7th, 2015).

I think we network--, certainly our touring exhibition business is ... built off the back of collaboration and working with others (P.S, personal communication, April 9th, 2015).

So, we have various sorts of business relationships, one of which is this coffee Company ... they've said, in the instance of the coffee cart, here have this, free on loan for this period as long as you're buying coffee from us ... I've tried to develop the whole sort of appearance of coffee within our organisation ... To do that involved quite a lot of design work ... the coffee supplier helped us out ... they paid half, we paid half ... (DM, personal communication, April 3rd, 2015).

These partnership examples warrant further research to establish if they are viable for the long term. For example, no data is currently available on the tax implications of the relationship between TP and its coffee supplier. Such implications could include the deprecation of assets during a loan period and the process for paying any associated costs. 


\section{Museum management and organisational culture}

The literature offers some insights into characteristics which may motivate museum management decisions in relation to revenue generation. Frey and Meier $(2006,1028)$ identified internalised or institutionalised perspectives as a motivating characteristic in managerial decision-making. In their models for analysing the behaviour of museums Frey and Meier $(2006,1029)$ highlight the fact that museum managers are primarily concerned with their own utility and reference group. The commentary of case study respondents would seem to reinforce these findings, for example:

The biggest contributor as far as I am aware ... is the hospitality side of the business. So, that would incorporate myself, the café and Espresso ... the functions team, who deliver private functions throughout the year. Another big one would be the travelling exhibitions ... retail is a big one as well (D.M, personal communication, April 3rd, 2015).

The limited scope of awareness acknowledged in this commentary has suggested a level of bias and as such, it is being acknowledged as a factor for consideration in interpreting the results of this research. Other factors for consideration in any interpretation of these results may also include the duration of employment of the responders:

I've been in the role that I'm in for about fifteen months, so my experiences ... are perhaps more limited than others. But, at the same time that probably gives me a ... fresher perspective ... (D.M, personal communication, April 3rd, 2015).

While duration of employment could imply that responders may have limited experience in what has been financially viable for their institutions, it also highlights a broader issue: the institutionalised nature of many museum cultures. As evidenced by the commentaries below, viable revenue generation in the case study institutions has been challenged by insularity, departmentalism, negativity, lack of ambition, and lack of realism. These problems are comparable with the findings of (Fleming 2015, 13).

One of the things about working for the council ... there is a way that something has been done for many, many years and ... it can be quite difficult to convince people of the need to change ... I think it is something that I have noticed in wider council, but of course because we work for the council and a lot of people have been here a long time, maybe there is a bit of that that's crept in. I think that everybody here is very positive and optimistic and they're very very creative. So, they can come up with a lot of ideas, but sometimes ... the implementation skills probably are a little lacking, but if they're very very motivated 
about something they'll implement it (Z.H, personal communication, April 7th, 2015).

I haven't really come across barriers ... I've actually been quite surprised about how accepting people have been ... Now I don't know if that's a new thing or whether that's because of this change of leadership or perhaps whether that's just how this organisation works ... the only barriers I really feel that we have are getting other people to like those ideas. ... it's just this sort of idea we'll do business this way and to change it is sort of difficult. Why do you want to change it? Let's continue doing it the way we do it (D.M, personal communication, April 3rd, 2015).

Teamwork and results I would say, are probably strengths. Weakness is probably pace, ..., as an organisation we can take too long to make decisions ... the red gates are a really good example ... when I asked, when I started, can't we open the red gates ${ }^{9}$ so people can come in that way and it was like, oh, no, we can't do that for these reasons ... Rick started ... and said let's just open them and you know, you start unpicking that and going back ... it went to board level as to whether or not we open the red gates and you just think really? Is it that big a deal? And no decision was ever made (P.S, personal communication, April 9th, 2015).

The problems identified in the above commentaries have been similarly highlighted in international studies, for example Fleming $(2015,13)$. Darren Milsom's commentary suggests that management is crucial in resolving these issues:

We've got some new leadership and I think that with that has come a ... need to look beyond the bounds of what we currently do. ... one of the weaknesses is that, such a big organisation ... That can potentially be a barrier ... let's say the chief executive has an idea ... he has ... to get a very large number of people on board with that idea. I think that's probably the weakness ... especially when so many people have worked here for so long, which is both fantastic, but can be problematic because they are kind of stuck in their way of doing things (D.M, personal communication, April 3rd, 2015).

The role of management in organisational culture was also articulated by Phillip Smith. Smith echoed the findings of Fleming $(2015,7)$, that clearly articulating a museum's vision and values internally could be a 'call to arms for staff':

During the last year when, we had some financial issues ... we were very transparent with staff around where those issues were, what we

\footnotetext{
${ }^{9}$ The 'Red Gates' are an external entrance at TP which brings visitors into the museums café, amphitheatre and outdoor exhibition Bush City.
} 
needed to do, where we needed to save money and by and large the team stepped up and helped us deliver that (P.S, personal communication, April 9th, 2015).

Clarifying the museum's mission, vision and values externally was also seen by interviewees as a way to generate viable new revenue sources. Jamie Bell offered the following example with regards to the NZCM:

We were sort of in a situation when I started when actually the funding that we got from New Zealand Cricket was defined as being part from New Zealand Cricket and part from ANZ. But we had no relationship with ANZ whatsoever ... they didn't get anything out of it. So, what I feel is that the program of activities that we've run for the Cricket World Cup, the touring exhibitions, those sort of things, the way that our presence online has built up, we've actually got a much better case for sponsorship (J.B, personal communication, April 7th, 2015).

Falk and Sheppard (2006, 23) established a wider perspective for the comments of Jamie Bell. They argue that sustainability in museums involves implementing new business models. The authors advocate for business models which focus on visitor needs and promote interrelationships. The success of such models involves not only investing in clear communication but also in a fair distribution of all resources. As Phillip Smith and Jamie Bell highlight:

We generate more revenue from visitors using our front of house facilities and our corporate hospitality business than we do from sponsorship, but sponsorship and fundraising is another area that's been underdeveloped and under-resourced within the organisation (P.S, personal communication, April 9th, 2015).

Resources, it's always going to be resources for anything we do, that's always the challenge. It's good now we've got some volunteers that can help with other aspects ... But yeah, resourcing is always our biggest challenge (J.B, personal communication, April 7th, 2015).

On the basis of these comments, it would appear that ultimately successful revenue generation can come down to resources. The above comments are a practical reflection of the arguments of Fleming:

Being clear about the mission, values and vision won't amount to much unless an organisation is capable of turning these notions into appropriate, and preferably measurable, activity that is responsive to changes in the environment in which the organisation operates" (Fleming 2015, 8). 
Following a qualitative and quantitative framework, this chapter has considered the results of the research conducted for this thesis. Case studies have illuminated key issues. Analysis has focussed on research gaps, reporting variations, knowledge, leadership, organisational culture and innovation theory. The next chapter will discuss perspectives on these issues and will look at some possible implications. 


\section{Chapter Four: Discussion of the Findings}

\section{Introduction}

The research presented in the previous chapters has demonstrated how innovative and non-traditional revenue supports the financial viability of three New Zealand (NZ) museums. This chapter discusses the key findings behind this contribution to our understanding of NZ museum economics. Prior research on revenue and theoretical and practical ideas are considered. The chapter is structured into thematic sections and opens with a discussion of revenue sources. Innovation theory is then considered. Specific reference is made to revenue terminology and organisational culture. Museum management, resourcing and volunteers are the next key areas discussed. The chapter also considers branding, the regulatory environment, support, and education. It concludes with a brief discussion of social inclusion and commercial operations.

\section{Sources of revenue}

Results of the revenue recorded analysis outlined in chapter one demonstrated that innovative and non-traditional revenue has contributed to the finances of the three case studies. This contribution is small; in the case of the New Zealand Cricket Museum (NZCM) innovative revenue made up just under two percent of the museums income in 2014/15. The motivation to pursue new revenue sources is not attributable to a sudden loss of traditional income. Traditional revenue sources continue to supply the majority of the case study institutions' income. It can also be noted that operating resources did not determine which revenue generating practices were undertaken by the three case study museums. All the case studies, regardless of resources, use innovative and non-traditional revenue generating practices. Any assumptions that organisational size determines revenue practices can be refuted.

If income is not the driving motivator, why do museums pursue these alternative revenue sources? It appears that non-traditional revenue practices offer practical solutions to operational issues. Revenue generation can contribute to a museum's viability beyond just income. A key example of this scenario is provided in the comments of Jamie Bell: 
Getting on Trade Me has been quite good, because we are really restricted [geographically] being where we are (J.B, personal communication, April 7th, 2015).

Non-traditional revenue has created an outlet for the museum beyond its physical boundaries. This 'workaround' could be a driver for innovations. Other drivers could include reduced funding, major crisis and the museum's leadership (Massey, Lewis, and Museum of New Zealand 2002, 30). Bell's leadership is entrepreneurial; see, for example, his comments-on the NZCM's licensing agreement:

We've found that there's a whole heap of restrictions under the licensing program, but there's still the opportunities ... (J.B, personal communication, April 7th, 2015).

In the case of TP, we can only speculate on whether the museum recognises the value of indirect revenue. Recent revenue initiatives at TP could be fruitful but appear to have unrealized opportunities; for instance, would targeted advertising on the museum's plaza coffee cart help museum outreach? Do coffee sales outside TP remind the purchasers of the museum and prompt later visits? Tracking interactions between TP and its coffee cart clientele could be useful. It may help to substantiate whether commercial operations in the museum are 'third spaces' (Connolly 2010) vehicles for social inclusion. The resulting data could assist with communicating the social purpose of museums to funding providers. An example of social inclusion intersecting with commercial and museum practice was Science Express at TP Science Express was a popular series of lectures held at the Espresso Café in TP in 2007. The museum seems to have walked the line between communicating stories and commercial practice. Although we can only speculate on the indirect benefits from these operations, a factor in past and present successes appears to be leadership. As Darren Milsom comments:

I think what the leadership team is now trying to cultivate is an attitude of: have you got an idea? yup, alright, let's just go with it ... let's see if it works and is it something that museums would normally do, no, does that mean that we can't do it (D.M, personal communication, April 3rd, 2015).

This policy of embracing innovation is strategic (Massey, Lewis, and Museum of New Zealand 2002) but it does not immunise an organisation from decline. As Hansen and Birkinshaw (2007) highlight, successful innovation is not just about ideas 
but the delivery of those ideas. Institutionalised perspectives in a museum can hinder the viability of any revenue source.

Viability and evolution in museums features in previous research (Rentschler et al. 2004). Some scholars, such as Suchy (2004), have suggested that museums are slow to change and to incorporate new ideas, but the rate at which museums absorb new ideas does not appear indicative of how they innovate. Some museums take a tentative approach to new revenue regardless. See, for example, the comments of Zara Hawthorne:

We have talked about these things, we're probably just observing at this stage what other museums and organisations are doing and how it's working (Z.H, personal communication, April 7th, 2015).

Although P. could be considered tentative with this approach, it does not appear to be reflective of the wider operations of the museum. P. operates in a facility shared by a group of organisations that bring the museum benefits. Analysis of the revenue records of $\mathrm{P}$. has demonstrated many forms of innovative revenue streams, such as their gallery commissions; there is no absence of innovative thinking at $\mathrm{P}$.

However, several factors may contribute to the conservative approach of P. Many innovative revenue initiatives are recent and so conclusions on their contributions are not definitive. The limited availability of costs and profits data makes it difficult to test revenue sources. Lack of centralised data recording and the absence of standardised terminology for innovative revenue generating practices hamper evaluations.

\section{Innovation theory and revenue generation}

This research reinforces the suggestion that the development of standardised terminology could be a useful and flexible tool in fostering innovative funds development in museums. For example, Anthony, Duncan, and Siren (2014) define innovation under two main categories. With some minor modifications, their terminologies could describe revenue in NZ museums. 'Core innovations' could become 'core revenue innovations' and define variations on traditional revenue streams. 'New-growth initiatives' could become 'new growth revenue' and define original revenue streams. 
Within any definition range there are many variables, for example, grouping revenue streams and initiatives could result in inaccurate data. By modifying existing definitions of revenue supply, this study may have lost some of the nuances in the revenue sources studied. For example, crowdfunding, and crowdsourcing were considered as a possible revenue source or approach. Peer to peer lending was not included in the definition of Brodie, Kane, and Clark (2012); it was not reviewed for this study. But, despite potential variables, there is value in establishing common ground in relation to financial terminology in museums. Common terms could help improve assessments of a revenue stream's viability. Summative testing of assessments could also provide a method for filtering issues.

Size, and its relationship to a museum's goals, is just one of the issues that this study has considered. Museums like TP could be striving to capture a different market to that of local museums. As Philip Smith's comments show:

you look at the metropolitan and the regional museums across New Zealand, their scale is so much smaller ... our retail business is three and half million, there's no one else in NZ museum-wise who's collecting anything near that level. There's more benefit for us in looking offshore at best practice (P.S, personal communication, April 9th, 2015).

Despite the opportunities which could arise from looking at foreign business practices, there are still benefits in looking at local museums. The flexibility of smallscale operations can allow specialisation. Small operations can cater to different audience groups and corner niche markets. This can have implications for funding such as reducing dependencies on single sources. Also, regardless of the scale, many revenue generation issues are common. Land capacity for car parking, for example, can be an issue for any organisation. Researching the revenue strategies of other organisations could offer new approaches for these issues. NZ museums are also branching out in revenue practices. In the United Kingdom, many museums are still focused on traditional revenue (Brodie, Kane, and Clark 2012, 370). What motivates a museum to focus on traditional sources is unknown. On the one hand a strategy of continuity could keep a museum in line with its goals but as communities evolve it would be logical for the focus of museums to change. 
Documented evidence of the determining factors in successful innovative practices in museums is scarce. However, operating circumstances do seem to be core to the viability of revenue sources. NZCM operational policies allow the generation of revenue from the sale of potential collection items not required for permanent collection. Their collection development policy has been structured in a manner which can accommodate this form of revenue generation. Stakeholder expectations and collection policies could prevent other museums from trying this. The NZCM has managed to create a fusion between museum practice and commercial operations. They have tailored their innovations to their specific operating circumstances.

The Minimum Viable Innovation System (MVIS) could offer one approach for tailoring innovations (Anthony, Duncan, and Siren 2014). MVIS considers innovation processes within an organisation as a series of interconnecting activities. In conjunction with the Innovation Value Chain (IVC), these two ideas could be used to develop a framework for implementing innovative revenues. To install these or any other organisational theory needs stakeholder buy-in. Fostering buy-in is challenging but critical for viability (Anthony, Duncan, and Siren 2014). Phillip Smith summarised both the need and the challenge of buy-in:

If you look at the touring exhibitions we really need the ... curators and collection managers to help create those touring products ... we've got to respect their expertise around the knowledge around those collections but then they've got to work with us and respect our expertise around us knowing what our customers want, knowing what will sell ... a successful commercial operation in a museum won't happen if you just look at the commercial team to deliver ... you need ... a whole organisation focus around it ... you need everyone to buy into operating commercially (P.S, personal communication, April 9th, 2015).

Restructuring an organisation could be one method for fostering buy-in. Fleming (2015) outlines one possible restructuring model using the National Museums Liverpool, UK. New staff structures, line management and a redistribution of resources were undertaken. Across the museum's senior management team, a dictatorial approach implemented the new structure. Staff recruitment and promotion fostered buy-in to the changes. Audience research supported restructure decisions and changed museum operations (Fleming 2015, 14). The changes which audience research brought about opened up an avenue for external stakeholders to have a voice. 
To generate internal buy-in, communication was the key. A number of museum operational models highlight the importance of communication, see for example the work of Falk and Sheppard (2006). Using a museum's internal and external environment, these authors argue for a clear operational model which encourages feedback. Restructuring an organisation is not without risk; it is possible for organisations to change through other methods. The first step for any organisation is to clarify its mission and values and challenge its status quo. If it does this successfully, it could achieve the same changes as a restructure over time.

\section{Museum management and organisational culture}

Feedback loops or channels in an operational structure can reflect transparency (Falk and Sheppard 2006). Transparency is a crucial component for making revenue generation viable. As Phillip Smith comments:

During the last year when we had some financial issues ... we were very transparent with staff around where those issues were, what we needed to do, where we needed to save money and by and large the team stepped up and helped us deliver that (P.S, personal communication, April 9th, 2015).

Besides transparency, Smith's comments highlight interdepartmental relationships as crucial for revenue generation. A museum's affiliations can benefit when operations are integrated. Implementing an operational model like Falk and Sheppard's (2006) can develop integrated operations. As well as improving relationships, this model could support innovation. There are parallels between this model and the innovation system MVIS (2014). Both are holistic and highlight the importance of dedicated management. Both recognise the need to integrate operations and consider relationships. Used together they could integrate business and museum practice. MVIS could provide the framework for developing revenue sources.

When conducting this study, time and its relationship to revenue generation was considered. It was noted that the majority of observations by the interviewees were about recent initiatives. The interviewees were also all recent employees of their organisations. Replicating interviews with other staff could establish whether duration of employment has bias. As a TP staff member, myself there is also the possibility that my experiences may have brought bias. It may be valuable for a non-TP 
employee to replicate this study. Bias can reflect how museum culture is often institutionalised. This institutionalised culture has challenged revenue generation in the case studies. Among the key issues are insularity, negativity, lack of ambition and a lack of realism. As Darren Milsom commented:

...it's very easy to get tied up in the notions that we're a museum and we have to operate solely as a museum. There is a big part of the business which is a commercial enterprise and although we acknowledge that, I think we need to broaden our [view], ... and try new things (D.M, personal communication, April 3rd, 2015).

Embracing new 'things' could involve shifting the mind-set of museum staff (Fleming $2015,30)$. One way to do this could be to promote the idea that staff will be better resourced as a result of commercial operations.

\section{Resources and revenue generation}

Investing in commercial operations can bring wider benefits to the viability of a museum. An investment in technical infrastructure for commercial operations can also build communication capacities. Evidenced-based research on commercial revenue streams can also support professional development of museum staff.

Providing professional development courses on revenue generation could help to make revenue streams more viable. At present, experience is often an issue, as Zara Hawthorne's comments show:

we actually suggested that they try a crowdfunding thing, but they weren't quite comfortable ... the friends, the committee, are retired people so they probably just had no experience of it (Z.H, personal communication, April 7th, 2015).

Presentations of recent revenue research papers could be one way to provide training. Samuele De Stefani's work on museum economics and relational capital would be relevant to disseminate ${ }^{10}$ (Victoria University 2016 ). Relational capital is the notion of relationships between institutions and people as a form of capital. Understanding and developing relational capital can sustain relationships between institutions and their stakeholders (Capello and Faggian 2005, 77). The work of Brabham (2016) could also be presented and debated from a NZ perspective.

\footnotetext{
${ }^{10}$ Samuele De Stefani is currently working on a $\mathrm{PhD}$ at Victoria University analysing Relational Capital, TP and Welllington Museums Trust.
} 


\section{Volunteers}

Perhaps the most valuable and under-represented resource for revenue generation is volunteers. Volunteers in NZ museums generate direct and indirect forms of revenue. Jamie Bell's comments show the varied nature of roles:

One's a designer, so we've been using him to help design the World War One exhibition panels ... the other ones sit behind the front desk ... welcoming people, selling stuff in the shop (J.B, personal communication, April 7th, 2015).

Existing research reflects the diversity of volunteer work but does not generally cover revenue. Few guidelines are available for working with volunteers on revenue generation. The ethical guidelines of Museums Aotearoa (2003) do not cover the subject. Volunteer management policies, which discuss revenue generation, need to be developed. They could assist museums with striking an ethical balance in commercial operations.

\section{Branding}

The question of ethical branding of museum revenue generation is an interesting challenge. As Zara Hawthorne commented:

The barrier would be that whole sort of thing, like, you know, it's a dirty secret that we have to make money and how it's just such a taboo sort of subject ... the barriers are probably that more external perception of the external expectation not to make money (Z.H, personal communication, April 7th, 2015).

While this commentary could reflect personal bias it still offers several points for discussion. At face value taboo associations with revenue may reflect the NZ 'Tall Poppy' culture, but in NZ entrepreneurship is popular (Scherer 2012). It is more likely that what is being expressed are notions of how museums are perceived. Some see museums as a 'temple', others a 'commercial operator' or a non-profit organisation. Many of these perceived roles sit in opposition with each other.

Creating a positive image of museums that facilitates revenue generation is not straightforward. For non-profit organisations, such as charities, re-branding perceptions around the organisation has been workable. For example, Christian Children's Fund is now known as Child Fund New Zealand. Public and private 
perceptions of museums are difficult to manage when re-branding. The TP brand has received ongoing criticism of its 'commercially positive' approach. During the 1990's critics labelled the museum as 'popularist' (Walkowitz and Knauer 2008, 33). TP responded to criticism by removing its interactive rides and increasing art exhibition spaces. Despite these changes criticism continues.

In trying to silence its critics TP may have missed an opportunity to support its visitors. Summative data is not available on the removal of the Our Space exhibition. We can only speculate on whether the exhibition supported kinesthetic learning and generated revenue. It is also unknown if this exhibition attracted a new audience to the museum, but anecdotal evidence from front of house staff at TP has suggested that it did. This example is an interesting tension between the visitor experience and the museum's critics.

Resolving the tension between 'authentic' education on the one hand and supposedly 'popular' entertainment experiences on the other could make revenue generation more viable. A relevant experiment in this resolution is the Innovation Hub (Hub) at TP Initial presentations have highlighted the idea that the Hub will have kinesthetic experiences. Visitors will take part in the development of new products. These products may result in new revenue for the museum (Firth 2015). Opportunities from the Hub go beyond kinesthetic experiences and revenue. They could enhance the museum's 'true' purpose, its mission. Businesses which 'graduate' from the Hub could form a new community for the museum (Ryan 2016). The Hub could also play a role in establishing if digital assets are under-represented in museum collections. Should museums be collecting defunct mobile applications by NZ developers? Could these digital items be part of our future history? The ultimate contribution of the Hub to TP may be as much about its indirect benefits as its revenue.

These observations are speculative; the Hub opened in August 2016 and is outside the parameters of this thesis. Whether the Hub will invigorate and add vibrancy to TP (Mack 2016) is a matter that still remains to be seen. Both the direct and indirect benefits of the Hub need further research. It would be appropriate to undertake this research as soon as possible as the Hub, now called Mahuki is set to run another program in July 2017. One way to do this may be to analyse Mahuki alongside other 
museum innovation centres. The New Museum in New York and the Australian Centre for the Moving Image could be valuable cases to study as well.

Further research may also provide some of the answers to branding issues. One strategy for successful re-branding could be to develop ethical guidelines for revenue generation. Guidelines could prove a museum's professional credibility and help commercial operations. At present, current guidelines produced by Museums Aotearoa (2003) offer little help on revenue generation.

\section{Regulatory environment}

Legislation and central and local government appear noncommittal to assisting museums to generate revenue. It is a situation that does appear to be at odds with itself. On the one side, there are papers acknowledging the value of arts participation. The duty of central and local governments in providing arts funding is also acknowledged (Creative New Zealand 2014, 23). At the same time the NZ public question rates rises and ask for transparency in funding; museums are operating in a small economy. I would argue that the ambivalent approach of legislation and local councils is unsustainable. Despite being flexible it offers little incentive to encourage museums to be self-sufficient.

One approach to encouraging self-sufficiency is to extend current incentives. Tax incentives are currently offered for gifts and foundation grants. The 'Boosted' NZ crowdfunding platform offers $33 \%$ tax breaks to Boosters.

Further tax incentives in New Zealand could promote revenue generation in museums. In-kind donations of goods and services are not currently tax deductible. Changing this situation could encourage more businesses to get involved with museums. Providing clarity around reimbursements of costs to businesses would also be valuable. What happens when an organisation produces donated goods for a museum and a museum covers their costs? There seems to be little clarity around the associated $\mathrm{GST}^{11}$ from the 'purchase' of that service.

\footnotetext{
${ }^{11}$ Goods and services tax (GST) is a New Zealand tax added to the price of most goods and services; currently set at $15 \%$.
} 
Tax is also a factor for consideration in the contribution of volunteers to museums. There is currently a lack of clarity around the withholding taxes associated with volunteer reimbursements and honoraria (Tan, Dunbar, and Cordery 2008, 69). Given that on average current payments to volunteers very rarely cover all costs, could all volunteer reimbursements be tax free? Should there be a distinction between volunteers who generate revenue and those who don't? Future research must consider these variables (Tan, Dunbar, and Cordery 2008, 70).

As for taxes, they could also make merchandising more viable for museums. Hypothetically, the income tax of a licensing agreement could be set up to favour a museum. A clause in the agreement could cover the licensor paying the tax for the museum's income. Developing this clause would need buy-in from external parties and the New Zealand government.

\section{Support for revenue generation in museums}

The work of external parties on revenue generation in museums has had mixed results. As Jamie Bell comments:

I'm aware of talks about initiatives ... there's always various kind of speakers funded by (...) MA and National Services that are going around ... it's

probably the implementation stuff that I'm not really aware of anything ... when it gets to the point where you are a museum, where you've got one, two, three staff members, actually being able to implement something like that is a completely different story (J.B, personal communication, April 7th, 2015).

Bell's comments raise interesting questions. Should the initiatives of third parties be considered for implementation? Are external parties idealistic about the capacity of museums? Or are museums unrealistic about third party support? Establishing what the priorities are for revenue generation could resolve some questions. This could involve working parties between museums and external advocates. To make the most impact external advocates may need to focus on ideas that can be implemented in all museums.

Outside of advocacy initiatives, business partnerships can also contribute to financial viability. As Darren Milsom demonstrates: 
So, we have various sorts of business relationships, one of which is this coffee company ... they've said, in the instance of the coffee cart, here have this, free on loan for this period as long as you're buying coffee from us ... I've tried to develop the whole sort of appearance of coffee within our organisation ... To do that involved quite a lot of design work ... the coffee supplier helped us out ... they paid half, we paid half (D.M, personal communication, April 3rd, 2015).

There are many issues raised in this commentary. There could be tax implications from the supply of in-kind goods. No data is available on the long-term impact of this relationship. To make relationships like this viable they need to be managed carefully through the opportunities and issues. Comparisons with research such as Sutherland (2006) could provide solutions and comparisons. Beyond research there may be structural ways that museums can support these relationships. Museum business models should include an external focus (Falk and Sheppard, 2006, 22).

\section{Foundations, Friends and training scheme developments}

Feedback and communication has been a recurrent theme that has emerged from the research presented in this thesis. One recent development in stakeholder communications is the establishment of foundations. Both P. and TP have created foundations, new initiatives at the time of this study. As a vehicle for communication, foundations may be significant for revenue generation. But in saying this, it is unknown if and how these foundations will communicate to new audiences. Is a foundation attractive only to traditional museum supporters?

It also seems reasonable to wonder about the question of motivation. What would make a person donate to a foundation? NZ has one of the lowest rates of philanthropy in the world, but it has recently had a rise in online giving. To increase philanthropy in NZ there is an argument for prioritising online giving. The National Digital Forum could initiate the documentation of successful museum crowdfunding campaigns. The NZCM and the Museum of Transport and Technology Auckland (MOTAT) are among the museums running crowdfunding pages on the Spark NZ Give-a-Little web page. Summative evaluation of their experiences could help other museums make informed decisions around crowdfunding. As there have already been many presentations at the forum on crowdsourcing (Dempsey 2013), it seems as though this would be a natural extension. 
When thinking about donation models could 'Friends' memberships be better targeted? Despite price variations the benefits are often generic. A family of Friends at TP gets the same benefits as an individual Friend. Tailoring Friends' memberships could be valuable. The NZCM is exploring tailoring from a marketing perspective. They have recently established a 'Friends' program for the museum and offer memberships via the Cricket Wellington website (Cricket Wellington 2016). This initiative resulted from Jamie Bell's recent secondment to Cricket Wellington. It offers yet another example of the value of partnerships to revenue generation in NZ museums.

As for other opportunities, merchandising agreements and workplace training schemes can bring dual benefits. Workplace training schemes can show how commercial museum operations create social inclusion. Upskilling future generations is a practical example of how museums could enhance communities. Merchandising agreements can also offer a new platform for museums to communicate with new audiences. Merchandise seems in many respects to be an underestimated part of the visitor experience. There seems to be no research that considers how merchandise creates connections. How many times do museum goers tell the stories of their experiences with the catalogues purchased? Value in this instance is as much about the emotional connection as the revenue generated. The idea that revenue generation has value outside of financial resources is a recurring theme.

Throughout this thesis, innovative and non-traditional revenue generation has been shown to contribute to the financial viability of three Wellington museums. The nature of this contribution takes both direct and indirect forms, and has provided solutions to operational issues such as geographical location. Internal and external 'buy-in' appear to be crucial factors in successful revenue generation. Organisational culture, resource management and external parties can play a role in improving revenue generation. Strategies such as standardising terminology could also improve revenue contributions. There appear to be unrealised opportunities around revenue. What follows in the conclusion of this thesis are a range of recommendations for revenue generation in the future. 


\section{Conclusion: The Future Benefits of Revenue Generation for New Zealand Museums}

This thesis investigated the central research question: do innovative and nontraditional revenue sources improve the financial viability of NZ museums? If so, how? This question is crucial to address for both museum practice and museum studies as knowledge of museum revenue is currently limited as the literature review demonstrated. Four key areas define the gap in current research: revenue ethics, forecasting, terminology and development. By undertaking an empirical analysis of revenue this study has added to our existing knowledge on these topics, and has contributed to the awareness of the operating circumstances of NZ museums.

An empirical and pragmatic analysis of current museum practice formed the basis of this thesis. Research was both qualitative and quantitative in method. The research framework drew upon theories from business management research and museum and heritage studies. The thesis began by considering the existing literature on innovative and non-traditional revenue. This review was then used to define the boundaries of the study, which in turn formed the basis for an analysis of three Wellington museums. By using case studies, the research captured some variations in NZ museum organisational structures. Some research boundaries were redefined as new information came to light during the study.

The first stage of the research analysed revenue records from the three museums. Despite some inconsistent data these records still generated useful findings. The second stage of the research involved a series of interviews with key staff involved in revenue generation in the three museums.

Complementary findings emerged from the data in the revenue record analysis and interviews. All the museums had similar revenue strategies despite differing in scale and revenue practices. Changes in the NZ economy had not driven any of the museums to start charging for existing services. New income streams were being explored for a wide range of reasons such as the locations of the museums. Revenue records showed that traditional revenue supplied the majority of the income of the case study museums. Innovative and non-traditional revenue delivered varying 
income, but growth was clear. Interview comments suggested that this growth took both direct and indirect forms.

Examples of the indirect benefits of revenue generation were found throughout the interviews. The director of the NZCM explained how selling on Trade Me has benefited the museum's communications. It appears that revenue can contribute more than just income. In theory improving audio guides could increase revenue and make a museum more accessible. Enhancing a website could generate revenue while making the museum more available. Building the capacity to use digital platforms may assist with building virtual museum communities. Improved communication may also strengthen museum communities and make museums more viable. Initiatives for revenue generation can have cross-over benefits to museum practice.

As for making revenue reliable, the interviewees highlighted many common dilemmas. The issue of ethically-sustainable revenue generation was raised by all respondents. There appeared to be no consensus around the use of volunteers when generating revenue. Some informants implied that volunteer involvement in revenue generation was unethical. Others talked about volunteers and revenue generation with reference to social inclusion. Increasing expertise in some of the functions associated with revenue was a common need. Empirical evidence was also highlighted as essential for viable revenue generation. Some museums were seeking evidence of success before pursuing innovative revenue forms.

Regarding successful revenue generation, partnerships were highlighted in the interview data. Partnerships provided direct support for revenue generation through the sharing of costs. They also provided indirect support such as free rent for museum premises. To speculate for a moment, could partnerships also assist with capacity issues in museums? For example, TP currently hires their car parking spaces after hours to a range of local businesses. This practice allows the museum to generate income without compromising visitor services, and could be a valuable model for other museums to consider. Although there may be many opportunities from partnerships, the results of this thesis demonstrated that not all external initiatives around revenue are constructive. While many museums acknowledged the value of sharing new ideas some felt that they lacked the resources to try them. 
Resources, research limitations and existing issues were all highlighted by interviewees. One of the key success factors in any revenue source was how it was supported internally and externally. Regardless of revenue source, successful revenue generation needed the whole organisation's support. This finding was reinforced on both a practical and theoretical level.

On a practical level, there are several steps that could be taken to address some of the findings of this research. One step for fostering internal support may be to tear down the 'brand values posters' often found in large museums. I would argue that all too often the values expressed are not put into practice. Instead of values, it would be helpful to see practice-based posters. For example, a museum whose goals are to save the planet could express this with a list of how it recycles. Revenue generation lists could explain how the income funds museum practice. Such an initiative would need a clear directive from museum leadership. Leadership was a common theme in the examples of successful revenue generation which emerged from the case studies. Part of the success of the NZCM in revenue generation could be attributed to the museum's leadership rather than a major crisis or funding loss.

Alongside leadership, communication and investment in internal resources may yield support for revenue generation. Under-resourced workers may not be motivated to support new museum practices. Addressing resourcing is not an easy issue, there are no-one-size-fits-all solutions. But perhaps the first step is not to view departmental budgets in isolation. Could the income from successful revenue generation be distributed across an organisation? If the benefits of an initiative only support one area of a museum, why would the other areas buy in? An organisation may be able to exploit staff goodwill in the short term but this study would suggest this is not a good long-term strategy. Exploiting the goodwill of staff will eventually affect an organisation's ability to attract high calibre staff.

In terms of staff relations, this study supports an argument in favour of work experience. In the past, TP implemented a plan whereby back office staff worked one day on the floor. This strategy was intended to make managers more compassionate and capable. It fostered relationships between front of house and back of house office 
staff and encouraged staff ownership of tasks. This sense of ownership seems to be crucial in the success of many revenue sources. Alongside these benefits this approach seemed to make staff better storytellers and fundraisers because it encouraged staff to confront the museum not from the perspective of staff but that of users. In the case of TP, the policy was unsustainable as it attempted to involve all back of house staff. But this should not discount it, as this strategy could be implemented for specific managers. If you design a commercial operation or an exhibition it is logical that you should learn from how it is used.

Strategies around internal communication could also benefit revenue generation. There could be more thought put into how museums communicate with staff. Is information accessible to those who may work shifts or without access to computers? Could operational changes, improvements and successes be announced via text message to staff? Would this be a valuable medium? To ensure staff are engaged with issues such as fund raising, it would be advisable to try a variety of forms of communication.

Greater transparency of museum finances may foster external engagement with a museum. In spite of the need for commercial sensitivity, it still seems reasonable to ask: why don't museums talk about funding? Anecdotal evidence from TP staff suggested many visitors believe the museum is fully funded. Why would a visitor donate if they believe the funding is already there? A public education program may therefore be required. In the case of TP, I would ask why the museum does not highlight the fact, throughout the facility, that it only receives $50 \%$ cent of its income from the government. It could be an opportunity to increase the public's sense of ownership of the museum. Information on museum finances is already available in museum annual reports, could this information be better disseminated?

Communications could be done in a strategic manner; disclosure criticisms could be a lesson in their own right.

As for strategy, it appears that organisational size does not determine or drive revenue generation. Respondents suggested that some explorations of revenue were to address specific issues. Looking at how other museums address those issues and revenue strategies could be constructive. Such research could consider revenue strategies at a 
theoretical level. My findings correlate with the Minimum Viable Innovation System (MVIS) (2014), the Innovation Value Chain (IVC) (2007) and the theories of Falk and Sheppard (2006), with some adaptations that I suggested in the last chapter which take account of the NZ situation. Implementing one or more of these theories in museum practice would support revenue generation in museums and offer strategies for managing revenue generation.

Many examples of revenue generation in the case studies exemplified the Knowledge Age model (KA) (Falk and Sheppard 2006). A merchandising agreement at the NZCM showed commercial operations integrating with museum communications. The TP cafe work experience trial demonstrated commercial operations integrating with social inclusion. Where these examples part with the KA model is in terms of assessment. Frameworks for summative assessment of these practices are not apparent in the case studies. I would suggest, however, that revenue assessment frameworks would be valuable for all museums. Beyond costs and income, assessment frameworks could establish if commercial operations generate other benefits. Assessment could be a device for changing attitudes about commercial operations and the data from assessments could also assist with tailoring revenue sources to museums.

On a similar note, it would be worth refining the KA model before it is implemented in NZ (Falk and Sheppard 2006). In terms of assessment, the framework should reflect the specifics of the NZ operating environment. The financial assets section of the KA model should also be contextualized for NZ. In the United States, many museums have endowments which can contribute roughly $5 \%$ of a museum's income (Bell 2012). This revenue source is not commonplace in $\mathrm{NZ}$ and has therefore been removed from the model. In the place of endowments, it seems pertinent to create a function that enables revenue development. A revised model is shown in Figure CON.1 


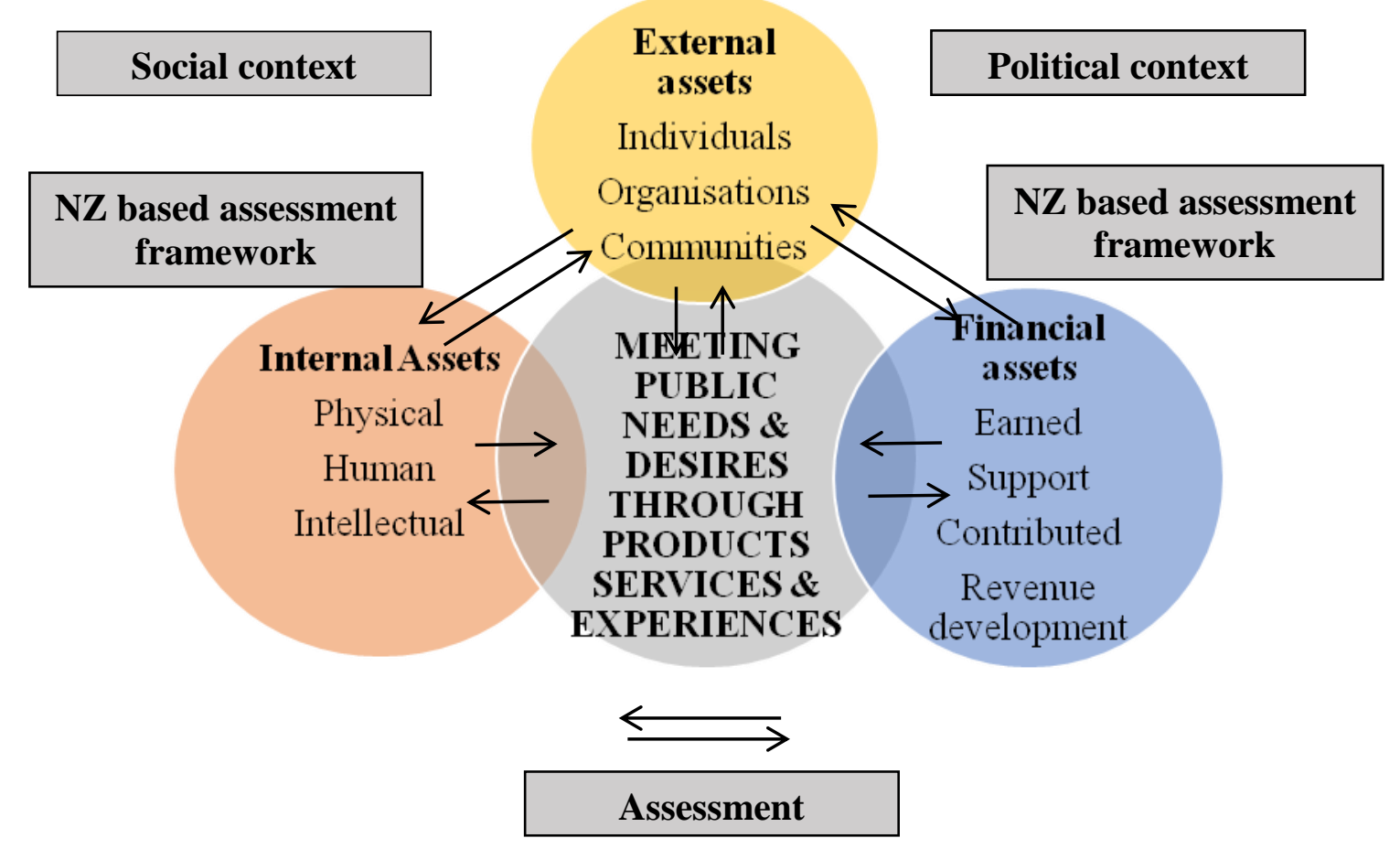

\section{Economic context}

Figure CON.1 KA model revised

Regardless of whether a museum considers the MVIS, the IVC or the KA model, further research is needed in order to realise the opportunities from this research. Innovation practice can differentiate offerings from that of competitors (Heidari, Marzuki, and Bahauddin 2011, 1). Further research could also benefit the partnerships between museums and external providers. Summative evaluation of external party initiatives in revenue generation would be useful. One approach for this could be to develop evaluation models for initiatives. Organisations such as TP National Services could be a partner for museums in this work. Partnerships with subject experts on specific types of revenue may also serve to future proof museums. Movie theatres have used variable pricing models for years and could offer valuable insights. Another approach for developing crowdfunding may be to work with platform providers. The NZ Give a Little crowdfunding website offers support to anyone wanting to start a new page or a campaign. Sue Taylor from Give-a-Little indicated that this support includes access to data from prior campaigns (S. Taylor, personal communication, August 24th, 2016). 
On the subject of this thesis, future research could refine the findings. A focus group could be used to scrutinise the findings, as this might address any possible biases. The definitions of revenue used in the thesis could be redeveloped for use. Some key areas for future research have also been highlighted in this study. One example is the relationship between revenue and social inclusion, which could be investigated through the TP cafe scheme. Further research on revenue ethics and tax legislation may also benefit revenue generation. Guidelines for best practice with volunteers could improve revenue generation and museum-volunteer relationships.

I now want to turn to consider implications and recommendations for professional practice which could arise from this research. Revenue generation research must move on from discussing the ethics of specific revenue sources. Practical applications of revenue generation are key for the future. Why is there no discussion in NZ about text donations for museums? Could museums build free services such as Wi-Fi in a manner that could allow visitors to opt to pay for this service? On an academic level, developing business theory alongside museology could promote interdisciplinary research and serve to bring together museum studies with economics. This type of integrated research could foster supportive relationships for museums and could also help with developing frameworks which capture the intangible values of museums.

Ultimately museums and commercial tourism (such as The Weta Cave) are both telling a story and selling an experience despite apparent differences in their mission and purpose. While the two may part ways in terms of ethos and philosophical aspirations they still have common issues when it comes to financial viability. I would not promote a purely commercial enterprise as the best possible strategy for not-forprofit museums. It would be a great pity if museums lost the rich tapestry of cultural heritage which defines their core. But it does seem to me reasonable to argue that there are benefits to walking the line on the issue of funds development. If a museum can embrace its commercial necessities as a valid part of its operations rather than operating with an 'us' and 'them' mentality, this offers a more viable mode of practice for the future. In a changing world, the funding for museums will always ebb and flow. How museums respond may be as much about their mindset as the revenue they choose. With sound management, museum practice and commercial operations 
can overlap and support each other. Innovative and non-traditional revenue generation in museums can contribute benefits beyond income. 


\section{References}

1992. Museum of New Zealand Te Papa Tongarewa Act. No 19. New Zealand

2002 Local Government Act. No 84.

2005 Charities Act. No 39. New Zealand

2016. "Creative leadership: how Te Papa and its Gallipoli exhibition delivered." NZ Business 30 (1):(Sp)8-(Sp)10.

Allan, Lynne Carmichael. 2008. "Giving and Receiving : A Case Study of the Stowaways Exhibit in Blood, Earth Fire - Whāngai, Whenua Ahi Kā at the Museum of New Zealand Te Papa Tongarewa."Master's thesis, Victoria University, Wellington, New Zealand.

Anderson, Gail. 2004. Reinventing the museum: Historical and contemporary perspectives on the paradigm shift. United Kingdom Rowman Altamira.

Anthony, Scott D, David S Duncan, and Pontus MA Siren. 2014. "Build an Innovation Engine in 90 Days." Harvard business review 92 (12):60-68.

Aotearoa, Museums 2003. Code of Ethics for Governing Bodies of Museums and Museum Staff: Museums Aotearoa.

Aquilina, Janick, D. 2011. "The Babelian Tale of Museology and Museography: A History in Words." Museology. International Scientific Electronic Journal $6: 1-20$

Arnold, Ken. 2015. "From Caring to Creating: Curators Change Their Spots." In The International Handbooks of Museum Studies, 317-339. John Wiley \& Sons, Ltd. 
Bailey, Stephen, and J Falconer. 1998. "Charging for Admission to Museums and Galleries: A Framework for Analysing the Impact on Access." Journal of Cultural Economics 22 (2-3):167-177.

Bakhshi, Hasan, Alan Freeman, and Graham Hitchen. 2009. "Measuring Intrinsic Value - How to Stop Worrying and Love Economics." IDEAS Working Paper Series from RePEc.

Barton, Adrian. 2008. "New Labour's management, audit and what works' approach to controlling the untrustworthy' professions." Public policy and administration 23 (3):263-277.

Baudet , Karryn. 2014. "Exit Through the Gift Shop " Museums Aotearoa Quarterly (Februrary ):11.

Bell, Ford W. 2012. "How Are Museums Supported Financially in the US?" United States Department of State, Bureau of International Information Programs (March 2012).

Bennett, Tony, and Robert Lumley. 1988. "Museums and 'the people'." The museum time-machine:63-85.

Bloom, D., R. Cuadra, J. Fassbender, \& E. Welden-Smith, and S. Graham. 2013. Foresight Research Report: Museums as Third Place.

Blundell, Sally. 2014. "Exhibitions of themselves." New Zealand Listener 30 Aug 2014, 26-31.

Boylan, Patrick J. 2006. "The Museum Profession." In Blackwell companions in cultural studies: Companion to Museum Studies., 415-430. Chichester, GB: Wiley-Blackwell.

Brabham, Daren C. 2016. "How crowdfunding discourse threatens public arts." New Media \& Society. doi: 10.1177/1461444815625946. 
Brodie, Ellie, David Kane, and Jenny Clark. 2012. "Income Generation in London's non-National Museums." accessed 14 August, 2014. www.museumoflondon.org.uk/index.php/download_file/view/..15684/.

Capello, Roberta, and Alessandra Faggian. 2005. "Collective learning and relational capital in local innovation processes." Regional studies 39 (1):75-87.

Carlton, Dennis W., and Jeffrey M Perloff. 1994. Modern industrial organization. 2nd ed. New York Harper Collins

Charities Services. 2016. "Social enterprise." accessed 1 Jan, 2015. https://www.charities.govt.nz/apply-for-registration/charitable-purpose/socialenterprise/. .

Chen, Xiaohua. 2014. "Understanding volunteers in cultural tourism organisations in New Zealand: exploring demographics and motivational factors." Master of International Hospitality Management, Auckland University of Technology.

Clare, Roy. 2014. "Mission, Vision, Values: Museums as Social Businesses." Museums Aotearoa Quarterly (February):10.

Clark, Kate. 2014. "The Value Proposition." Museums Aotearoa Conference (MA14): The Business of Culture, Napier, New Zealand Wednesday 2 - Friday 4 April.

Coman, Adela, and Izebela. Pop. 2012. "Entrepreneurship-the key for a successful museum." International Conference Entrepreneurship Education-A Priority for the Higher Education Institutions, Bucharest, Romania, 8-9 October 2012.

Connolly, Robert. 2010. "Museums as Third Places." accessed August 6th 2016. https://rcnnolly.wordpress.com/2010/08/02/museums-as-third-places/.

Creative Commons, Aotearoa New Zealand. 2014. "Licences explained." http://creativecommons.org.nz/licences/licences-explained/. 
Creative New Zealand. 2014. "Engaging audiences through crowdfunding ". http://www.creativenz.govt.nz/assets/ckeditor/attachments/769/webinar_5_eng aging_audiences_through_crowdfunding.pdf?1370466317.

Cricket Wellington. 2016. "Supporters Club." accessed 22 October 2016. http://www.cricketwellington.co.nz/fanzone/supportersclub/.

Cultural Philanthropy Taskforce. 2010. Growing the Pie: Increasing the Level of Cultural Philanthropy in Aotearoa New Zealand,. Ministry of Culture and Heritage

Davidson, Lee, and Ian Shaw. 2015. Museums Aotearoa 2014 sector survey report. Wellington: Museums Aotearoa.

Dempsey, Chris. 2013. "Crowdsourcing in New Zealand - Lessons from Wanganui." National Digital Forum Wellington 25-27 November.

Dickenson, Victoria. 1993. "The economics of museum admission charges." Curator: The Museum Journal 36 (3):220-234. doi: doi:10.1111/j.21516952.1993.tb00795.x.

Doherty, Heather 2011. Social Enterprise and museums Scotland Museums Galleries Scotland

Donoghue, T. . 2013. "Basin Still Houses Legacy of Cricket Leader's Drive." Dominion Post Oct 05 http://search.proquest.com/docview/1439312985?accountid=14954

Dubuc, Élise. 2011. "Museum and university mutations: the relationship between museum practices and museum studies in the era of interdisciplinarity, professionalisation, globalisation and new technologies." Museum Management and Curatorship 26 (5):497-508. 
Espiner, Guyon. . 2015. "Te Papa doc.", Last Modified April 23, accessed October 1. http://www.noted.co.nz/archive/listener-nz-2015/te-papadoc/?wpmp_switcher=mobile.

Evans J, and Kerrie Bridson. 2013. "Demonstrating Impact - Four Case Studies of Public Art Museums." Asia Pacific Social Impact Leadership Centre, Melbourne Business School.

https://www.google.co.nz/search?q=demonstrating+impact+four+case+studies $+\&$ ie $=$ utf- $8 \&$ oe $=$ utf-8\&aq=t\&rls=org.mozilla:en-US:official \&client=firefox-

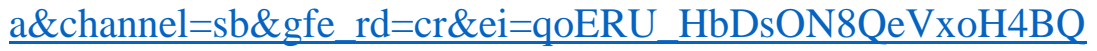

Falk, John H, and B Sheppard. 2006. Thriving in the Knowledge Age : New Business Models for Museums and Other Cultural Institutions. UK: Altamira Press.

Feldstein, Martin S. 1991. The Economics of Art Museums. Chicago: National Bureau of Economic Research.

Finney, H. A. 1944. General accounting. New York: Prentice-Hall, inc.

Firth, Melissa. 2015. "Te Papa's innovation hub: An incubator for cultural start-ups " National Digital Forum, Wellington, NZ.

Fleming, D. 2015. "The Essence of the Museum: Mission, Values, Vision." In The International Handbooks of Museum Studies., 1:1:3-25.

Ford, Katharine. 2012 "Sustainability | aspirations and actions." London Museums Group Blog http://londonmuseumsgroup.blogspot.co.nz/search?q=museums+are+already+ social+enterprises.

Frey, Bruno S. 1998. "Superstar museums: an economic analysis." Journal of Cultural Economics 22 (2-3):113-125.

Frey, Bruno S, and Stephan Meier. 2006. "The economics of museums." Handbook of the Economics of Art and Culture 1:1017-1047. 
Genoways, H.H, and L.M Ireland. 2003. Museum Administration an Introduction: Alta Mira Press.

Gilbert-Potts, Jennifer 2014. "Museum Profile: The New Zealand Cricket Museum." Museums Aoteaoroa.

Grampp, William Dyer. 1989. Pricing the priceless: art, artists, and economics: Basic Books.

Hansen, Morten T, and Julian Birkinshaw. 2007. "The Innovation Value Chain." Harvard Business Review 85 (6):121-42.

Hazledine, Tim. 2011. "Arts funding in New Zealand: a proposal for reform." Cultural Trends 20 (1):65-84.

Heidari, Hanieh Varasteh, Azizan Marzuki, and A Bahauddin. 2011. "A Framework for Innovative Activities in Museums." 2nd Regional Conference on Tourism Research.

Henning, Michelle. 2013. "With and Without Walls: Photographic Reproduction and the Art Museum." In The International Handbooks of Museum Studies, 577602.: John Wiley \& Sons Australia, Ltd.

Heritage, Elizabeth. 2014. "Te Papa’s openly licensed images." Creative Commons Aotearoa New Zealand, Last Modified November 10 2014, accessed 2016. http://creativecommons.org.nz/2014/11/te-papas-open-images/.

Hewison, Robert, and John Holden. 2013. "The Cultural Leadership Handbook How to Run a Creative Organization." In. USA: Ashgate Publishing Ltd. http://VUW.eblib.com/patron/FullRecord.aspx?p=714105 (accessed July 1st 2014).

Holden, John. 2004. Capturing cultural value: How culture has become a tool of government policy. UK: Demos 
Hong, Bev. 2014. "National cultural indicators in New Zealand." Cultural Trends 23 (2):93-108. doi: 10.1080/09548963.2014.897450.

Hudson, Kenneth. 2014. "The Museum Refuses to Stand Still " Museum International 66 (1-4):136-143. . doi: doi:10.1111/muse.12067.

International Council of Museums. 2004. "Code of Professional Ethics (revised)." accessed 1 Jan, 2016 http://icom.museum/the-vision/code-of-ethics/1museums-preserve-interpret-and-promote-the-natural-and-cultural-inheritanceof-humanity/.

International Council of Museums. 2007. "Museum Definition." accessed March 1st. http://icom.museum/the-vision/museum-definition/.

Ipsos, MORI. 2003. "The impact of free entry to museums." London, UK.

Johnson, Peter, and Barry Thomas. 1998. "The economics of museums: a research perspective." Journal of Cultural Economics 22 (2-3):75-85.

Johnson, R Burke, and Anthony J Onwuegbuzie. 2004. "Mixed Methods Research: A Research Paradigm Whose Time Has Come." Educational Researcher 33 (7):14-26.

Kingston, Adrian , and Philip Edgar. 2015. "A review of a year of open access images at Te Papa." MWA2015: Museums and the Web Asia 2015.

Kotler, Neil, and Philip Kotler. 2000. "Can Museums Be All Things to All People?: Missions, Goals, and Marketing's Role." Museum Management and Curatorship 18 (3):271-287.

Labrum, Bronwyn, and Conal McCarthy. 2005. "Museum studies and museums: Bringing together theory and practice." Te Ara Journal of Museums Aotearoa $30(2): 4-11$. 
Legget, Jane. 2006. "Mapping What Matters in New Zealand Museums Stakeholder Perspectives on Museum Performance and Accountability."Doctoral thesis, Massey University, Auckland, New Zealand

Lloyd-Jenkins, Douglas. . 2014. "The business of culture, Introduction to MA 2014 " Museums Aotearoa Quarterly (February ):6.

Lord, Gail Dexter, and Barry Lord. 2009. The Manual of Museum Management. 2nd ed. Lanham, MD AltaMira Press.

Luoni, David. 2011. "Museum Leadership in Practice: A New Zealand Case Study."Master's dissertation, Victoria University, Wellington, New Zealand

Mack, Ben 2016. "Idealog takes a looky at Mahuki, Te Papa's new innovation hub." accessed 15th August 2016. http://idealog.co.nz/venture/2016/08/idealogtakes-looky-mahuki.

Maddison, David, and Terry Foster. 2003. "Valuing Congestion Costs in the British Museum." Oxford Economic Papers 55 (1):173-190.

Mason, David D. M., and Conal McCarthy. 2008. "Museums and the culture of new media: an empirical model of New Zealand museum websites." Museum Management and Curatorship 23 (1):63-80. doi: 10.1080/09647770701865386.

Massey, Claire, Kate Lewis, and National Services. Museum of New Zealand. 2002. Enterprising museums. Wellington, NZ Museum of New Zealand Te Papa Tongarewa

Massey, Claire, Peter. Quinn, and National Services. Museum of New Zealand. 2001. Exhibiting Enterprise : Generating Income in New Zealand Museums : A Report Wellingon, NZ Museum of New Zealand Te Papa Tongarewa.

McCarthy, Conal. 2011. Museums and Māori : Heritage Professionals, Indigenous Collections, Current Practice. Wellington Te Papa Press. 
McCarthy, Conal. 2014. "Museums." Last Modified 2014, October 22 accessed September 1st. http://www.TeAra.govt.nz/en/museums

Mertens, Donna M. 2015. Research and Evaluation in Education and Psychology: Integrating Diversity with Quantitative, Qualitative, and Mixed Methods. Fourth ed: Gallaudet University.

Morris Hargreaves McIntyre. 2012. Audience Atlas New Zealand 2011 report Creative New Zealand

Museum of New Zealand, Te Papa Tongarewa. 2015. Te Papa Statement of Intent 2012/13, 2013/14, 2014/15.

Museum of New Zealand, Te Papa Tongarewa. 2016. "Te Papa Foundation ", accessed 10 Jan, 2016. https://www.tepapa.govt.nz/support-join/te-papafoundation.

Museum of New Zealand, Te Papa Tongarewa, and Mark Lindsay. 1994. Admission Charges: The Issues. Wellington Museum of New Zealand Te Papa Tongarewa.

Museum Shops Association of Australia. 2010. "Mission Statement ". Museum Shops Association of Australia, accessed 22 December http://www.museumshops.org.au/.

Museums Aotearoa. 2003. Code of Ethics for Governing Bodies of Museums and Museum Staff: Museums Aotearoa.

Museums Aotearoa. 2005. A Strategy for the Museum Sector in New Zealand: Museums Aotearoa.

Oldenburg, Ray. 1989. The great good place: Café, coffee shops, community centers, beauty parlors, general stores, bars, hangouts, and how they get you through the day: Paragon House Publishers. 
Oomen, Johan, and Lora Aroyo. 2011. "Crowdsourcing in the cultural heritage domain: opportunities and challenges." Proceedings of the 5th International Conference on Communities and Technologies, Brisbane, Australia.

Orinda, Group 2008. 2007 Museum Revenue Generation and Fundraising Study. Los Angeles: Orinda Group

Pātaka Art + Museum. 1999. March 1999 Exhibition Information [Brochure]. edited by Pataka Art + Museum. Wellington, New Zealand

Pātaka Art + Museum. 2016. "History ", accessed 10 December, 2015 http://www.pataka.org.nz/about-us/gallery-history/.

Pātaka Foundation. 2016. "We are on a mission." accessed 10 January, 2016 http://www.patakafoundation.org.nz/index/home.

Pekel, Joris. 2014. "Democratising the Rijksmuseum. Why did the Rijksmuseum make available their highest quality material without restrictions, and what are the results?". Europeana Foundation, accessed 22 September, 2014. pro.europeana.eu/documents/858566/.../Democratising+the+Rijksmuseu...

Png, Ivan. 1998. Managerial economics. USA: Blackwell Publishers

Powell, Sarah. 2016. "Towards A Connected Commons: Two case studies examining New Zealand collecting domains establishing Open GLAM practices for digital collections " Master in Museum and Heritage Studies Museum and Heritage Studies Victoria University

Puklowski, Tracy. 2014. "What will museums be like in the future? Short essay collection by museum leaders and innovators from around the world." http://www.museum-id.com/idea-detail.asp?id=283.

Putnam, Robert D. 2001. Bowling Alone: The Collapse and Revival of American Community: Simon and Schuster. 
Rega, Julie N. 2011. "Museum membership programs: Innovation in a troubled economy."

Rentschler, Ruth, Anne-Marie Hede, and Tabitha R. White. 2007. "Museum pricing: challenges to theory development and practice." International Journal of Nonprofit and Voluntary Sector Marketing 12 (2):163-173. doi: 10.1002/nvsm.289.

Rentschler, Ruth, F Kerrigan, P Fraser, and M Ozbilgin. 2004. "Museum marketing: understanding different types of audiences." Arts marketing:139-158.

Ryan, Kathryn. 2016. Museums: portals to the past, windows to the future. In Nine To Noon, edited by Elizabeth Merrit.

Scherer, Karyn 2012. "Successful Kiwi entrepreneurs." New Zealand Listener, September, 29th, 18-25.

Scott, C. A. . 2015. "Museum Measurement: Questions of Value." In The International Handbooks of Museum Studies, 1:5:97-122.

Scott, Carol. 2014. "Emerging paradigms: national approaches for measuring cultural value." Cultural Trends 23 (2):79-81.

Selwood, Sara, and Stuart Davies. 2015. "Policies, Frameworks, and Legislation: The Conditions Under Which English Museums Operate." In The International Handbooks of Museum Studies. John Wiley \& Sons, Ltd.

Shaw, Lucy 2014. "Future of Museums: Entrepeneurial and Creative.". http://www.museum-id.com/idea-detail.asp?id=283.

Silberberg, Ted, and Gail Lord. 2015. "Balancing Mission and Money: Issues in Museum Economics." In The International Handbooks of Museum Studies. , 2:7:155-178. John Wiley \& Sons, Ltd. 
Steiner, Faye. 1997. "Optimal Pricing of Museum Admission." Journal of Cultural Economics 21 (4):307-333.

Stuart, Pat 2014. "Admission Charges " Museums Aotearoa Quarterly (February ):8.

Suchy, Sherene. 2004. Leading with Passion : Change Management in the 21stcentury Museum. Lanham, MD: AltaMira Press.

Sutherland, Tamarisk. 2006. "More than a one night stand : evolving partnerships between public museums and corporate organisations." Master in Museum and Heritage Studies Museum and Heritage Studies Victoria University

Tan, Letisha, David Dunbar, and Carolyn Joy Cordery. 2008. Tax and volunteering: empirical evidence to support recommendations to solve the current problems surrounding the tax treatment of volunteers' reimbursements and honoraria in New Zealand.

Tashakkori, Abbas, and Charles Teddlie. 2010. Sage Handbook of Mixed Methods in Social \& Behavioral Research. 2nd ed. Los Angeles: Sage.

Thau, Barbara. 2008. "The art of retail: museum shops sharpen their merchandising strategies." HFN The Weekly Newspaper for the Home Furnishing Network, October 20, 2008.

http://go.galegroup.com.helicon.vuw.ac.nz/ps/i.do?id=GALE\%7CA19866596 $\underline{0 \& v=2.1 \& u=v u w \& i t=r \& p=I T O F \& s w=w \& a s i d=9 b e 0636 d 08 c 918 c 096 \mathrm{cbd} 0 \mathrm{c} 1}$ $10499 \mathrm{e} 41$.

The New Zealand Cricket Museum. 2016. "Plan your Cricket Museum Visit." accessed 1st December, 2015. http://nzcricketmuseum.co.nz/visit/.

Tramposch, William J. 1998. "Te Papa: Reinventing the Museum." Museum Management and Curatorship 17 (4):339-350.

Treasury, The. 2014. "Crown Entities." Last Modified 20 Aug 2014, accessed 16 December 2015. www.treasury.govt.nz/statesector/crownentities. . 
Turner, Caroline. 2001. "Tomorrow's Museums." The Future of Museums, named issue of Humanities Research 8 (1):1-3.

Tusa, John. 2007. Engaged with the Arts: Writings from the Frontline: IB Tauris.

Vergo, Peter. 1997. New Museology: Reaktion books.

Victoria University. 2016 "Museum and heritage studies research." accessed 1 September, 2016 http://www.victoria.ac.nz/sacr/research/museum-heritage.

Walkowitz, Daniel, and Lisa Maya Knauer. 2008. Contested histories in public space: memory, race, and nation: Duke University Press.

Weil, Stephen. 1990. Rethinking the museum and other meditations. USA:

Smithsonian Institution Press.

Williams, Paul. 2005. "A breach on the beach: Te Papa and the fraying of biculturalism." Museum and Society 3 (2):81-97.

Wright, Malcolm., and Gavin Lees. 2003. "Item order effects in Juster Scale pricing research." Australasian Journal of Market Research 11 (1):11-15.

Yin, R. K. 1984. Case Study Research : Design and Methods. Newbury Park, CA: Sage publications.

Yunus, Muhammad. 2007. Creating a world without poverty: Social business and the future of capitalism: PublicAffairs. 


\section{A P P E N D I C E S}

Appendix 1: Information Sheet

Appendix 2: Consent Form

Appendix 3: Interview Questions 


\section{A P P E N D I X 1 : I N F O RMAT I O N S H E E T}

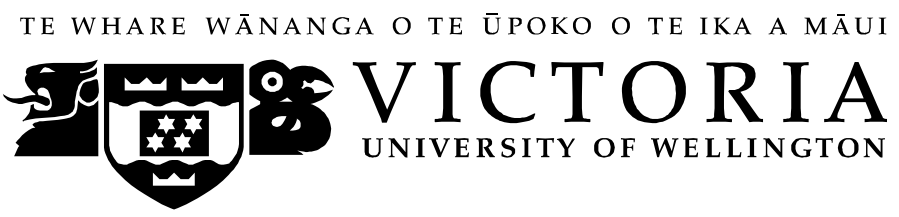

\section{How can innovative and non-traditional revenue sources, improve the financial viability of (NZ) museums?}

\section{Researcher: Anna Abernethy}

Thank you for considering taking part in this research. The following text explains how the research will be used and who it will be disclosed to. The purpose of this research is to consider; how can innovative and non-traditional revenue sources improve the financial viability of New Zealand museums. The finding of this research will add to the existing body of knowledge on revenue generation in New Zealand museums and may improve their sustainability by identifying critical needs for professional development in the museum sector, possible strategic partnerships and opportunities for income diversification.

Your involvement will take the form of an interview. The interview will be conducted at a time/location most convenient to you. The interview is expected to take a maximum of one $1 / 2$ hours, with the possibility of a follow-up interview if necessary (and if you agree). A schedule of the possible topics for discussion will be given to you a week in advance of the interview. You will also have the opportunity to verify a summary of the interview data, and to check quotes from the interviews which may appear in the final text of the dissertation. You can select not to answer any question and withdrawal from this research by verbal or written indication up until November 30th 2015.

The research has been reviewed and approved by the Human Ethics Committee at Victoria University Wellington. All information supplied will be kept securely and destroyed after a period of three years. 
After reading this, if you agree to participate would you please sign the consent document. If you have any questions or would like to receive further information my details are as follows:

Anna Abernethy,

Phone,

e-mail aberneanna@myvuw.ac.nz

Or you can contact my thesis supervisor.

Dr Conal McCarthy

\section{Programme Director}

School of Art History, Classics and Religious Studies

conal.mccarthy@vuw.ac.nz

Phone:

Location: 


\section{A P P E N D I X 2: C O N S E N T FORM}

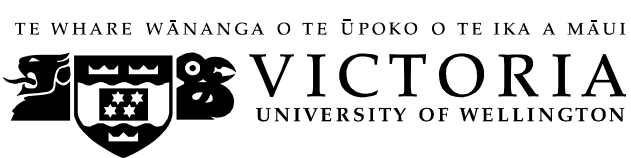

\section{PROJECT PARTICPANT CONSENT}

I, (name of participant) $\ldots \ldots \ldots \ldots \ldots \ldots \ldots \ldots \ldots \ldots$ PLEASE PRINT

Have been given and have understood an explanation of this research project. I have had an opportunity to ask questions and have had them answered to my satisfaction.

I understand that my involvement will take the form of an interview of a maximum of one $1 / 2$ hours, with the possibility of a follow-up interview if necessary (and if I agree).

I will be provided with a summary of the interview data before it is used for analysis.

I understand that I can withdraw from this research by verbal or written consent anytime up until November $30^{\text {th }} 2015$.

I, the person interviewed, agree that any recording of my interview and material pertaining to my interview can be held by the interviewee Anna Abernethy for a period of 3 years.

\section{COMMENTS}

SIGNED

Participant. Date

Contact details (Email or address, optional)

Phone (Optional) 


\section{A P P E N D I X 3 : I N T E R V I E W Q U E S T I O N S}

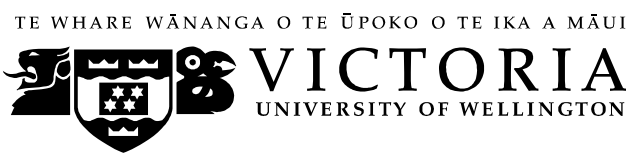

Interviewee:

Organisation: Date of Interview:

\section{Part 1\# - Introduction}

1. Can you tell me about your role in $\mathrm{X}$, and about the organisation as a whole?

2. What is your perception of revenue generation in your organisation?

3. How do you feel that this compares with similar organisations around the country?

4. What would you consider best practise for commercial development within museums?

\section{Part 2\# - Internal assets}

5. What are the revenue streams in your organisation?

6. What enables revenue generation in your organisation?

7. Have your organisation's approaches to revenue generation changed over the last few years?

8. Do you use volunteers? 
Yes $\bigcirc$ No

8a. If no, why not?

8 b. If yes, how do you source and retain them?

9. What is the nature of their contribution?

Do you agree, partially agree or disagree with the following statements?

10. People in our department come up with independent initiatives on a regular basis
$\bigcirc$ Agree
Partially
$\bigcirc$ Disagree Agree

11. Novel ideas are readily developed in the culture of our organisation.
$\bigcirc$ Agree
Partially
$\bigcirc$ Disagree Agree

12. Our people typically collaborate on innovation and projects across departments.
$\bigcirc$ Agree
$\bigcirc$ Partially
$\bigcirc$ Disagree Agree

13. Products, innovative ideas and services from outside our organisation are valued to the same level as internal strategies.
$\bigcirc$ Agree
Partially
$\bigcirc$ Disagree
Agree 
14. What are the characteristics of enterprising behaviour?

14b.Which of these are the strengths and weaknesses of your organisation?

15. Are there barriers to revenue generation within your organisation?

16. Can you give me an example of something enterprising that your organisation has done in the last three years?

17. What, according to you, is enterprising about this example?

\section{Part 3\# - Financial assets}

18. Complete the sentence: Our organisation is generating revenue for:

19. How transparent should an organisation be about where the revenue is spent?

20. When did revenue generation become necessary?

21. Where do you feel your role fits within that?

22. From what sources, does support for your organisation arrive?

23. By what means does your organisation address operational resource gaps?

Do you agree, partially agree or disagree with the following statement?

24. Revenue generating innovations are appropriately funded.
$\bigcirc$ Agree
Partially
$\bigcirc$ Disagree Agree 


\section{Part 4\# - Meeting public needs \& desires}

25. What is your target audience?

26. Have level of services changed with the changing economic climate, e.g., is the organisation now charging for services that were once free?

27. Does the organisation have a role in the region's economic development?

\section{Do you agree, partially agree or disagree with the following statements?}

28. The organisation penetrates all possible communities, customer groups and regions with new products and services.
$\bigcirc$ Agree
Partially
$\bigcirc$ Disagree Agree

29. There are established future plans and strategies for revenue generation and sustainability?
$\bigcirc$ Agree
Partially
$\bigcirc$ Disagree Agree

30. New product development projects finish on time.
$\bigcirc$ Agree
Partially
$\bigcirc$ Disagree Agree

31. We roll out new products and services in a timely fashion.
$\bigcirc$ Agree
$\bigcirc$ Partially
$\bigcirc$ Disagree
Agree 


\section{Part 5\# - External assets}

32. Are you aware of any initiatives to support revenue generation at a national level?

33. Should museums collaborate?

34. Is there anyone else outside of the museum sector that museums should collaborate with?

35. What are your thoughts on digital developments and revenue generation in museums? 